\title{
The Processing and Analysis of Graphene and the Strength Enhancement Effect of Graphene-based Filler Materials: A Review
}

DOI:

10.1016/j.mtphys.2020.100257

\section{Document Version}

Accepted author manuscript

Link to publication record in Manchester Research Explorer

Citation for published version (APA):

Shen, C., \& Oyadiji, S. O. (2020). The Processing and Analysis of Graphene and the Strength Enhancement Effect of Graphene-based Filler Materials: A Review. Materials Today Physics, 100257.

https://doi.org/10.1016/j.mtphys.2020.100257

Published in:

Materials Today Physics

\section{Citing this paper}

Please note that where the full-text provided on Manchester Research Explorer is the Author Accepted Manuscript or Proof version this may differ from the final Published version. If citing, it is advised that you check and use the publisher's definitive version.

\section{General rights}

Copyright and moral rights for the publications made accessible in the Research Explorer are retained by the authors and/or other copyright owners and it is a condition of accessing publications that users recognise and abide by the legal requirements associated with these rights.

\section{Takedown policy}

If you believe that this document breaches copyright please refer to the University of Manchester's Takedown Procedures [http://man.ac.uk/04Y6Bo] or contact uml.scholarlycommunications@manchester.ac.uk providing relevant details, so we can investigate your claim.

\section{OPEN ACCESS}




\section{Journal Pre-proof}

The Processing and Analysis of Graphene and the Strength Enhancement Effect of Graphene-based Filler Materials: A Review

Chen Shen, S.O. Oyadiji

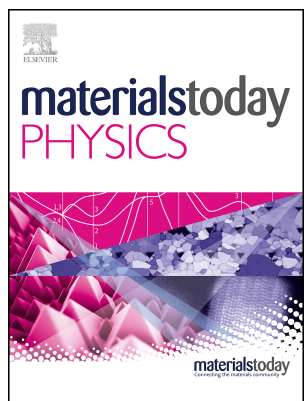

PII:

S2542-5293(20)30081-X

DOI: https://doi.org/10.1016/j.mtphys.2020.100257

Reference: MTPHYS 100257

To appear in: Materials Today Physics

Received Date: 22 June 2020

Revised Date: 28 July 2020

Accepted Date: 1 August 2020

Please cite this article as: C. Shen, S.O. Oyadiji, The Processing and Analysis of Graphene and the Strength Enhancement Effect of Graphene-based Filler Materials: A Review, Materials Today Physics, https://doi.org/10.1016/j.mtphys.2020.100257.

This is a PDF file of an article that has undergone enhancements after acceptance, such as the addition of a cover page and metadata, and formatting for readability, but it is not yet the definitive version of record. This version will undergo additional copyediting, typesetting and review before it is published in its final form, but we are providing this version to give early visibility of the article. Please note that, during the production process, errors may be discovered which could affect the content, and all legal disclaimers that apply to the journal pertain.

() 2020 Elsevier Ltd. All rights reserved. 


\section{Graphical Abstract}

This review is about the application of graphene family materials in material strength enhancement field. Apart from detailed mechanical data of graphene enhanced material, the background information, manufacture, classification and processing methods of graphene family materials are introduced. This article is suitable for beginners doing research in graphene to acquire necessary knowledge of graphene and the approach to enhance the mechanical strength of common materials.

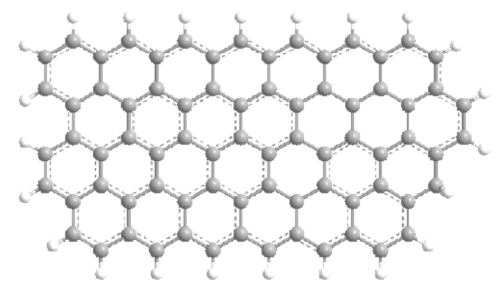

\begin{tabular}{|c|c|c|c|}
\hline Material & $\begin{array}{l}\text { Change of Young's } \\
\text { Modulus (GPa) }\end{array}$ & $\begin{array}{l}\text { Change of } \\
\sigma_{\mathrm{Utr}}(\mathrm{MPa})\end{array}$ & $\begin{array}{l}\text { Change of } \\
\text { strain (\%) }\end{array}$ \\
\hline Aluminum & & $330 \rightarrow 260$ & \\
\hline Aluminum & & $86 \rightarrow 110$ & $52 \rightarrow 43$ \\
\hline Aluminum & & $154 \rightarrow 249$ & $26 \rightarrow 13$ \\
\hline $\begin{array}{c}\text { Aluminum } \\
\text { Oxide }\end{array}$ & $380 \rightarrow 398$ & & \\
\hline Aluminum & & $\begin{array}{c}252 \pm 4.5 \rightarrow 280 \pm \\
5\end{array}$ & $\begin{array}{c}13.4 \pm 2 \rightarrow 9.53 \\
\pm 1.5\end{array}$ \\
\hline Aluminum & & $175 \rightarrow 285$ & $51 \rightarrow 35$ \\
\hline Copper & & $150 \rightarrow 320$ & \\
\hline Copper & $102 \rightarrow 131$ & $255 \rightarrow 335$ & $38 \rightarrow 13$ \\
\hline Copper & & $175 \rightarrow 240$ & $28 \rightarrow 9$ \\
\hline Copper & $82 \rightarrow 132$ & $230 \rightarrow 320$ & $35 \rightarrow 12.5$ \\
\hline Copper & & $210 \rightarrow 230$ & $55 \rightarrow 42$ \\
\hline Magnesium & $7.4 \pm 0.3 \rightarrow 14 \pm 0.16$ & $164 \pm 5 \rightarrow 260 \pm 5$ & \\
\hline PVDF & $0.9 \rightarrow 6.2$ & & \\
\hline
\end{tabular}




\title{
The Processing and Analysis of Graphene and the Strength Enhancement Effect of Graphene-based Filler Materials: A \\ Review
}

\author{
Chen Shen, S. O. Oyadiji \\ Faculty of Science and Engineering, School of Engineering, \\ Department of Mechanical, Aerospace and Civil Engineering, \\ University of Manchester, Manchester M13 9PL, UK
}

\begin{abstract}
Research on graphene, a single-atom thick material, has been an intensive research area since the end of the $20^{\text {th }}$ century, especially after the discoverers of graphene were awarded the Nobel prize in 2010. The material has attracted much interest and in the past decade the development of graphene can only be described as outstanding. Tens of thousands of papers relevant to the application of graphene have been published. Graphene has good physical properties including strength, electrical conductivity and thermal conductivity. It also has stable chemical properties. Among all of the outstanding properties of graphene, its mechanical properties are one of the best. Ideally its Young's modulus can reach $1 \mathrm{TPa}$ and its tensile strength can reach $130 \mathrm{GPa}$. These theoretical values are higher than those of all metals and are the highest values among all materials discovered so far. The potential applications of graphene products have even exceeded those of silicon material. For some time, this has led to a greater research activity on graphene than on silicon. Currently the research on graphene is mainly focused on medical equipment, composites, conductive materials and super capacitors.

This review will introduce the processing and analysis of graphene and the application of graphene in the material strength enhancement field. The application of graphene family material in this area will be introduced along with its processes. At this moment, the application of graphene in material enhancement is limited by the lack of
\end{abstract}


large volume of graphene and cost. Graphene and graphene-based materials can enhance material strength to some extent, but it is not yet cost-effective enough. Currently, the application of graphene and graphene-based materials for strength enhancement is more realistic in the military and aerospace sectors.

\section{Introduction}

In recent years, many advanced materials have been discovered and which have arisen huge research interests. Among them, silicon carbide (SiC), silicon carbide nanowires (SiCnw), carbon nanotube (CNT) and graphene are currently the most intensely-researched materials. Since single layer 2D structured carbon material graphene had been first exfoliated by Geim and Novoselov from HOPG (highly oriented pyrolytic graphite, a kind of high quality and high purity graphite material) in 2004 and awarded the Nobel Physics Prize in 2010 [1], tens of thousands of researches have been conducted in this area. Research on this advanced material has been treated as one of the most important research directions in the past decade.

One of the most significant properties of graphene is its outstanding mechanical properties, especially its theoretical tensile strength, which could reach $130 \mathrm{GPa}$ [2]. Its specific surface area could reach $2630 \mathrm{~m}^{2} / \mathrm{g}$. A vivid example to describe these values is a high quality graphene "hammock" of $1 \mathrm{~m}^{2}$ surface area that weighs 0.77 mg only and, which ideally can be able to hold a $4 \mathrm{~kg}$ cat [3]. Theoretically, graphene is the "strongest" material that has been discovered so far and has been applied to material enhancement to some extent. Most of the researches relevant to material enhancement using graphene are based on solid solution strengthening method which involves mixing it into the composite matrix in order to fabricate an advanced composite, or sintering it with metal powder to produce an enhanced alloy.

In this review, materials from the graphene family (graphene, graphene oxide, reduced graphene oxide) and their current applications will be introduced first. The reduction of graphene oxide to graphene as well as graphene material enhancement will be reviewed in detail in the following sections. Basic measurement and analysis equipment and test methods related to graphene will be discussed at the end. 


\section{Graphene and Graphene Family Materials}

\subsection{Differences in morphological and physical properties}

Graphene is a 2D single atom thick $s p^{2}$ bonded carbon atom. Its microstructure is based on the benzene-ring. Graphite, the most commonly available carbon material in a laboratory, could be treated as an accumulation of huge amounts of single-atom thick and multi-atom thick graphene. Novoselov et al. [1] used adhesive tape to peel graphene from highly oriented pyrolytic graphite (a kind of high-purity graphite material) directly and produced this material for the first time. During the past decade, the application of this advanced material has developed rapidly. In 2010, Andre Geim and Konstantin Novoselov from the University of Manchester were awarded the Nobel Prize in Physics due to their "outstanding pioneering research, discoveries and groundbreaking experiments on graphene, a two-dimensional material".

Graphene can be treated as a general term for a family of materials. Most commonly used graphene types are pristine graphene $(\mathrm{G})$, graphene oxide $(\mathrm{GO})$ and reduced graphene oxide (rGO). Table 1 compares their differences approximately. Pristine graphene, as its name suggests, has the best and closest properties to 'pure graphene'. It is a mixture of single layer (majority) to multilayer graphene. Its structure is shown in Table 1, in which the gray atoms represent carbon. Graphene oxide is exfoliated from graphite oxide and usually dispersed in water, its manufacture still follows the Hummer's method which was first applied in the $19^{\text {th }}$ century [4]. As shown in Table 1, its micro-structure contains a large number of oxygen atoms (shown in red in Table 1), which typically appears in the hydroxyl ion. By removing the majority of the oxygen containing functional groups from GO, reduced graphene oxide can be obtained. Its micro-structure still contains a small amount of oxygen but its property is close to pristine graphene. It is the most commonly used graphene family material in research and applications.

Table 1: Comparison of Commonly Used Graphene

\begin{tabular}{lll}
\hline & Difficulties of & Properties \\
Structure & Manufacture & \\
\hline
\end{tabular}




Pristine Graphene High, normally

If we classify graphene by its thickness, then it will be classified as monolayer graphene, bilayer graphene (or double-layer graphene), and few-layer graphene (3-9 layers). When layers of single atom thick graphene exceed 10 layers, due to the thickness it can no longer be treated as a $2 \mathrm{D}$ material. Therefore, commercial graphene typically has up to ten layers. For more than 10 layers, the material will be treated as graphite [5].

The properties of graphene can be modified by a chemical method. Graphane can be obtained after the hydrogenation of graphene. This process adds hydrogen to graphene structure. Ideally, in a pure sample of graphane, each carbon atom bonds with one hydrogen atom, which endows the material with magnetic property which traditional graphene does not possess. The new $\mathrm{C}-\mathrm{H}$ bond within the graphene structure would be in $s p^{3}$ hybridization compared with the initial $s p^{2}$ C-C bond [6]. Similarly, fluorination process of graphene could break the $s p^{2}$ bond within graphene and form $\mathrm{C}-\mathrm{F} s p^{3}$ bond to add fluorine into graphene structure in order to influence the electronic and optical properties of the new material [7]. Fluorination can be conducted on different types of graphene including exfoliated graphene, CVD (chemical vapour deposition) grown graphene and reduced graphene oxide [8]. Chlorine modified chlorographene can give graphene superlow sliding friction coefficient after the modification [9].

Apart from the types of graphene mentioned above, there are other types of graphene 
that are commonly reported in the literature. Graphene nanosheet (GN), which refers to high quality single layer graphene, is usually treated as a general name for graphene in the literature. Graphene nanoplatelet (GNP) refers to material with nanometric thickness from 3-100nm. It is typically multi-layer, more likely to be applied in industrial products, and is being used for the strength enhancement of polymer composite and to boost the thermal performance (thermal conductivity) when embedded in epoxy resin [10]. Nevertheless, the use of 'nano-' in the description of graphene material is not necessary due to the fact that the thickness of graphene material is always ultra-small $(<100 \mathrm{~nm})$ and already in the nanoscale range. Therefore, 'Graphene nanosheet' and 'Graphene nanoplatelet' are probably over defined [11].

\subsection{Differences in methods of manufacture}

Large scale production of high quality graphene is one of the current bottlenecks for the application of graphene. The methods of manufacture can be divided into direct methods and indirect methods. Direct methods produce pristine graphene while indirect methods produce rGO, which is the commercial replacement of graphene in applications, via the reduction of GO. The most commonly used methods for graphene manufacture include exfoliation, epitaxial growth on $\mathrm{SiC}$, chemical growth (CVD method) and reduction from graphene oxide. More methods can be seen in figure 1 . 


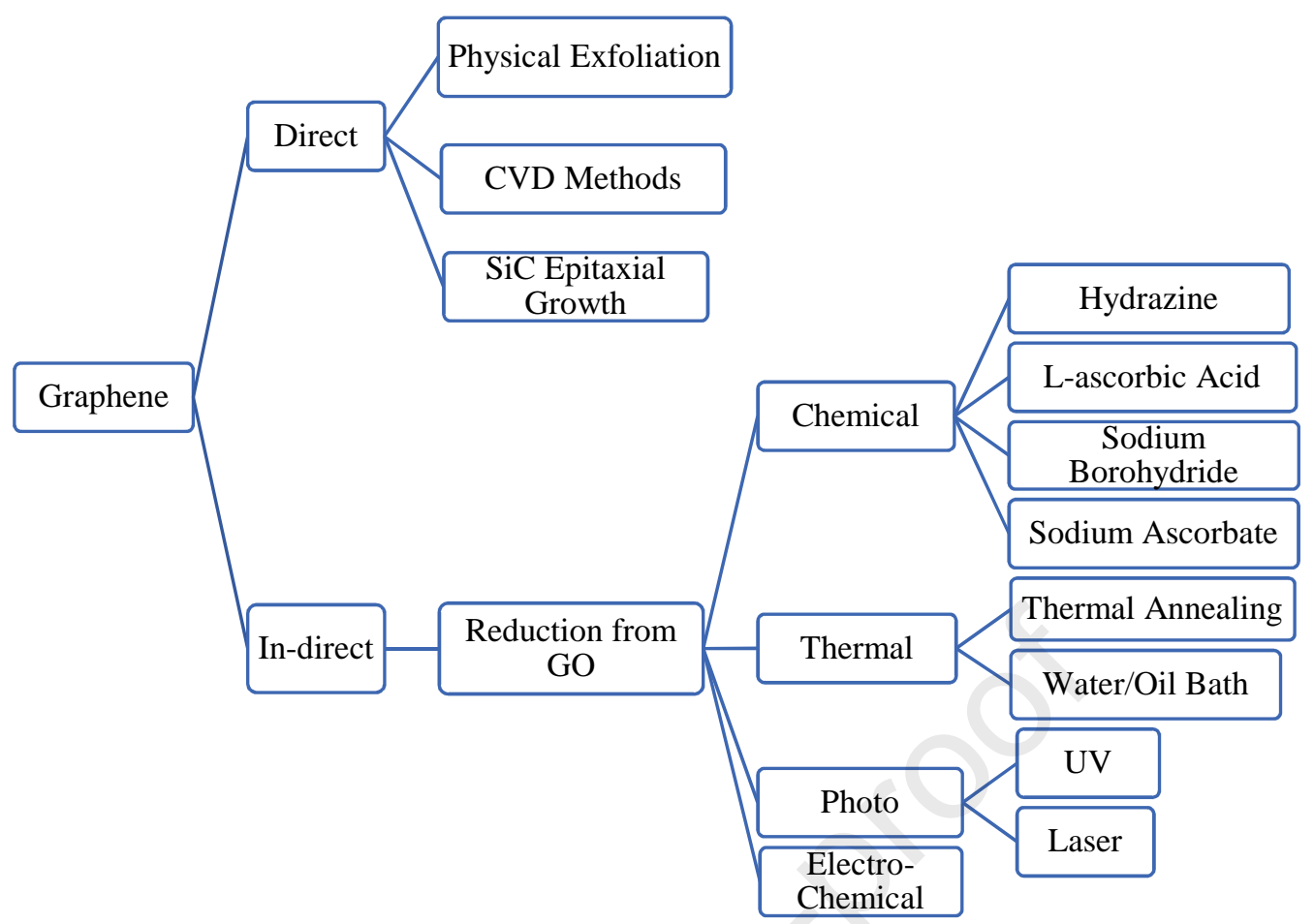

Figure 1: Fabrication methods of Graphene Family Materials

\subsubsection{Direct Methods}

Normal graphite can be treated as multiple layers of graphene that are connected together by Van der Waals force. The exfoliation method is a purely physical approach. Its main mechanism is to break the bond between adjacent layers of graphene and separate them from the raw graphite material. Approaches from mechanical peeling [1] to ultrasonic [12] and hydro-exfoliation [13, 14] can all be applied. Mechanical peeling using adhesive tapes was first applied in 2004 and it can be considered to be the first successful fabrication of graphene. Chemical vapor deposition (CVD) method is a commonly used method in the laboratory. Generally, the base material (for graphene to grow) will be heated up and placed in a chamber with constant $\mathrm{H}_{2}$ flow at high temperature. This procedure is to remove residue air. $\mathrm{CH}_{4}$ and $\mathrm{H}_{2}$ will then be pumped across the material for few hours and this gas flow will be gradually reduced until it stops. The material will then be allowed to cure for graphene to form and grow [15]. As for the epitaxial growth on $\mathrm{SiC}$, the process can be treated as the sublimation of $\mathrm{SiC}$ and was first reported by Bommel et al. [16] in 1975. The growth of graphene is achieved by heating up a piece of $\mathrm{SiC}$ wafer in a vacuum environment under high 
temperature. Silicon atoms are vaporized to leave a thin layer of carbon atoms on the surface, i.e. graphene, under a specific direction [17]. The product is typically large scale with high quality.

\subsubsection{Indirect Methods}

In practice, using reduced graphene oxide as graphene is a well-accepted method considering its performance in application and the difficulties of fabrication. In the following sections, most of the references to 'graphene' in the papers reviewed are actually references to 'reduced graphene oxide'. The most common method to synthesize graphene oxide was proposed by Hummers and Offeman in 1958. It involves adding graphite to a $\mathrm{H}_{2} \mathrm{SO}_{4}-\mathrm{NaNO}_{3}-\mathrm{KMnO}_{4}$ mixture and gradually adding water. After it is further diluted, filtered, dried, washed and dispersed in warm water, graphite oxide solution is formed [4]. This method is called conventional Hummer's method and is still in use 60 years later. Precisely, the material fabricated from Hummer's method is graphite oxide, which can be treated as multi-layer graphene oxide. The properties of graphene oxide and graphite oxide are similar despite their different structures. To synthesis graphene oxide from graphite oxide, it still needs further exfoliation operation [18]. The biggest problem with the conventional Hummer's method is the toxic and flammable gases such as $\mathrm{NO}_{2}, \mathrm{~N}_{2} \mathrm{O}_{4}$ and $\mathrm{ClO}_{2}$ that are produced during the reaction process. In recent years, researchers have optimized the process by changing the raw material and the ratio of raw material (eg. replacement of $\mathrm{NaNO}_{3}$ with a 9:1 mixture of $\left.\mathrm{H}_{2} \mathrm{SO}_{4} / \mathrm{H}_{3} \mathrm{PO}_{4}\right)$ to minimize the hazardous gas emission and enhance the level of oxidation for better fabrication quality [19]. Common methods of graphene oxide reduction are thermal method, chemical method and photo-reduction, which will be discussed in section 2.3.

\subsubsection{Comparison of production methods}

Each method of manufacturing graphene has its own advantages. The main advantage of exfoliation is its cost. The required materials are graphite and some cheap chemicals. Part of the output product of this process, on one hand, has high quality. On the other hand, the average quality of the graphene flakes produced is not easy to 
control and the quantity of flakes produced is relatively small. Consequently, the estimated price of a piece of hand size high quality graphene is more than a $£ 1000$. On the contrary, the price of high quality graphene oxide in the UK market is around $£ 80$ per gram, which is almost three times the market price of a gram of gold. However, the cost of industrial-grade graphene (low grade graphene), on the contrary, is relatively low and varies from $10 \mathrm{p} / \mathrm{g}$ to $£ 10 / \mathrm{g}$ depending on the quantity of graphene layers. Exfoliation method is more suitable for small scale laboratory use which is limited by the productivity and difficulty of operation. So far, CVD method is the most popular approach to fabricate a relatively large piece of graphene. It can not only produce large graphene sheets but also can guarantee the quality and uniformity of graphene to some extent regardless of the production time required.

\subsection{Reduction of Graphene Oxide to Reduced Graphene Oxide (Comparisons of GO to rGO reduction methods)}

As mentioned in the previous section, graphene is a hexagonal benzene ring shape $\mathrm{sp}^{2}$ 2D structure material. Graphene oxide, which is the oxidation of graphene, has the same structure and shape as graphene except that it also contains an oxygen functional group (typically as carboxyl or hydroxyl groups) at the edge of each ring, as the red dots in Figure 2 shows [20]. The oxygen functional group will weaken the properties of the original graphene material and the properties of GO can be improved via the reduction achieved by either chemical or thermal method.
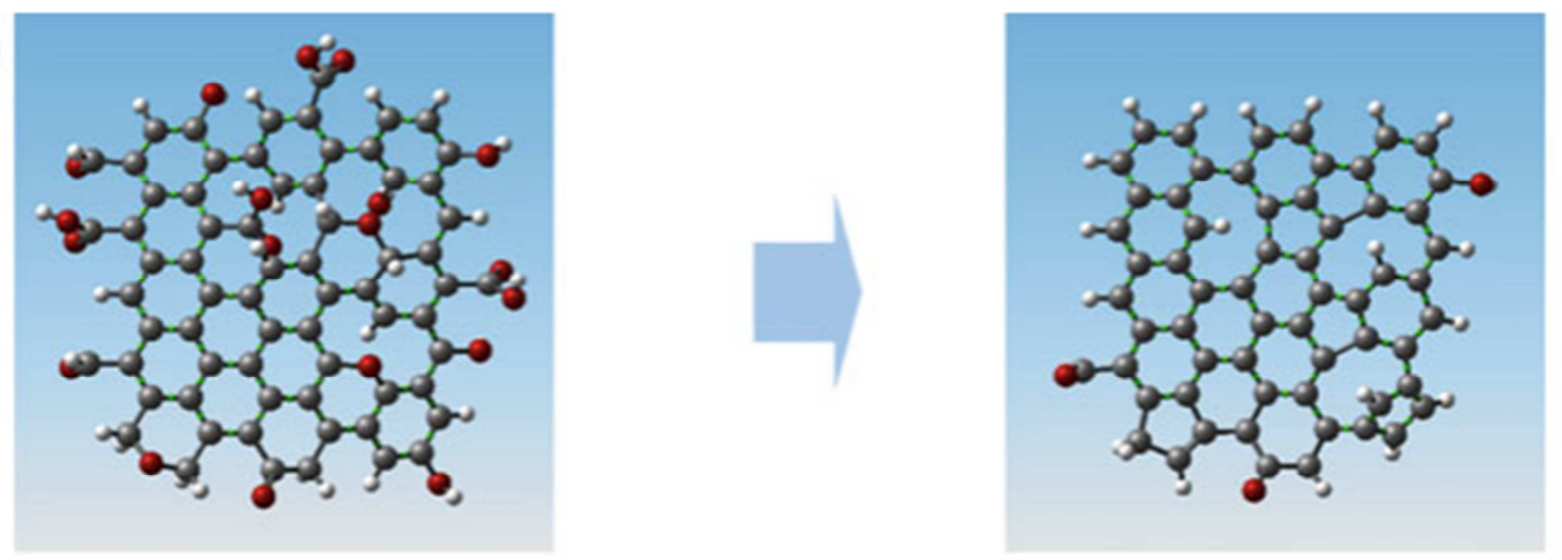

Figure 2: Reduction process of GO to rGO [20] 


\subsubsection{Thermal Reduction}

The core mechanism of thermal reduction is using temperature increment to boost the reaction between carbon and oxygen. The oxygen will be removed from GO and emitted as gas. The process always involves heating up GO at high temperature. Figure 3 [21] shows a detailed reduction process from graphene oxide to reduced graphene oxide under different ranges of temperature. GO crystal will be gradually heated up to $130^{\circ} \mathrm{C}$, the first critical temperature point, then the water in the material is vapourised and a small amount of GO is peeled off. When the temperature reaches $140^{\circ} \mathrm{C}-180^{\circ} \mathrm{C}$, residual water within the GO structure will be evaporated. The next stage is between $180^{\circ} \mathrm{C}$ to $800^{\circ} \mathrm{C}$, in which oxygen from the carboxyl and hydroxyl groups will form $\mathrm{CO}_{2}$ and will be removed through out-gassing. Then in the $800^{\circ}-1000^{\circ} \mathrm{C}$ range large amount of defect in the product's structure will be generated due to the removal of epoxide group $(-\mathrm{CH}(\mathrm{O}) \mathrm{CH}-)$ and the breaking of $\mathrm{C}-\mathrm{C}$ bond. Within $1000^{\circ}-2000^{\circ} \mathrm{C}$, layers of rGO crystal will slowly grow stacking onto the bottom layer to form thick rGO. However, it needs to be noted that the final product is a mixture of different quality of $\mathrm{rGO}$, which means the quality of the final product is not being perfectly controlled.

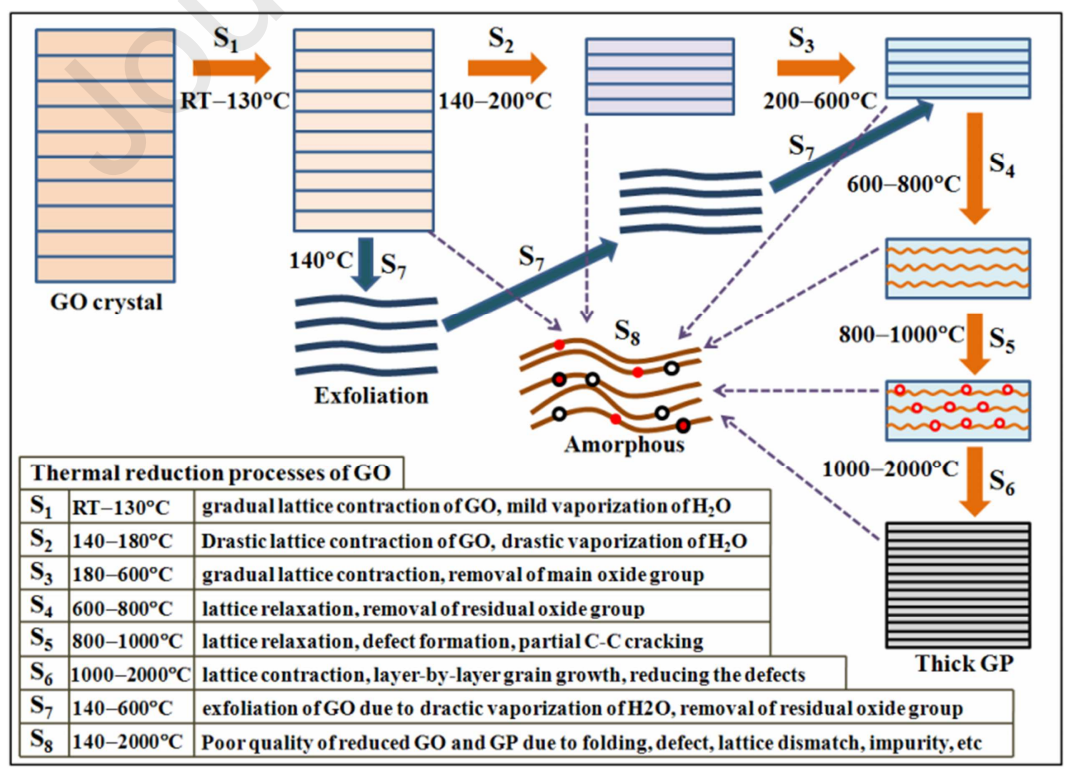

Figure 3: Process of the reduction of graphene oxide [21]

Another commonly applied thermal method to reduce graphene oxide is rapid heating. Schniepp et al. [22] successfully acquired single sheet graphene by placing pre-dried 
graphite oxide into a quartz tube rapidly pre-heated $\left(>2000^{\circ} \mathrm{C} / \mathrm{min}\right)$ to $1050^{\circ} \mathrm{C}$ for 30 seconds in Argon flow. Similarly, the reduction mechanism is the vaporizing of $\mathrm{CO}_{2}$. The rapid heating process can also be defined as thermal annealing. Likewise, Li et al. [23] reduce $\mathrm{GO}$ at $800^{\circ} \mathrm{C}$ temperature to form rGO sheet, while Zainy et al. [24] produced $\mathrm{rGO}$ under 20 seconds $1000^{\circ} \mathrm{C}$ thermal treatment. However, not surprising, the purity of rGO systhesised from rapid heating is high yet the product is typically a mixture of rGO of different numbers of layers.

Mild reduction is another possible method. Unlike rapid heating, the heating rate is relatively low and commonly conducted in liquid phase GO dispersion. The GO dispersion is reduced to rGO using different mild temperature conditions including a $150^{\circ} \mathrm{C}$ oil bath [25], $200^{\circ} \mathrm{C}$ thermal treatment for 12 hours in an inert environment [26], $125^{\circ} \mathrm{C}$ thermal treatment for 3 hours [27], $165^{\circ} \mathrm{C}$ microwave-assisted treatment [28] and $300^{\circ} \mathrm{C}$ reduction [29-31]. The quality of the final product differs depending on the reduction time.

To improve the quality of thermally annealed rGO, researchers have tried several possible improvements. Adding chemicals such as melamine [32] and surfactant will improve the quality of the product to some extent. Consequently, small amounts of impurity will be added into the final product and will reduce the product's purity. Changing the raw material from GO to coronene trichlorobenzene solution and pre-polishing the base material for rGO to grow will make the final product relatively better [33]. Low temperature $\left(90^{\circ} \mathrm{C}\right)$ and long time (5-9 days) annealing [34] could synthesis good quality of rGO as well.

To summarise, thermal reduction of GO to $\mathrm{rGO}$ is a good approach to acquire $\mathrm{rGO}$. The temperature of reduction varies from dozens of degrees to few thousand degrees. Treatment time also differs from few seconds to few days. The quality of synthesized rGO is not easy to control.

\subsubsection{Chemical Reduction}

Chemical method is also an option for the reduction of graphene oxide. The most commonly applied chemical reduction regents are hydrazine [35-43], sodium 
borohydride [44-46] and hydrohalic acid [47, 48]. Other materials such as sodium ascorbate[49], L-ascorbic acid [50, 51], sodium-citrate [52] can be used as well.

The mechanism of chemical reduction of GO to rGO is a complicated process. So far this question has not been fully answered by researchers. For halogen acid, Pei et al. [47] believe that halogenation agents like $\mathrm{HBr}$ acid and $\mathrm{HI}$ acid can catalyze the convertion of epoxy groups into hydroxyl groups. Under specific temperature, halogen atoms are easy to be attached or removed from graphene without breaking the structure of the carbon lattice. The epoxy group at the edge of a graphene flake will be broken via ring-opening reaction and the hydroxyl group will be substituted by a halogen atom, which is easy to be removed because the binding energy of C-halogen atom is lower than $\mathrm{C}-\mathrm{H}$ bond. The reason for using $\mathrm{HI}$ acid is because C-I binding energy is the lowest among all C-halogen bonds.

As for hydrazine, Stankovic et al. [37] suggest that small amounts of carbonyl-containing oxygen functional group react with hydrazine to form hydrazones and partly remove the oxygen in the GO structure. Though this reaction is not the dominant reason. The majority of oxygen is assumed to be removed through the reduction of epoxide group by hydrazine to form hydrazine alcohol (open ring epoxides+hydrazine) first. The next process is dehydration to form aminoaziridine. The 2-stage process is illustrated in Figure 4 [37]. However, this theory still needs to be further validated. The reduction mechanism of using L-ascorbic acid is similar to using hydrazine [51]. The underlaying principle of the mechanism for the chemical reduction of graphene oxide is still an open question.

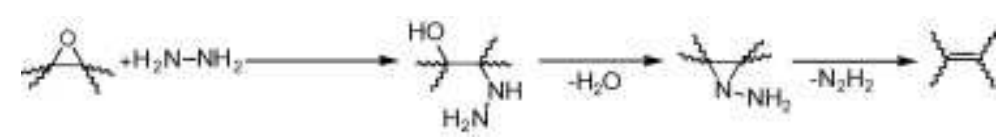

Figure 4: Possible mechanism of chemical reduction of graphene oxide [37]

\subsubsection{Photo Reduction}

Photo-reduction is typically laser-assisted. The thermal effect caused by laser irradiation could generate local high temperature and break the chemical bond 
between oxygen-containing functional group and carbon atoms of GO in areas exposed to the laser in order to remove oxygen as $\mathrm{CO}_{2}$. In other words, photo-reduction method is similar to thermal method to some extent and could be considered as an extremely high temperature thermal method. Figure 5 shows a piece of rGO synthesized by Calina et al. [53] by exposing a freestanding GO film to $660 \mathrm{~nm}$ continuous wave diode laser. The colour of the sample transforms from brown to black after reduction.

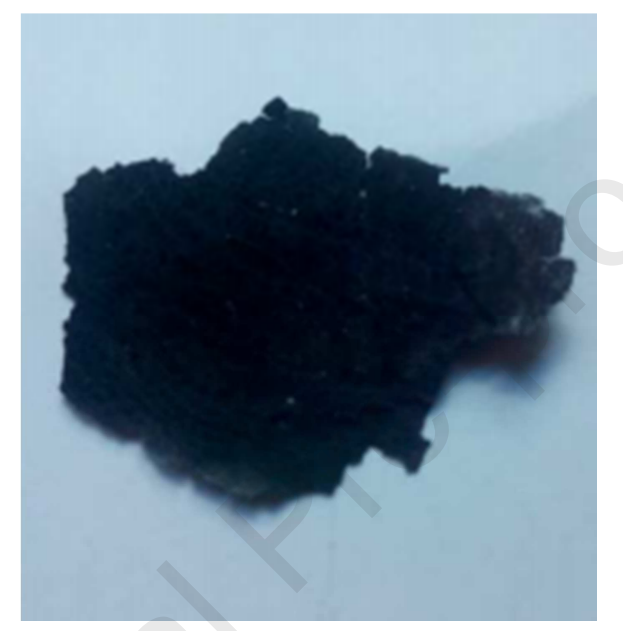

Figure 5: Laser reduced solid rGO acquired after continuous wave laser beam exposure of GO [53]

The output power of the laser beam depends on the laser generator and input voltage. Wavelength is the other important parameter for a laser beam. It could be used to calculate the power of a photon, which follows the equation of motion for photon $E=h c / \gamma$, in which $E$ represents the power of a photon $(K J), h$ is the Planck constant $6.62 \times 10^{-34} \mathrm{~J} \cdot \mathrm{s}, \mathrm{c}$ is the speed of light, $3 \times 10^{8} \mathrm{~m} / \mathrm{s}$, and $\gamma$ is the wavelength of light $(\mathrm{nm})$. The definition of individual photon's energy should not be confused with the power of a laser beam generated by the laser machine. The calculated value using the equation only represents the power of a single photon, which typically is a very small value though a beam of laser consists of millions of photons and the power can reach an extremely high value.

Commonly applied coating methods to coat GO onto a substrate material before laser reduction includes drop casting [53-57], spin coating [58-61], electro-spray coating [62], electroplating [63, 64] and even direct immersing [65-67]. Before coating, a sample needs to be entirely cleaned to remove oil, dirt and rust on the surface of 
material to ensure good bonding quality. High temperature annealing, plasma etching, dry ice blasting, laser blasting, chemical cleaning are the most commonly used methods of cleaning [68]. In real application the distribution of GO droplet on a sample may not be as uniform as expected. The non-uniformity of the liquid distribution is defined by the coffee ring effect [69]. This effect could be suppressed by adding surfactant [70] and for graphene oxide, titanium oxide is one of the suitable surfactants [55]. Other approaches like wet transfer [71, 72], direct CVD [71, 73-76], Langmuir-Blodgett film [23] and ultrasonic kinetic spraying [77] could be used as well. However, each of these methods requires special equipment and it is relatively complicated to operate. Consequently, the coating quality using these methods is relatively more uniform.

The operation for the reduction of solid phase graphene oxide is relatively simple. After GO solution has been coated onto a base material, it is cured and dried until it is totally dried. The laser will then be used to scribe on the dried GO in order to reduce graphene oxide to reduced graphene oxide. Figure 6(a) shows rGO sample attached on polyethylene terephthalate (PET) wafer produced by Marquez et al. [78], Figure 6(b) shows a SEM picture of laser scribed area with clear scribing lines, the magnify rate is around 400,000 times [79].

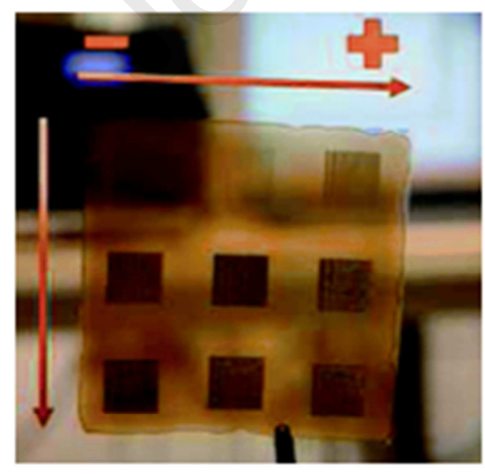

(a)

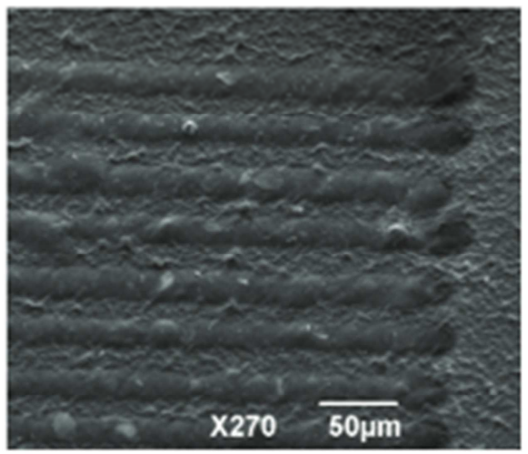

(b)

Figure 6: (a) rGO sample on PET substrate [78], (b) SEM image of laser irradiation line on GO [79] A major advantage of laser reduction method to produce $\mathrm{rGO}$ is that a programmable laser machine can be used to produce the rGO of any desired shape and size. Due to that flexibility, laser reduced graphene oxide is commonly applied to produce 
products with complicated shapes. The product varies from $\mu \mathrm{m}$ level electrical circuit to hand size super capacitor. Figure 7 shows rGO samples of different complicated shapes produced by Gao et al. [80] at Rice University.

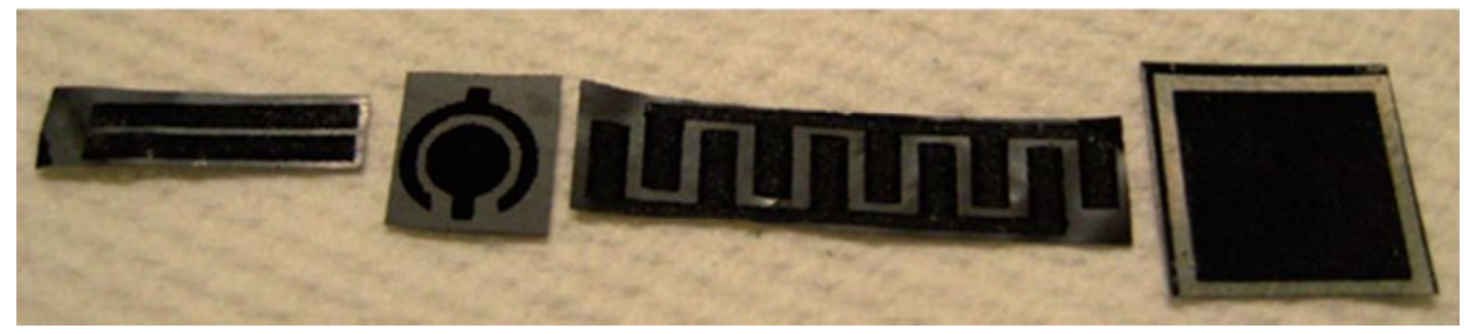

Figure 7: Schematics of laser reduced rGO in different patterns [80]

Liquid phase GO solution can also be directly reduced via direct irradiation using pulse laser [81-86]. The entire reduction process is swift: it only takes few minutes. The reduction time depends on the power of the laser and the distance between the laser head and the solution. Figure 8 shows some examples: Figure 8 (a) from Huang et al. [81] shows the application of a $248 \mathrm{~nm} \mathrm{KrF}$ excimer laser to irradiate GO solution for 5 min and Figure 8 (b), from Kumar et al. [84], shows the irradiation of GO solution (brown) using a $300 \mathrm{~mJ}$ excimer laser for $1 \mathrm{~h}$ to produce a rGO solution (black). The product shows clear changes from brown-yellow colour GO solution to black colour rGO solution before and after reduction, respectively.

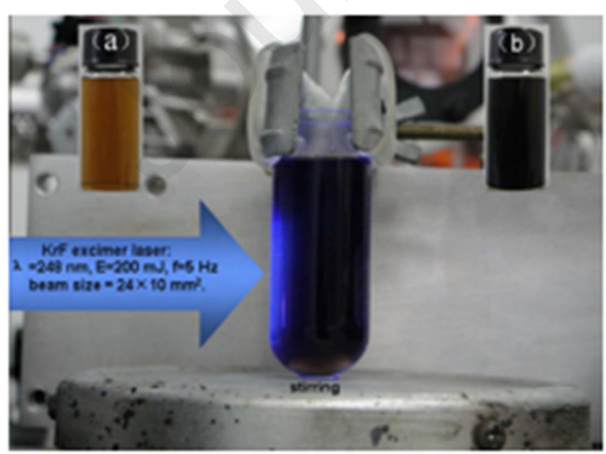

(a)

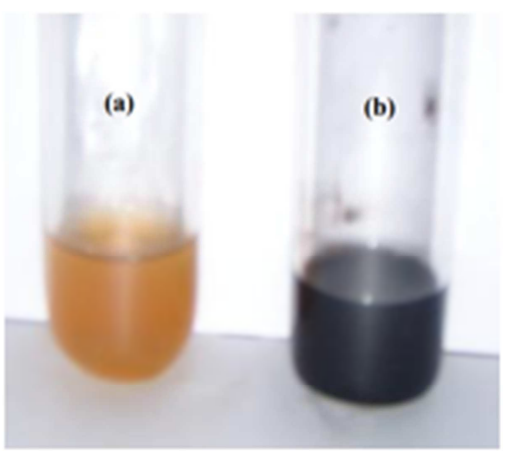

(b)

Figure 8: KrF excimer laser reduced liquid GO to liquid rGO: (a)Huang et al. [81], (b)Kumar et al. [84]

Table 2 compares parameters of the laser used for GO reduction.

Table 2: Laser parameters for the reduction of GO

\begin{tabular}{|c|c|c|c|c|c|c|c|}
\hline Laser Type & Wavelength & $\begin{array}{c}\text { Pulse } \\
\text { Duration }\end{array}$ & Frequency & $\begin{array}{c}\text { Laser } \\
\text { Size }\end{array}$ & $\begin{array}{c}\text { Irradiation } \\
\text { Time }\end{array}$ & $\begin{array}{l}\text { Laser } \\
\text { Power }\end{array}$ & Source \\
\hline \multicolumn{8}{|c|}{ Liquid Phase GO } \\
\hline KrF excimer & $248 \mathrm{~nm}$ & $10 \mathrm{~ns}$ & & & & $4-72$ & [59] \\
\hline
\end{tabular}




\section{Journal Pre-proof}

\begin{tabular}{|c|c|c|c|c|c|c|c|}
\hline laser & & & & & & $\mathrm{mJ} / \mathrm{cm}^{2}$ & \\
\hline $\begin{array}{c}\text { KrF excimer } \\
\text { laser }\end{array}$ & $248 \mathrm{~nm}$ & $20 \mathrm{~ns}$ & $5 \mathrm{~Hz}$ & $\begin{array}{c}240 \\
\mathrm{~mm}^{2}\end{array}$ & $5 \mathrm{~min}$ & $\begin{array}{c}83 \\
\mathrm{~mJ} / \mathrm{cm}^{2}\end{array}$ & [81] \\
\hline $\begin{array}{l}\text { KrF excimer } \\
\text { laser }\end{array}$ & $248 \mathrm{~nm}$ & & $10 \mathrm{~Hz}$ & & $1 \mathrm{~h} / 2 \mathrm{~h}$ & $\begin{array}{c}300 \\
\mathrm{~mJ} / \\
530 \mathrm{~mJ}\end{array}$ & [82] \\
\hline $\begin{array}{l}\text { Nd:YAG } \\
\text { pulsed laser }\end{array}$ & $532 \mathrm{~nm}$ & $5 \mathrm{~ns}$ & $10 \mathrm{~Hz}$ & $\begin{array}{c}28 \\
\mathrm{~mm}^{2}\end{array}$ & $15-300 \mathrm{~min}$ & $\begin{array}{c}320 \\
\mathrm{~mJ} / \mathrm{cm}^{2}\end{array}$ & [83] \\
\hline $\begin{array}{c}\text { KrF excimer } \\
\text { laser }\end{array}$ & $248 \mathrm{~nm}$ & & $5 \mathrm{~Hz}$ & & & $300 \mathrm{~mJ}$ & [84] \\
\hline $\begin{array}{l}\text { Nd:YAG } \\
\text { pulsed laser }\end{array}$ & $532 \mathrm{~nm}$ & $5 \mathrm{~ns}$ & $10 \mathrm{~Hz}$ & $\begin{array}{c}28 \\
\mathrm{~mm}^{2}\end{array}$ & $1,2,3,4 \mathrm{~h}$ & $\begin{array}{c}320 \\
\mathrm{~mJ} / \mathrm{cm}^{2}\end{array}$ & [85] \\
\hline $\begin{array}{c}\text { Ti: Sapphire } \\
\text { laser }\end{array}$ & $800 \mathrm{~nm}$ & $35 \mathrm{fs}$ & $1 \mathrm{kHz}$ & & $75 \mathrm{~min}$ & $2 \mathrm{~W}$ & [86] \\
\hline \multicolumn{8}{|c|}{ Solid Phase GO } \\
\hline $\mathrm{CO}_{2}$ laser & & & & & & $2 \mathrm{~W}$ & [54] \\
\hline $\begin{array}{c}532 \mathbf{~ n m} \\
\text { continuous } \\
\text { wave laser } \\
\text { system }\end{array}$ & $532 \mathrm{~nm}$ & & & & & $\begin{array}{l}6 \mathrm{~W} / \\
\mathrm{cm}^{2}\end{array}$ & [57] \\
\hline $\begin{array}{c}\text { Continuous } \\
\text { wave diode } \\
\text { laser }\end{array}$ & $660 \mathrm{~nm}$ & & & & & $80 \mathrm{~mW}$ & [53] \\
\hline LightScribe & $788 \mathrm{~nm}$ & & & & $25 \mathrm{~min}$ & $5 \mathrm{~mW}$ & [60] \\
\hline $\begin{array}{l}\text { Ti: Sapphire } \\
\quad \text { laser }\end{array}$ & $800 \mathrm{~nm}$ & $100 \mathrm{fs}$ & $1 \mathrm{kHz}$ & & & $\begin{array}{c}35 \\
\mathrm{~mJ} / \mathrm{cm}^{2}\end{array}$ & [61] \\
\hline Ad hoc laser & $550 \mathrm{~nm}$ & & & & & $\begin{array}{l}65 \\
\mathrm{~mW}-10 \\
5 \mathrm{~mW}\end{array}$ & [78] \\
\hline $\begin{array}{l}\text { Picosecond } \\
\text { laser }\end{array}$ & $1064 \mathrm{~nm}$ & & $100 \mathrm{KHz}$ & & $10-50 \mathrm{~mm} / \mathrm{s}$ & $\begin{array}{l}10-300 \\
\mathrm{~mJ} / \mathrm{cm}^{2}\end{array}$ & [79] \\
\hline $\begin{array}{l}\text { Nanosecond } \\
\text { laser }\end{array}$ & $355 \mathrm{~nm}$ & & & & $20 \mathrm{~s}$ & $2.3 \mathrm{~W}$ & [87] \\
\hline $\begin{array}{l}\text { Pulse Fiber } \\
\text { laser }\end{array}$ & $1064 \mathrm{~nm}$ & $100 \mathrm{~ns}$ & $20 \mathrm{kHz}$ & $\begin{array}{l}460 \\
\mu \mathrm{m}\end{array}$ & $\begin{array}{c}2 \mathrm{~m} / \mathrm{s}, 2 \text {-time } \\
\text { scanning }\end{array}$ & $\begin{array}{l}1.87 \mathrm{k} \\
\mathrm{W} / \mathrm{cm}^{2}\end{array}$ & [88] \\
\hline $\begin{array}{c}\text { Nd:YAG } \\
\text { pulsed laser }\end{array}$ & $532 \mathrm{~nm}$ & $7 \mathrm{~ns}$ & $30 \mathrm{~Hz}$ & $6 \mathrm{~mm}$ & $\begin{array}{c}6,10,30 \\
60,180 \mathrm{~s}\end{array}$ & $\begin{array}{l}30-80 \\
\mathrm{~mJ} / \mathrm{cm}^{2}\end{array}$ & [89] \\
\hline $\begin{array}{c}\text { Nd:YAG } \\
\text { pulsed laser }\end{array}$ & $266 \mathrm{~nm}$ & $5 \mathrm{~ns}$ & $10 \mathrm{~Hz}$ & & $\begin{array}{l}1.5 \mathrm{~mm} / \mathrm{s} \\
10^{4} \text { pulses }\end{array}$ & $\begin{array}{l}200 \\
\mathrm{~mJ} / \mathrm{cm}^{2}\end{array}$ & [90] \\
\hline $\begin{array}{c}\text { Fiber-rod } \\
\text { amplified } \\
\text { femtosecond } \\
\text { laser }\end{array}$ & $1030 \mathrm{~nm}$ & $280 \mathrm{fs}$ & $2 \mathrm{MHz}$ & & & $20 \mathrm{~W}$ & [91] \\
\hline LightScribe & & & & & & & [92] \\
\hline
\end{tabular}


in DVD

drive

DVD laser

$788 \mathrm{~nm}$

To aquire the best quality of synthesised laser reduced graphene oxide, it is necessary

to choose a laser of appropriate power and the irradiation time/scribbing speed need to be adequate. Also, the base material should be entirely cleaned and polished in order to remove the barrier between graphene layer and base material so as to improve the quality and purity of coating. In addition, the sample needs to be kept flat during the laser reduction process. If possible, the sample should be left in an inert atmosphere or vacuum enviroment during drying and reduction process to improve the quality of reduced graphene.

\subsubsection{Other Approaches}

There are other methods to reduce graphene oxide into rGO apart from those three most commonly used approaches. For instance, electrochemical approach, using alternating current passed through metal electrodes immersed in GO solution to produce $\mathrm{rGO}$ via local heating and the rGO produced will be deposited on the electrodes [96-98]. UV reduction, similar to laser irradiation, is another modified photo-reduction approach. It involves the replacement of a laser power source by UV light $[99,100]$. Another method is the hydrothermal approach. It uses an autoclave to heat up GO solution for few hours followed by a period of cooling down during which the GO reduction occurs [101]. The GO reduction method employed depends on the availability of equipment in a laboratory and the quality requirement for the product.

\subsubsection{Discussion}

The most commonly used methods to reduce GO to rGO are thermal, chemical and photo-reduction methods. Each method has its own advantages and disadvantages. The thermal method can produce a relatively large sheet of rGO. However, it requires thermal annealing equipment. Unlike commonly used laboratory furnace, the furnace 
used for thermal annealing has rapid heating function achieved by an accurate temperature control system and sample delivery system. Consequently, this equipment is not easy to access in many laboratories considering its massive weight and high cost. Moreover, the complicated control system is not easy to operate. For the chemical method, it does not require specific equipment, a standard flask is enough. The operation is relatively simple and not risky. Nevertheless, the final product is typically a water dispersion, it needs post processing to acquire the final product and is environmentally unfriendly with toxic waste gas emission. In addition, the reduction may not be successful every time. As for photo-reduction, it can be used to manufacture rGO in any wanted pattern. The main shortcoming of this method is that GO coating before laser induction needs a long time to cure, typically at least $24 \mathrm{~h}$ to entirely dry. The distribution of rGO on the substrate is not uniform and the quality of rGO is not easy to be controlled.

Currently, the best approach to synthesis good quality graphene is not by GO reduction. Reduction method is more suitable to fabricate enhancement micro-filler, capacitor and conductive electronics due to the quality and purity. Laboratory-grade high quality graphene for analysis and research still relies on low productivity but high quality CVD and exfoliation methods. If the high cost of $\mathrm{SiC}$ wafer is acceptable, $\mathrm{SiC}$ epitaxial growth is a good option for large-scale laboratory-grade high quality graphene.

\subsection{Physical and Mechanical Properties}

To take graphene into applications in real life, the properties of graphene needs to be understood firstly. In this section, the physical and mechanical properties of graphene will be introduced. This section will also focus on the introduction of its mechanical properties at both micro- and macro-levels and comparison of the differences between them.

\subsubsection{General Physical Properties}

Table 3: Physical properties of graphene

\begin{tabular}{cll}
\hline Properties & Value & Reference \\
\hline
\end{tabular}




\begin{tabular}{ccc}
\hline Colour & Black & \\
Specific Surface Area & $2630 \mathrm{~m}^{2} / \mathrm{g}$ & {$[102]$} \\
Intrinsic Mobility & $200000 \mathrm{~cm}^{2} / V \cdot s$ & {$[103]$} \\
Theoretical Young's Modulus & $1 \mathrm{TPa}$ & {$[2]$} \\
Theoretical Tensile Strength & $130 \mathrm{GPa}$ & {$[2]$} \\
Thermal Conductivity & Around $5000 \mathrm{~W} / \mathrm{mK}$ & {$[104,105]$} \\
Electric Resistance Rate & $200 \Omega / \mathrm{m}$ & {$[106]$} \\
Optical Transmittance & $97.7 \%$ & {$[35]$} \\
Melting Temperature & $4510 \mathrm{~K}$ & {$[107]$} \\
Dissolvability & Hydrophobic & {$[108]$} \\
Chemical Stability & Prominent & {$[109]$} \\
\hline
\end{tabular}

Table 3 lists the most important properties of graphene. From the data, it can be concluded that graphene has outstanding properties. Its chemical stability is prominent. Graphene does not easily react with other materials and it is stable under normal conditions [109]. As for its physical properties, it has low electric resistance rate of close to $200 \Omega / \mathrm{m}$, which is attributed to its good electrical conductivity [106]. Its thermal conductivity is close to $5000 \mathrm{~W} / \mathrm{mK}[104,105]$ and its melting temperature is $4510 \mathrm{~K}$ [107]. Graphene's absorption rate of white light is $2.3 \%$ [35], it is highly hydrophobic and it forms a good dispersion in water [108].

Graphene can be applied in various areas. Many researchers are currently trying to combine the high electrical conductivity of graphene with commercial electronic parts to produce better performance electrode for cell systems [110-112], super capacitors [113-115], flexible sensors for wearable devices [116-118] electronic textiles [119, 120], and batteries with long lifetime [121, 122]. However, graphene-based electronics does not have significant improvement on its power storage capability but incurs significant increase in production cost. Therefore, it is not currently cost-effective to apply graphene electronics in daily life. Researchers from the University of Manchester have developed graphene-based ions sieve for the desalination of sea water. This is considered to be one of the most successful applications of graphene in recent years [123]. It provides a relatively low cost solution compared with currently used sea water desalination methods to solve the shortage of drinking water problem in dry areas.

The main objective of this review is the application of graphene for material 
enhancement, which will be introduced in detail in the following sections.

\subsubsection{Differences in micro and macro mechanical properties}

As introduced in previous sections, the theoretical values of graphene's Young's modulus and tensile strength are up to $1 \mathrm{TPa}$ and $130 \mathrm{GPa}$, respectively [2]. This extremely high value of tensile strength is more than 600 times of the tensile strength of steel which makes graphene to be the strongest material discovered so far. One explanation for this ultrahigh value is that the ultrathin mesh of carbon atoms has an hexagonal honeycomb pattern. It has a large specific surface area $\left(2630 \mathrm{~m}^{2} / \mathrm{g}\right)[102]$, and contains large amounts of high strength carbon-carbon bonds [3]. However, in the real world, to tear a piece of graphene apart is as easy as tearing a piece of paper. The reason is because graphene sheet always contains large numbers of micropores, in other words, bad quality. Besides, unlike traditional method using tensile test to assess a material's mechanical properties, the measured values of graphene properties are derived at micro-level on ultra-small sample pieces. The tensile strength value of 130GPa was measured using AFM (atomic force microscope) nanoindentation method. This method uses a silicone membrane full of circular wells of $500 \mathrm{~nm}$ depth with $1.5 \mu \mathrm{m}$ and $1 \mu \mathrm{m}$ diameters, which is placed on a $300 \mathrm{~nm}$ thick $\mathrm{SiO}_{2}$ glass wafer as base, as shown in Figure 9(a) and Figure 9(b). Graphene layers are deposited onto the micro holes and an AFM is used to carry out nano-indentation of the free segments of the graphene layers covering the micro holes. Figure 9(c) illustrate the process of the nano-indentation: the curved cantilevered stylus of the AFM breaks the graphene segment covering the micro-holes (shown in Figure 9(d)) and the AFM records the breaking force and the breaking strain, which are used to derive the Young's modulus [2]. The same measurement procedure has been performed by Zhang et al. [124] and they obtained a result of $0.89 \mathrm{TPa}$, which is less that the $1 \mathrm{TPa}$ value reported by Lee et al. [2]. The nanoindentation process can be simulated via molecular dynamic packages and the simulation results confirms this value [125]. However, the AFM experiment performed by Frank et al. [126] obtained a relatively low value of elastic modulus of only $0.5 \mathrm{TPa}$, which is significantly smaller than the values obtained by 
other investigators.
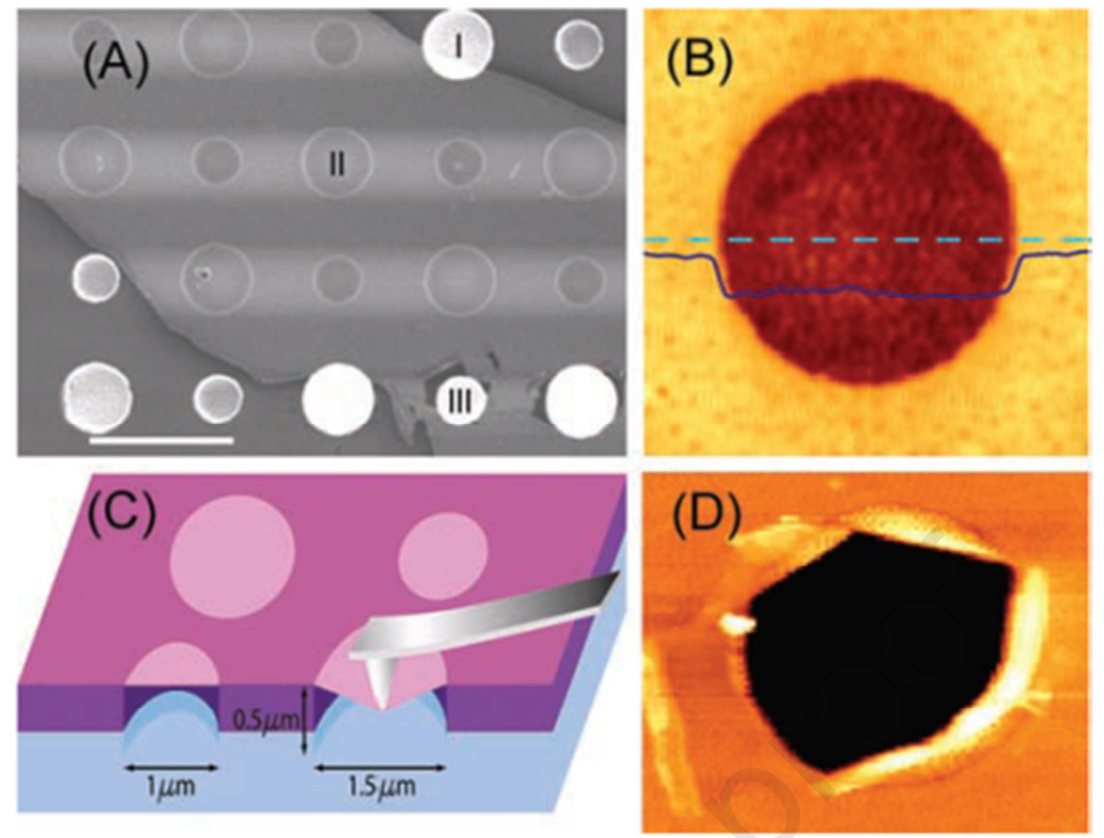

Figure 9: Schematic of AFM nanoindentation method (a) Top view of wafer with micro-holes covered by graphene, (b) Depth profile of micro-hole, (c) Schematic of the measuring process through AFM nanoindentation, (d) Photo of broken graphene flake [2]

Another method being used to measure the micro Young's modulus of graphene was performed by Lee et al. [127] using Raman spectroscopy to derive Young's modulus of graphene. Raman test uses a laser beam irradiated sample and records the spectrum of the reflected beam. Unlike AFM-nanoindentation method, Raman spectroscopy records the change of graphene spectrum before and after deformation caused by applying a vacuum. This process is shown in Figure 10(a). The spectrum will first be measured on a flat sample under normal pressure, then in an evacuated chamber to cause negative pressure on the surface of graphene and make the sample deform to measure the new spectrum. From the difference in the Raman spectroscopic, as shown in Figure 10(b), the value of the micro Young's modulus of graphene is derived to be $2.4 \pm 0.4 \mathrm{TPa}$. From another Raman spectroscopic experiment Weng et al. [128] did derive a value of 1.48 TPa for the Young's modulus of graphene. 


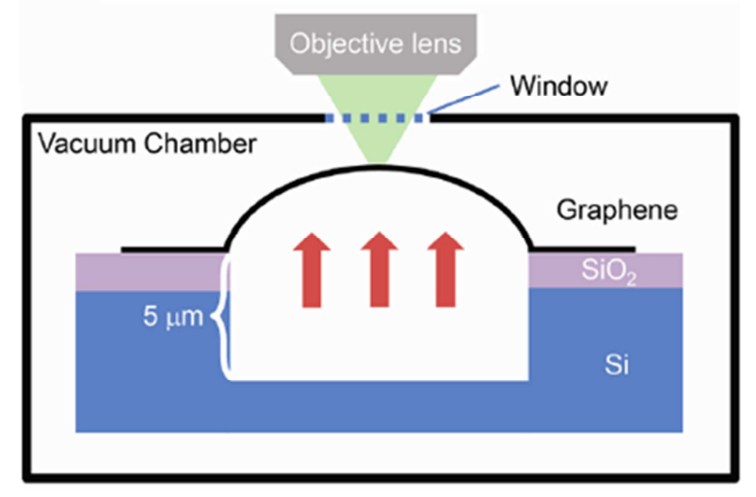

(a)

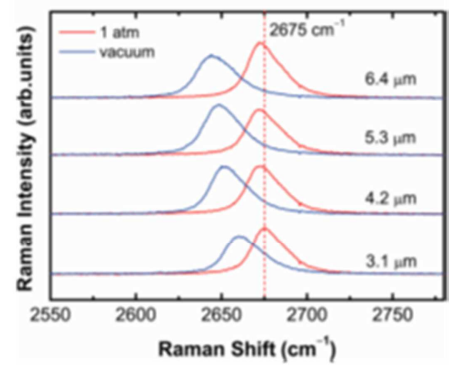

(b)

Figure 10: (a) Schematic of graphene elastic property measurement using Raman spectrum, (b) Change of Raman spectrum of graphene before and after apply vacuum used for elastic property measurement. Red:Raman spectrum under 1 atm, blue:Raman spectrum under vacuum [127]

In addition to previously mentioned AFM nanoindentation method and Raman analysis, numerical simulation using molecular dynamics software such as LAMMPS [125, 129-133], ABINIT [134], TINKER [135] and QUANTUM-ESPRESSO [136] have also been used to derive the theoretical values of the mechanical properties of graphene. The values of the Young's modulus predicted using these simulation are astonishingly close. They lie within the range 0.8 to $1.15 \mathrm{GPa}$ as shown in Table 4 . In addition, traditional tensile test method can be used to determine the elastic properties of graphene oxide paper. A large sheet of graphene is not easy to manufacture. Therefore, GO paper and $\mathrm{rGO}$ paper are widely used to represent graphene in macro-level strength test. Dikin et al. [137] synthesised GO paper through filtration of pre-prepared GO colloidal dispersions via an anodisc membrane filter. The GO paste is air dried and peeled off from the filter to form a large GO paper and is cut into a 5 $\mathrm{mm} * 30 \mathrm{~mm}$ strip to test, as shown in Figure 11 [137]. The average Young's modulus of their GO paper is $32 \mathrm{GPa}$ and the average tensile strength is $70.7 \mathrm{MPa}$. The maximum Young's modulus is $42 \pm 2 \mathrm{GPa}$ and maximum fracture stress is $133 \mathrm{MPa}$. 


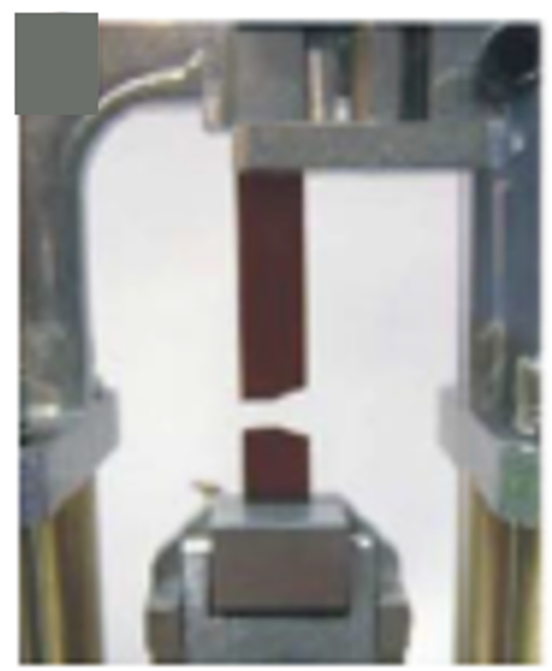

Figure 11: Tensile test under film tensile clamp [137]

Chen, et al. [138] used a similar film tensile test equipment to run a tensile test on chemically reduced graphene oxide paper, which is closer to graphene. The result is slightly higher than the values obtained by Dikin et al. [137]. The Young's modulus reached 41.8 $\mathrm{GPa}$ and the greatest failure stress was 293.3 MPa. Zhang et al. [139] performed a tensile test on different types of chemically modified rGO. The highest value of ultimate tensile strength obtained was $614 \pm 12 \mathrm{MPa}$, which is close to the ultimate tensile strength of 304 stainless steel (585 MPa). Table 4 compares the elastic properties of graphene tested or calculated by various researchers.

Table 4: Elastic Properties of Graphene from Various Sources (some values are roughly calculated from stress-strain curve in the paper)

\begin{tabular}{|c|c|c|c|c|c|}
\hline Sample Size & $\begin{array}{l}\text { Young's } \\
\text { Modulus }\end{array}$ & $\begin{array}{c}\text { Fracture } \\
\text { Strain }\end{array}$ & $\begin{array}{c}\text { Ultimate Tensile } \\
\text { Strength }\end{array}$ & Method & Source \\
\hline$\Phi 1.5 \mu \mathrm{m} \times 0.335 \mathrm{~nm}$ & $1.0 \pm 0.1 \mathrm{TPa}$ & 0.25 & $130 \pm 10 \mathrm{GPa}$ & $\begin{array}{c}\text { AFM } \\
\text { Nanoindentation }\end{array}$ & [2] \\
\hline $1568 \mathrm{~nm}^{2}$ & $0.89 \mathrm{TPa}$ & & & $\begin{array}{c}\text { AFM } \\
\text { Nanoindentation }\end{array}$ & [124] \\
\hline & $0.5 \mathrm{TPa}$ & & & $\begin{array}{c}\text { AFM } \\
\text { Nanoindentation }\end{array}$ & [126] \\
\hline & $2.4 \pm 0.4 \mathrm{TPa}$ & 0.19 & & Raman Analysis & [127] \\
\hline & $1.48 \mathrm{TPa}$ & & & & [128] \\
\hline \multirow[t]{2}{*}{$23.53 \AA ̊ \times 262.24 \AA$} & $3.4 \mathrm{TPa}$ & & & $\begin{array}{c}\text { Molecular } \\
\text { Mechanics and } \\
\text { ANSYS Simulation }\end{array}$ & [135] \\
\hline & $0.95 \mathrm{TPa}$ & & & LAMMPS & [125] \\
\hline
\end{tabular}


Journal Pre-proof

\begin{tabular}{|c|c|c|c|c|c|}
\hline & $1.15 \mathrm{TPa}$ & & & LAMMPS & {$[129$} \\
\hline \multirow[t]{3}{*}{$21 \mathrm{~nm} \times 25 \mathrm{~nm}$} & $950 \mathrm{GPa}$ & 0.24 & $170 \mathrm{GPa}$ & LAMMPS & {$[131$} \\
\hline & $1050 \mathrm{GPa}$ & 0.208 & $107.4 \mathrm{GPa}$ & ABINIT simulation & {$[134$} \\
\hline & $805.6 \mathrm{GPa}$ & 0.38 & & $\begin{array}{c}\text { Molecular } \\
\text { Mechanics Method } \\
\text { (Calculate) }\end{array}$ & {$[140$} \\
\hline $5 \mathrm{~mm} \times 30 \mathrm{~mm}$ & $42 \pm 2 \mathrm{GPa}$ & & $133 \mathrm{MPa}$ & Tensile Test (GO) & {$[137$} \\
\hline \multirow[t]{2}{*}{$3 \mathrm{~mm} \times 15 \mathrm{~mm}$} & $41.8 \mathrm{GPa}$ & & $293.3 \mathrm{MPa}$ & Tensile Test (rGO) & {$[138$} \\
\hline & & $6.67 \pm 0.44 \%$ & $614 \pm 12 \mathrm{MPa}$ & Tensile Test (rGO) & {$[139$} \\
\hline $3 \mathrm{~mm} \times 27 \mathrm{~mm}$ & & & $85 \mathrm{MPa}$ & Tensile Test (rGO) & [52] \\
\hline
\end{tabular}

The data presented in Table 4 shows that all the values of graphene's mechanical properties acquired through tensile test are far less in magnitude than the values from micro-level measurement and simulation. The main reason for this could be structural defect in the tensile test samples. Taking a look at sample size, AFM nanoindentation sample is in $\mu \mathrm{m}^{2}$ micro level while tensile test is in $\mathrm{mm}^{2}$ macro level. The size differences are more than $10^{6}$ times, which means that there may be a much larger number of micro defects in a macro sample than in a micro sample, resulting in the large differences in test results. Besides, for micro-level measurement, any systematic errors and random experimental errors will be greatly magnified. Therefore, a small amount of error will influence the final result significantly. Also, because of the sharp stress concentration at the tip of the AFM cantilever beam, the AFM nanoindentation is only valid within the probe tip region [141]. Thus, it can be seen from the statistics in Table 4 that the simulation values of graphene properties, which are obtained via molecular dynamics analysis, are higher than the measured nanoindentation value. The main contribution of molecular dynamics simulation is to eliminate the influence of micro-defects and, thereby, obtain a more accurate property data of the flawless material. Furthermore, Young's modulus may not be constant at the micro level of the strain range. Thus, current analytical equations may be unable to describe accurately the mechanical relationships at the micro level resulting in some differences between the property values at the micro and macro levels. Therefore, it will be useful to simulate at the macro level by using many layers and including intra-layer and inter-layer hypothetical defects.

In conclusion, the chemical properties of graphene is stable and the theoretical 
physical properties of graphene are outstanding, especially its micro-level elastic properties that can reach an extremely high level. However, the micro-level elastic properties of graphene are still not easy to be applied since it is complicated to combine micro-level properties with macro-level objects. This is a potential research area for future work on the application of graphene.

\section{Analysis of rGO Quality}

As introduced in previous sections, the quality of rGO is not easy to be controlled during reduction and its quality will influence its application. Thus, before rGO is applied, its quality needs to be checked.

\subsection{Colour Differences between GO and rGO}

The simplest way to observe and determine the transformation process from GO to rGO is to watch the changing colour during reduction. Many publications describe graphene oxide dispersion as a 'brown-yellow colour liquid'. As reduction proceeds, the brown-yellow colour liquid gradually turns into black, as previously shown in Figure 8 for laser direct irradiation. Similarly, Figure 12 shows the change of colour before and after for other methods of GO reduction.

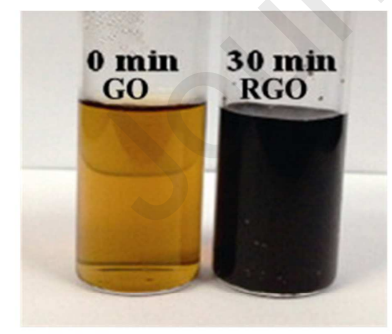

(a)

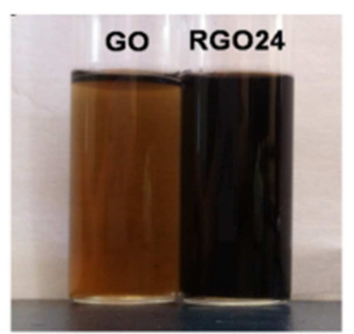

(d)

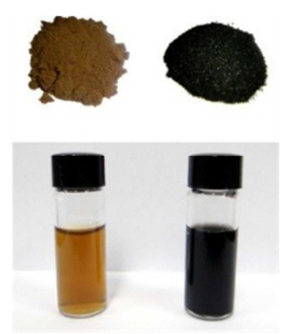

(b)

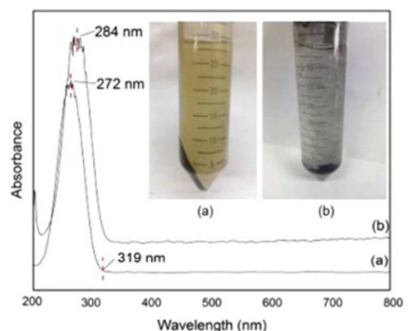

(e)

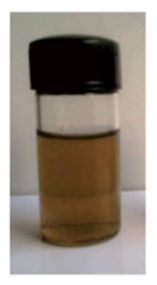

GO

(c)

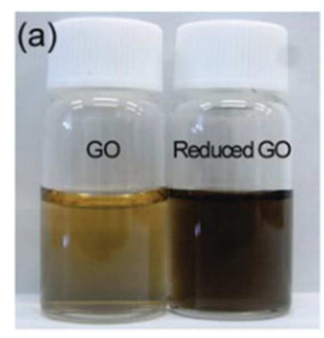

(f)

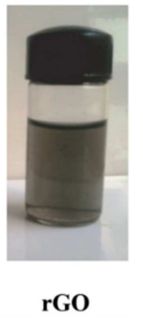

rGO

Figure 12: GO dispersion before and after reduction (a) Reduction of graphene oxide through chemical reduction method [142], (b) Reduction of graphene oxide achieved using plant leaf extracts [143], (c) 
Vegetable extracts reduced graphene oxide [144], (d) UV reduced graphene oxide for $24 \mathrm{~h}$ irradiation[145], (e) Hydrazine reduced graphene oxide after centrifugation [146], (f) UV method reduced graphene oxide[147]

However, the colour of the solution can affect the identification of the material. Sometimes the colour of GO dispersion is black if the concentration of GO is high. Figure 13 shows three concentrations of GO solutions, which are shown on the website of a UK graphene retailer GO-Graphene, with three distinct colours. The figure shows that the $0.5 \mathrm{mg} / \mathrm{ml} \mathrm{GO}$ dispersion has brown-yellow colour, while the $1 \mathrm{mg} / \mathrm{ml} \mathrm{GO}$ dispersion has deep brown colour. The $2 \mathrm{mg} / \mathrm{ml} \mathrm{GO}$ dispersion is almost pure black. Therefore, the colour of a $\mathrm{GO} / \mathrm{rGO}$ dispersion cannot be used to establish the concentration and material type. It can only be used as an approximate estimation.

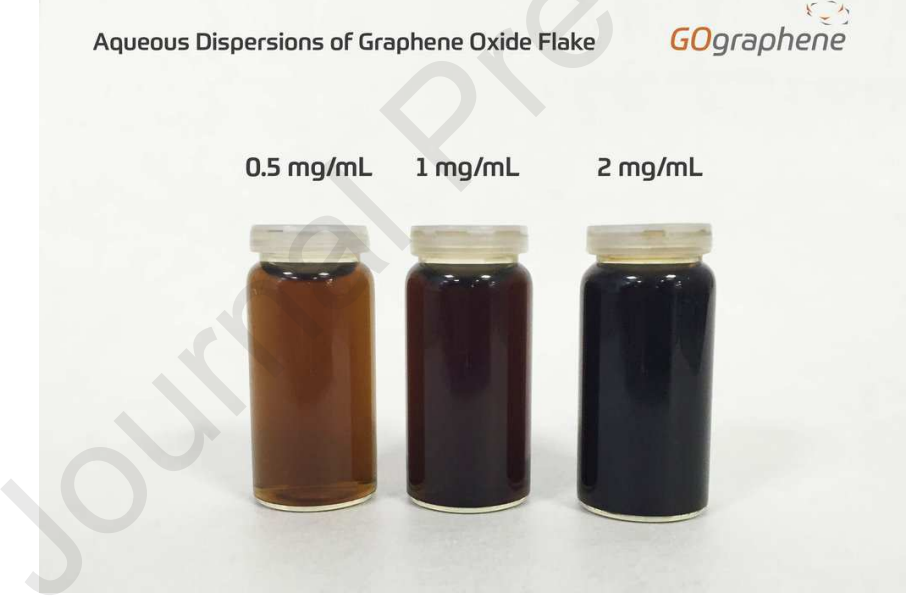

Figure 13: Colours of GO dispersions of different concentrations [148]

\subsection{Observation of Morphology and Layers of Graphene}

The number of layers of graphene is one of the most important parameters to assess the quality of synthesized graphene at micro-level. In real life, graphene and rGO products are likely to be a mixture of single and multi-layer flakes in which as defined before, each layer represents a single atom thick graphene or rGO flake. If the particles in dispersion are too aggregated in multi-layer then it might affect the application and requires further treatment like sonication to improve the quality.

To determine the morphology of synthesized GO or rGO in dispersion and decide whether further treatment should be applied, specific optical analysis equipment 
including conventional electron-microscope (EM), transmission electron microscope (TEM) and scanning electron microscope (SEM) need to be used. TEM [149, 150] and SEM [151-155] are more commonly used for the detail analysis of graphene.

The working principles of these three types of microscopes are not the same. Their operating principles are compared in Figure 14 [156]. The main difference between EM and TEM / SEM is that EM is an optical technique while TEM / SEM require the assistance of an electron beam. The EM employs two lenses to enlarge the image, which will display on the screen. The output image is in $2 \mathrm{D}$. Some advanced electron microscope can do image fitting and produce a 3D model using in-built algorithms. Considering its magnify rates (600-1000 times), the application of EM is to roughly observe the aggregation of graphene flakes in a liquid mixture or in the cross-section of solid composites. It should not be used for precise morphology analysis such as the observation of micro-defect at the edge of particles or the thickness of the produced rGO and the morphology of GO/rGO flakes. For TEM, it requires a beam of electron to pass through the sample and display the image on the display board underneath. Due to its working principle, the sample needs to be extremely thin. Otherwise, the electron beam cannot pass through the sample. The thickness of sample is typically between $50-100 \mathrm{~nm}$ and the magnification rate can reach ten thousands to million times. SEM is suitable to capture 3D image. Its imaging mechanism uses electron beam to hit the sample. The reflected electrons will fall on detectors to form the image. Its magnification rate can reach 200,000 times and could be adjusted through changing the applied voltage. The images acquired by SEM has large depth of field and broad view, which can be used to illustrate the rugged surface. However, the power of the electron beam may damage the material. Therefore, SEM is not suitable for observing a delicate material surface. 


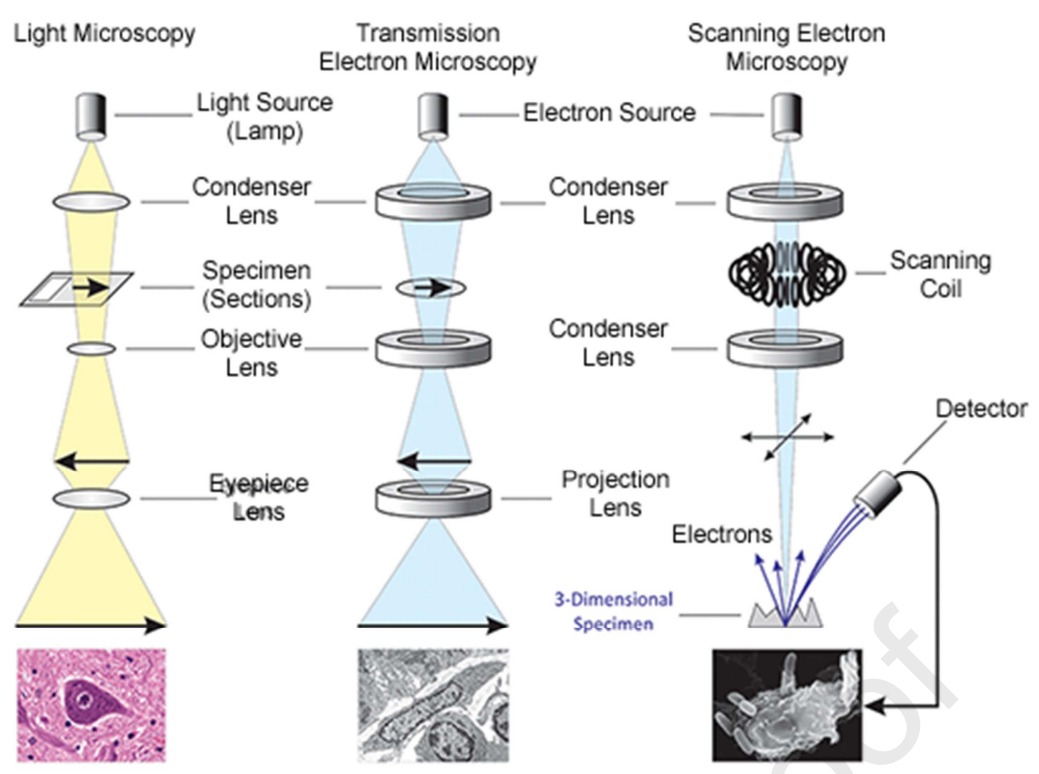

Figure 14: Working mechanism of different kinds of microscopes [156]

Apart from EM, TEM and SEM, scanning tunneling microscope (STM) and atomic force microscope (AFM) [157] are two other instruments for the observation of sample morphology. These two approaches can plot a similar 3D figure, which provides a full view of the captured area and also uses analysis software to observe and measure the detailed profile of selected cross-sections. Both STM and AFM use a measurement probe and their working principles are similar. However, STM is more suitable for conductive material, while AFM can be used for all types of materials. In both instruments, when the measurement probe tip is extremely close to the sample surface (in nanometer level), the sensor records ultra-small changes and plots the microstructure using their in-built algorithms. Both instruments provide a full view of the captured area as well as detailed profile of selected cross-sections, as shown by the AFM figure of thickness profile in Figure 15 [157]. Therefore, the surface flatness of graphene can be analysed using the thickness profile of AFM or STM.
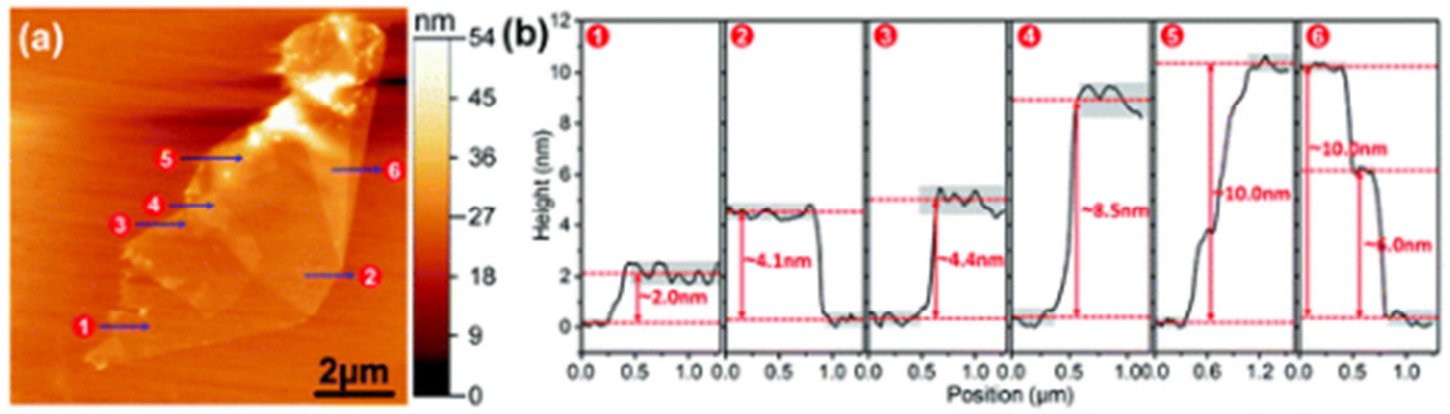
Figure 15: AFM image with multilayer graphene flakes and thickness profile in different position [157]

Nevertheless, due to the extremely close distance required between the probe tip and sample surface during the measurement process, it is possible for the probe tip to scratch and damage the surface of the sample. In practice, STM and AFM are more suitable for samples with hard surface. Consequently, the best equipment to analyse a sample may not be the one with the highest magnification rate. Table 5 compares properties of the different types of microscopes. The equipment should be chosen according to the properties of material and analysis requirement.

Table 5: Comparison of property differences between different microscopes

\begin{tabular}{cccccc}
\hline & EM & TEM & SEM & STM & AFM \\
\hline Magnification & $10^{3}$ & $10^{6}$ & $10^{5}$ & $10^{8}$ & $10^{9}$ \\
Resolution & mm & Sub-microscopic & Sub-microscopic & Atomic & Atomic \\
& level & level & level & level & level \\
Plot Shape & $2 \mathrm{D} \&$ & 2D & $3 \mathrm{D}^{*}$ & $3 \mathrm{D}^{*}$ & Real 3D \\
$\begin{array}{c}\text { Damage to } \\
\text { sample }\end{array}$ & No & No & Yes & Possible & Possible \\
Special & & Ultra-thin sample & & Conductive & \\
Requirement & & & sample &
\end{tabular}

*3D image may not be a real 3D capture, it might be a $3 \mathrm{D}$ view or a $3 \mathrm{D}$ image reconstructed by algorithms in a computer. However, a real 3D capture is a pure 3D model.

To obtain a view of the details at the edge of graphene flakes, the GO solution needs to be ultrasonicated or mechanically vibrated first, otherwise graphene flakes will stick together and the scanning instrument cannot capture enough details of the flakes to produce detailed plots to analyze. Figure 16 [153] compares aggregate graphene nanopletelets with and without sonication treatment. It is obvious that the left view graphene flakes stick together while in the right view graphene flakes spilt away. 


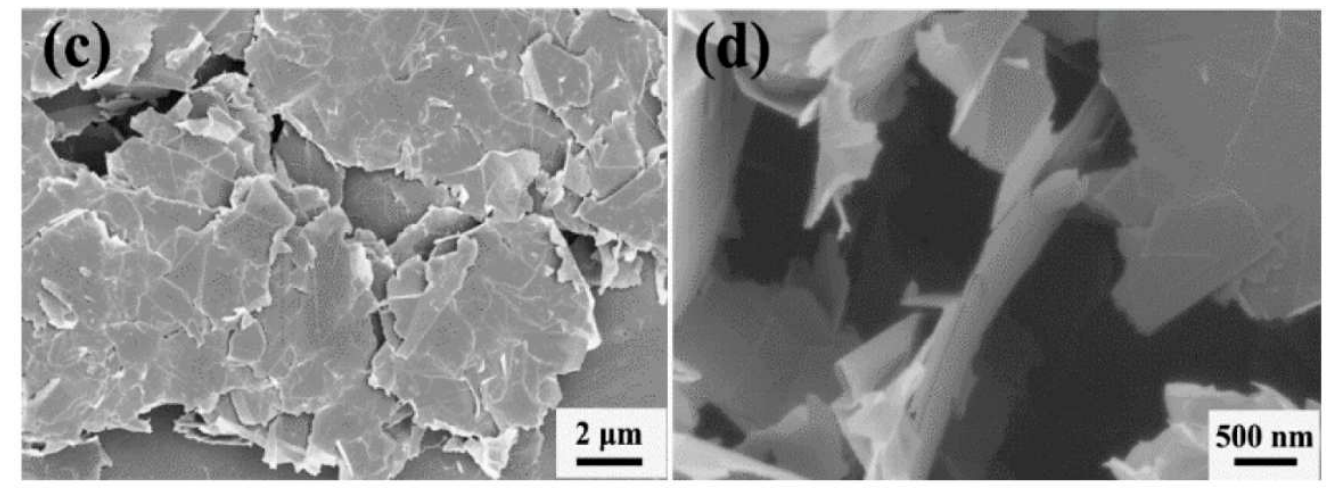

Figure 16: SEM images of graphene nanoplatelets with (c) and without (d) ultrasonic treatment [153] However, from Figure 16 [153], although the morphology of graphene flakes can be observed, valuable information like the overlapping region, number of layers and micro-defects at the edges of flakes are not easy to be directly determined. Even with the higher magnification rate of the TEM image shown in Figure 17 [150], which clearly shows the hexagonal benzene ring shape, the information is still not easy to be obtained. With the assistance of the JEMS software, designed for high resolution electron microscopy image simulation, it is possible to estimate the layers of different regions. Figure 18 [149] shows an example of the output of the JEMS software. The orange region represents single layer region. Green and purple areas represent double layers and triple layers.

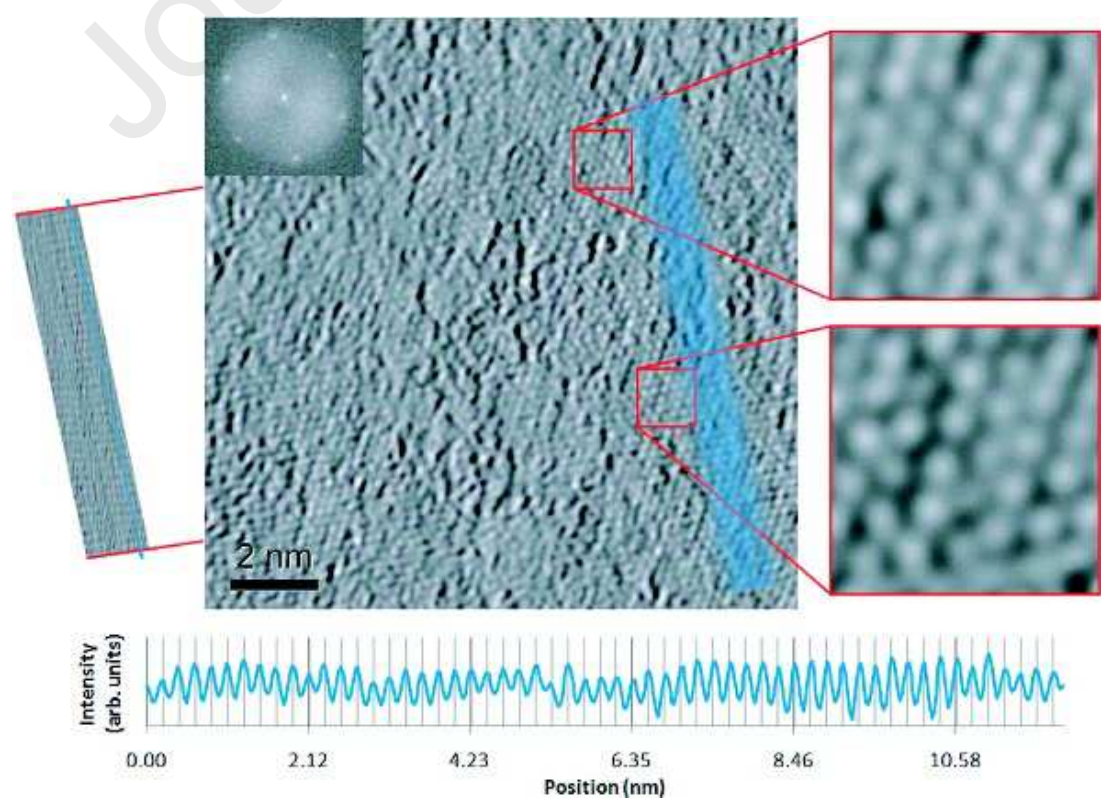

Figure 17: HR-TEM of hexagon shape graphene oxide microstructure [150] 


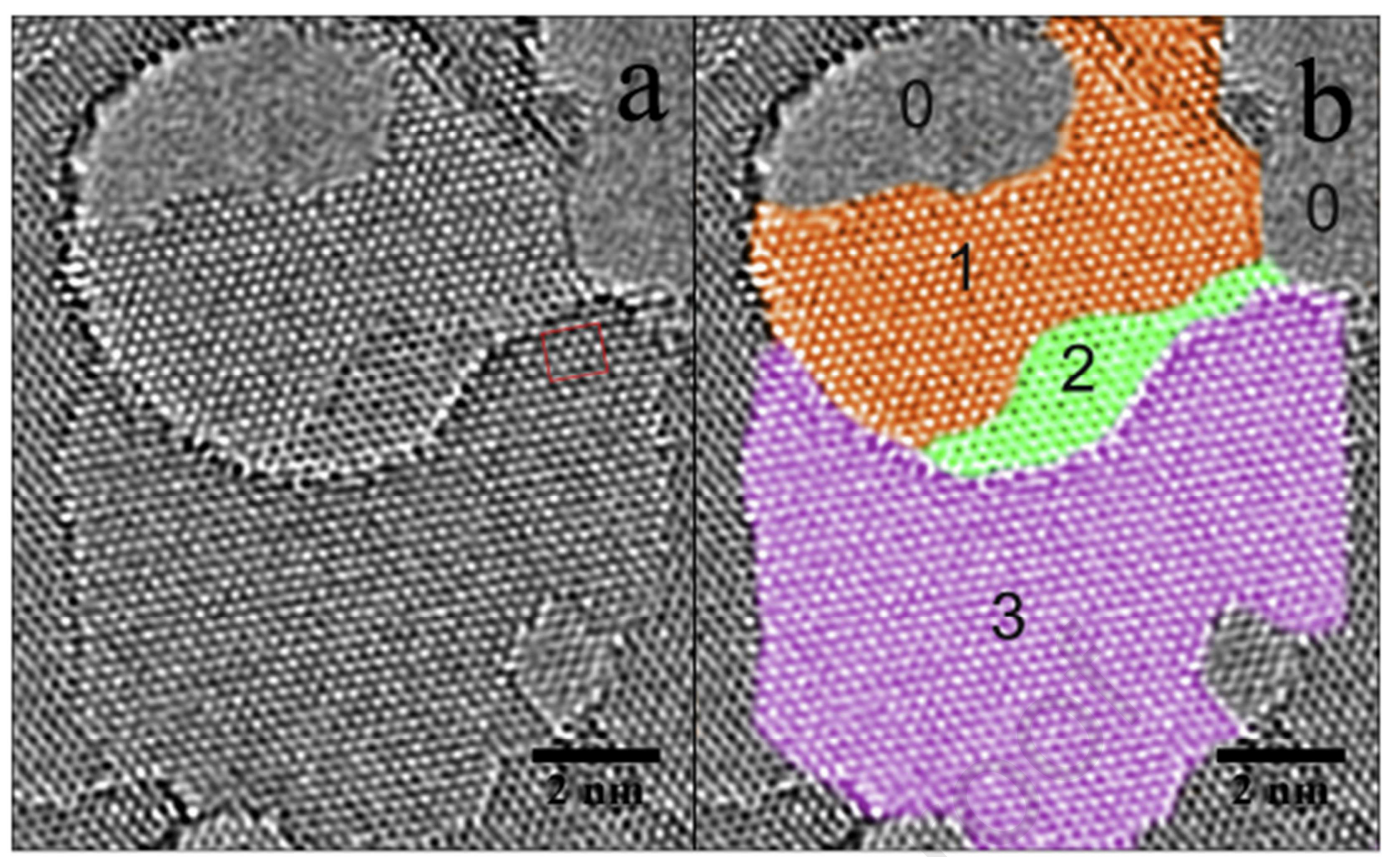

Figure 18: HR-TEM of hexagon shape graphene microstructure with different 0-3 layer region [149]

\subsection{Comparisons of Sample Analysis Techniques}

\subsubsection{Fourier Transform Infrared Spectrum (FT-IR)}

The main difference between graphene oxide $(\mathrm{GO})$ and reduced graphene oxide ( $\mathrm{rGO}$ ) is the oxygen-containing functional groups. To further analyse the content of material and the level of oxidation of $\mathrm{rGO}$, several experiments can be performed. FT-IR test is the one which can be used to analyse various functional groups within the microstructure of a material sample. Infrared light is shown on the surface of the sample and the reflected infrared light is collected and is Fourier transformed into a spectrum. The peaks and valleys on the spectrum contain information about functional groups. In a FT-IR spectrum, different functional groups show as different peaks in specific ranges. As Figure 19 shows, spectra a, b, c represent graphite, GO and rGO, respectively. Spectrum d is not important. For instance, in Figure 19, valleys (troughs) can be found at $1396 \mathrm{~cm}^{-1}, 1246 \mathrm{~cm}^{-1}, 1116 \mathrm{~cm}^{-1}$ and $3412 \mathrm{~cm}^{-1}$ of GO spectrum, which represent the hydroxyl, epoxy, alkoxy and carboxyl groups in turn. Comparing with the spectrum of graphite which does not contain these valleys, it is easy to identify an oxidation process. Further comparing with rGO spectrum, the oxide valleys reduce in intensity or disappear. 


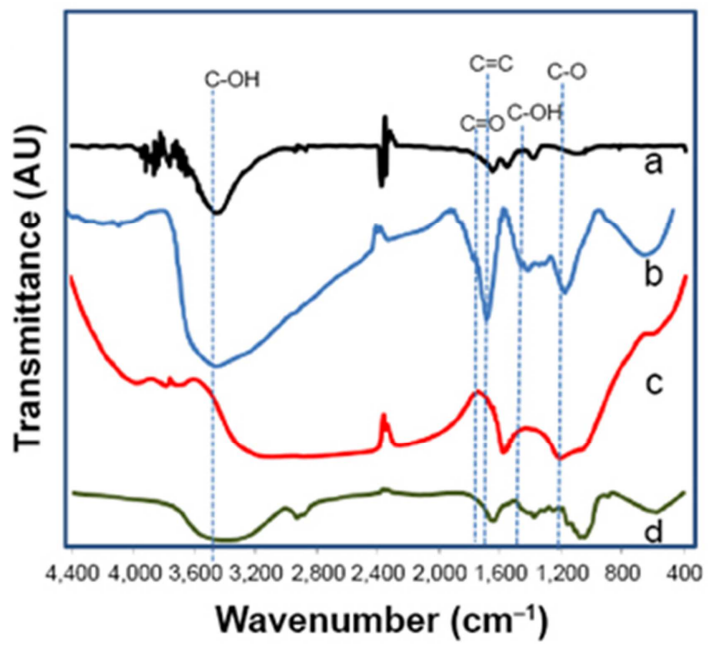

Figure 19: FTIR spectra of (a) graphite, (b) GO, (c) rGO, (d) ganoderma lucidum extract [158]

Precisely, the same functional groups with different vibration mode have eigen peak in different range. For example, Coates [159] states that the methyl C-H antisymmetric stretching has functional peak within $2970-2950 \mathrm{~cm}^{-1}$ range while the peak of methyl C-H symmetric stretching appears in the range $2880-2860 \mathrm{~cm}^{-1}$. The peak of conjugated $\mathrm{C}=\mathrm{C}$ locates at $1600 \mathrm{~cm}^{-1}$ yet alkenyl $\mathrm{C}=\mathrm{C}$ stretch shows at $1680-1620 \mathrm{~cm}^{-1}$. Detailed eigen peaks can be found from handbooks, for example [159-161]. The FT-IR spectrum is complicated to read and not easy to analyse. Although it can provide detailed information of a material's microstructure, it cannot be used to analyse the quality of product through the thickness. Besides, the eigen peaks are not very accurate to read. In the analysis of graphene, FT-IR is mainly used to provide information of functional groups and the reduction level of GO.

\subsubsection{Raman Test}

Raman test is a widely used method to verify the type of material and to determine the quality of material. For graphene, the thickness and defects can be assessed through the intensity of characteristic peaks. A material can be approximately identified by observing the prominent peak of its Raman spectrum obtained from Raman test. Different kinds of materials have their own eigen peaks which show up at a relatively fixed position or a specific range on the wavenumber axis of a Raman spectrum. For carbon-based material, as shown in Figure 20 [162] for the Raman spectrum of graphite, the characteristic band is located at $1355 \mathrm{~cm}^{-1}$ and $1575 \mathrm{~cm}^{-1}$. The 
wavenumber $1355 \mathrm{~cm}^{-1}$ (D band) represents the distortions in the structure, $1575 \mathrm{~cm}^{-1}$ ( $\mathrm{G}$ band) is the relative movement of $\mathrm{sp}^{2}$ pairs of atoms, which is the main indicator that the examined material consists of carbon. In graphene test, the ratio between D band and $\mathrm{G}$ band is related to the quality of graphene. With more disorder within the micro structure, the intensity of $\mathrm{D}$ band will be higher. The higher the ratio of the $\mathrm{D}$ band intensity to the $\mathrm{G}$ band intensity is, the worse the quality of generated graphene will be [163].

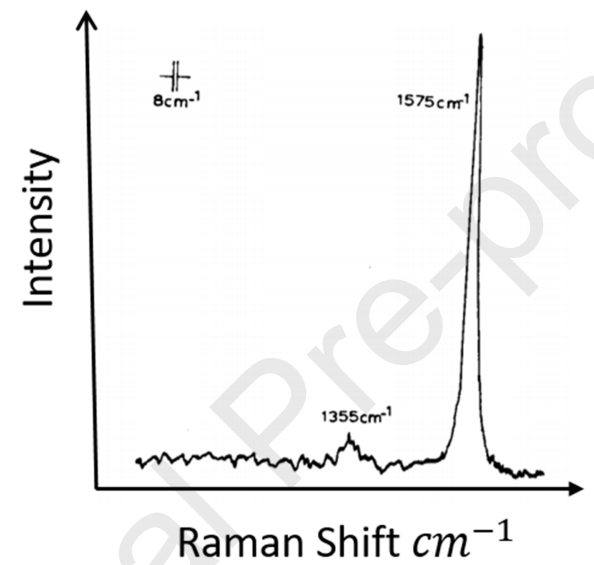

Figure 20: Eigen peaks (D band at $1355 \mathrm{~cm}^{-1}$ and $\mathrm{G}$ band at $1575 \mathrm{~cm}^{-1}$ ) of single crystal graphite [162] Figure 21 [164] shows the comparison of Raman spectrum of graphite, GO and rGO. It is clear that all characteristic peaks appear in a similar location on the wavenumber axis. This means that the three materials are carbon based. Their differences are the intensities of different bands. D band is typically very weak in graphite and high purity graphene. With a large number of defects in the structure, the intensity of this band will be high and significant. $G$ band is related to the number of layers of $\mathrm{G} / \mathrm{GO} / \mathrm{rGO}$ in a sample. With a large number of layers, the intensity of $\mathrm{G}$ band will be high and will be located rightwards on the wavenumber axis though it will affected by the environmental temperature and slight deformation in the sample. 


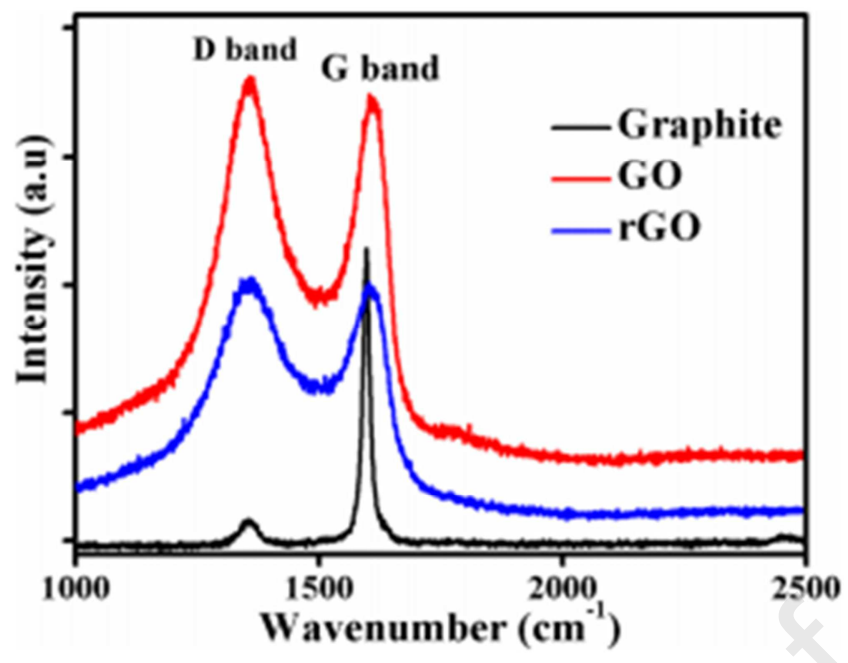

Figure 21: Comparison of Raman spectra of graphite, GO and rGO [164]

The 2D peak, shown in Figure 22 [165] at around $2700 \mathrm{~cm}^{-1}$, on the wavenumber axis, is another prominent peak that is used to verify the quality of graphene. The $2 \mathrm{D}$ band is the second order of the $\mathrm{D}$ band. It is the exhibition of a two phonon lattice vibrational process. For single layer of graphene, the 2D band is a single symmetric peak. With increased layers of graphene, the 2D band will split into few bands and the level of symmetry will decrease. The ratio between $I_{2 D}$ and $I_{G}$ can be used to describe the thickness. Ideally, for single layer graphene, $\mathrm{I}_{2 \mathrm{D}} / \mathrm{I}_{\mathrm{G}}$ should equals to 2 . The reduction of this value refers to increased thickness of the sample. The value of $\mathrm{I}_{2 \mathrm{D}} / \mathrm{I}_{\mathrm{G}}$, insignificant D peak and highly symmetric 2D peak is always used in Raman test to describe a good quality graphene sample. Application of Raman test for graphene analysis can also be found for example in $[37-39,54,60,76,86,88,91,146,151$, 166-169]. It is easy to operate and does not require too much specific treatment of a sample.

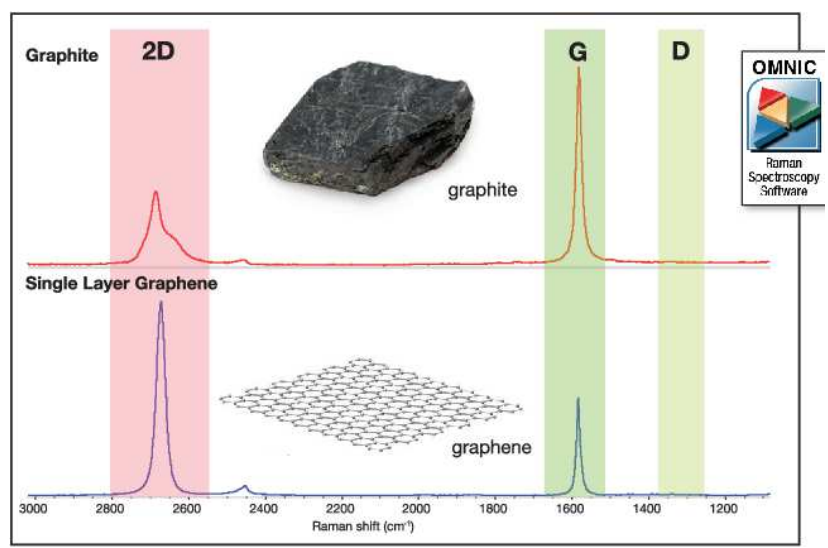


Figure 22: Ration between $\mathrm{I}_{2 \mathrm{D}} / \mathrm{I}_{\mathrm{G}}$ represent different thickness of sample [165]

\subsubsection{X-Ray Diffraction (XRD)}

Similar to Raman test, XRD can also be used to determine a material and its content. X-ray was first discovered at the end of the $19^{\text {th }}$ century. It can pass through almost all types of material and is widely applied in the chemical and medical fields. Unlike Raman test, the working mechanism of XRD is the diffraction of $\mathrm{x}$-ray within the lattice of a material when X-ray passes through the material. X-ray will be enhanced or weakened in some specific direction and cause unique diffraction pattern. Through decades of development, the diffraction patterns of individual material have already been standardized and a material can be determined through the processed XRD curve.

On an XRD curve, the content of analyzed material will be shown as the position of $2 \theta$ axis. The value of $2 \theta$ angle (diffraction angle) of characteristic peak shows the type of content and the intensity of peak represents the level of contents. Figure 23 [163], as an example, illustrates the changing characteristic peak during the reduction process of GO to rGO. On the graphite curve, the peak appears at around $26^{\circ}$. The intensity peak of graphene oxide appears at $10^{\circ}$. Through Bragg's equation $n \lambda=2 d \sin \theta$, in which $n$ represent the level of reflection (typically $n=1$ ), $\lambda$ equals to the wavelength of X-ray, $\theta$ is the reflection angle on the $\mathrm{x}$-axis. It needs to be noted that the value on $\mathrm{x}$-axis is $2 \theta$. The interlayer distance $d$ can be calculated and the change of interlayer distance caused by oxidation will be derived. After reduction, the XRD pattern of rGO is shown as the blue curve in Figure 23. The peak of GO at $10^{\circ}$ disappears while around the location of the graphite peak, a wider and weaker peak appears. The disappearance of the $10^{\circ}$ peak represents material that has been fully reduced and oxygen that has been removed. Comparing with graphite, the amorphousness of rGO is reduced and causes the change of peak shape for rGO curve. 


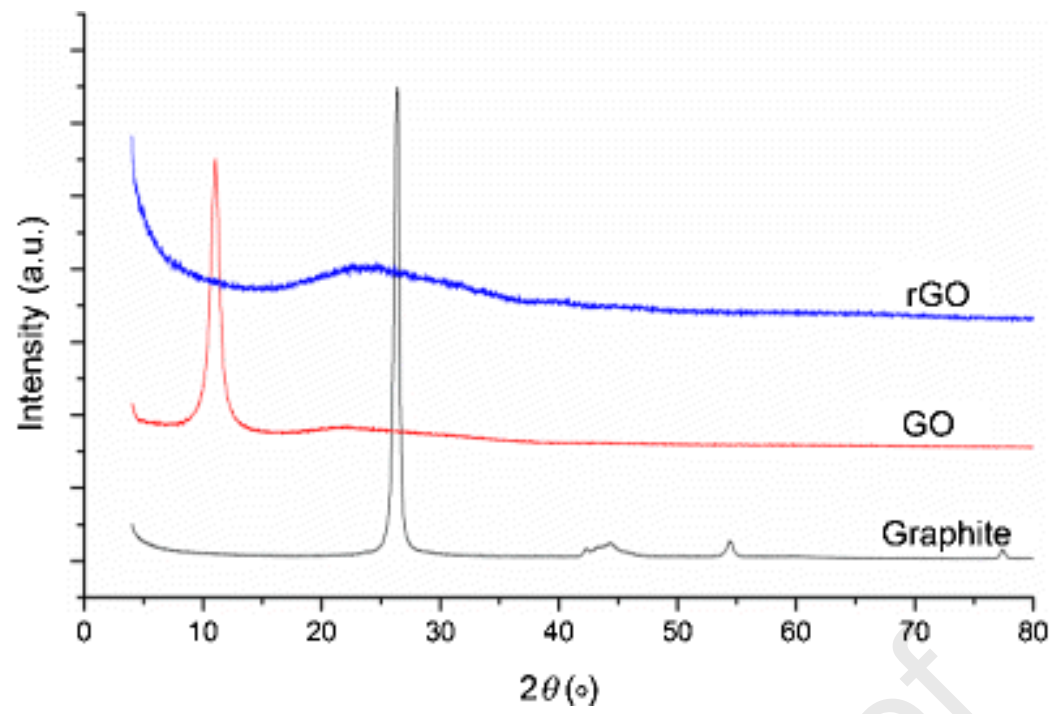

Figure 23: XRD spectra of graphite, graphene oxide and reduced graphene oxide [163]

XRD has been used to verify the quality of produced graphene and analyse its content, for example in ref. [24, 28, 38, 40, 66, 81, 82, 88, 142, 151, 164, 166, 170-172]. On the other hand, however, XRD is more difficult to operate than Raman test and the sample requires special treatment before conducting the test.

\subsection{Summary of Analysis Techniques}

Various pieces of equipment can be used to analysis synthesised graphene before it goes into application. Optical magnification equipment can be used to observe the aggregation of graphene flakes in solution or in solid material and to decide if further treatment is needed. However, it is not easy to use an optical magnification equipment to directly observe the details of thickness, micro-defects and overlapping areas. Also the morphology of flakes cannot be used to determine the type of material unless using specific analysis software. To sum up, the most suitable application for optical magnification equipment is to observe micro structure and aggregation.

To determine material types and analysis the quality of graphene, using other methods are more suitable. XRD can be used to verify the type of material through the location of its characteristic band and to derive the inter-layer distance. FT-IR method can verify detailed functional groups in a material. However the range of functional group band is wide and it can provide large amount of detailed information about functional groups and is not very easy to conclude an accurate result. It is more suitable to be used to check and monitor the process of graphene production. Raman test can assess 
the quality of rGO from the level of reduction and its thickness. It could be treated as the most useful test for the assessment of the quality of rGO.

Besides, for EM, AFM and Raman test, the test sample does not require complicated pre-processing and can be observed directly. For SEM, TEM, STM, FT-IR and XRD tests, samples require special treatment before being tested. The treatment of a sample includes, but is not limited to, grinding, coating and manufacturing thin film of the material. When choosing the equipment to assess the quality of rGO, the difficulties in preparing the sample should be taken into consideration. All the analysis techniques are compared in Table 6.

Table 6: Summary of commonly used graphene analysis techniques

\begin{tabular}{|c|c|c|c|c|}
\hline Technique & $\begin{array}{l}\text { Operating } \\
\text { Principle }\end{array}$ & Application & $\begin{array}{c}\text { Maximum } \\
\text { Magnification }\end{array}$ & Limitations \\
\hline EM & $\begin{array}{c}\text { Electron } \\
\text { transmission }\end{array}$ & Observe aggregation & $10^{3}$ & Low magnification \\
\hline TEM & $\begin{array}{c}\text { Electron } \\
\text { transmission }\end{array}$ & Observe aggregation & $10^{6}$ & $\begin{array}{l}\text { Ultrathin sample; } \\
\text { Specially prepared }\end{array}$ \\
\hline SEM & $\begin{array}{c}\text { Electron } \\
\text { backscatter }\end{array}$ & Observe aggregation & $10^{5}$ & $\begin{array}{c}\text { Specially prepared } \\
\text { sample }\end{array}$ \\
\hline STM & $\begin{array}{c}\text { Scanning Probe } \\
\text { \& Voltage }\end{array}$ & Observe aggregation & $10^{8}$ & $\begin{array}{r}\text { Conductive sample; } \\
\text { Specially prepared }\end{array}$ \\
\hline AFM & $\begin{array}{l}\text { Scanning } \\
\text { Probe }\end{array}$ & $\begin{array}{l}\text { Observe aggregation \& } \\
\text { assess surface flatness }\end{array}$ & $10^{9}$ & $\begin{array}{c}\text { Probe can damage } \\
\text { sample surface }\end{array}$ \\
\hline FR-IR & $\begin{array}{l}\text { Infra-red ray } \\
\text { reflection }\end{array}$ & $\begin{array}{l}\text { Detailed identification of } \\
\text { functional groups }\end{array}$ & N/A & $\begin{array}{l}\text { Special sample } \\
\text { treatment; Difficult } \\
\text { to analyse spectra }\end{array}$ \\
\hline $\begin{array}{c}\text { Raman } \\
\text { Test }\end{array}$ & $\begin{array}{l}\text { Laser beam } \\
\text { Scattering }\end{array}$ & $\begin{array}{l}\text { Identification of material } \\
\text { group; thickness and } \\
\text { distortion of sample; } \\
\text { assess sample quality }\end{array}$ & N/A & $\begin{array}{l}\text { Cannot identify } \\
\text { specific material }\end{array}$ \\
\hline XRD & $\mathrm{X}$-ray reflection & $\begin{array}{l}\text { Identify type of material } \\
\text { and the inter-layer } \\
\text { distance; Assess sample } \\
\text { quality }\end{array}$ & N/A & $\begin{array}{c}\text { Specially prepared } \\
\text { sample }\end{array}$ \\
\hline
\end{tabular}

\section{Application of Graphene (rGO) for Material Strength}

\section{Enhancement}




\subsection{Traditional Material Strength Enhancement}

When parts are being manufactured, due to the manufacturing process, the properties of parts may not reach the same level as those of the pristine material. Therefore, in real application, the part needs to be treated before it goes into application to ensure that the part can attain the best material performance. For metal material, the most commonly applied traditional reinforcement methods in real life are work hardening [173-177], solid solution strengthening [178-182] second phase particle strengthening [183-187] and grain-boundary strengthening [188-194]. These four approaches have been applied for decades and their application is relatively mature. In industry, the process is defined as post-processing, which is a necessary step before parts go into application in order to extend their lifetime. The main mechanism of these methods is to modify the material from its lattice structure or create local plastic deformation, i.e. without adding a large amount of other materials.

Apart from modifying the inner structure of the material, an addictive method can enhance the mechanical strength of the material in order to repair the small cracks in the material and extend its lifetime. Laser cladding and laser surface alloying are possible approaches to achieve that purpose. The working principle of these techniques is to use a material in powder form to fill the cracked/damaged region. Then, a laser beam is used to melt the cladding metal powder, which re-solidifies on the damage and repairs it. Typically, a cladding material has self-flux ability (does not require the addition of other flux to wet the substrate during heating) [169, 170, 225-230] and usually contains nickel and cobalt to ensure a good combination with the base substrate $[228,230]$. During the cladding process, not only the cladding powder will be melted, part of the base material will be melted to ensure perfect bonding to the cladding material in order to form a stronger composite and repair the damaged material.

\subsection{Composite Material and its Interfacial Properties}

As introduced in section 4.1, traditional material strength enhancement methods tend to locally modify a material's structure or add small amount of another material to the 
existing material. The operation is not so complicated but the enhancement effect is limited. A composite is a kind of hybrid material which is made from at least two kinds of materials whose properties have significant differences [195, 196]. Typically, comparing with traditional material, a composite at least has one or more of the following advantages: greater mechanical stiffness and strength, lower density, cheaper price, extra chemical resistant and better wear resistant ability [197]. By delicate design and systematic test, a composite can have the properties of all components and attain maximum performance. Consequently, the cost of development and the complexity of fabrication is far higher than traditional approaches. Composites are now widely applied in aerospace, automobile, military, robotic, medical and construction fields [198].

Composites are formed by a matrix and reinforcement materials. Generally, the matrix constitutes the highest proportion of the composite and is usually continuous while the reinforcement is distributed within the matrix. Details of the development, fabrication and application of composites will not be discussed in this review.

During the forming process, the matrix spreads around the reinforcement and solidifies after curing to form a bulk piece. The process of the matrix entirely covering the reinforcement along with the reduction of Gibbs free energy is known as 'wetting', while the ability of the matrix material in liquid form, that is before curing, to spread around the reinforcement is defined as wettability. The wettability is positively correlated with the composite quality. The interface region of composites refers to the micro region where the matrix and reinforcement couple, which ensures the integrity of the composite structure. Thus, the interface region is distinct from the rest of the composite which is made up of 'two separate and identifiable materials mixed together'. Figure 24 shows a schematic of a composite interface structure. 


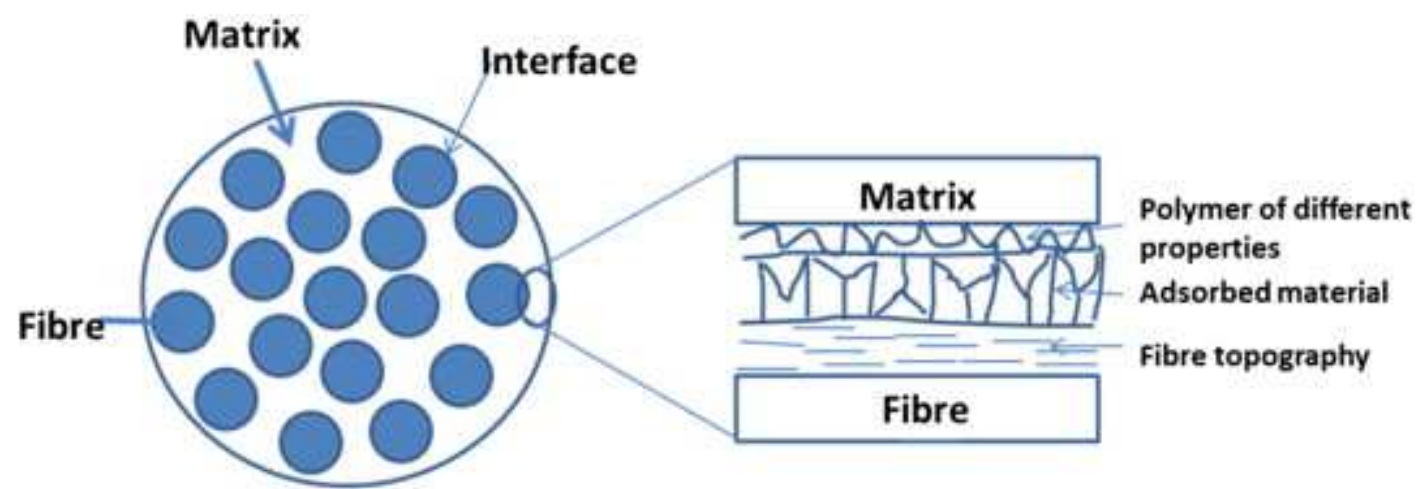

Figure 24: Schematic of composite interface structure [199]

The strength enhancement phenomenon comparing with the base materials of composites can be attributed to the interfacial stress caused by the differences of elastic modulus and is determined by the quality of coupling between the matrix and reinforcement materials in the interface region [200]. Hence, smoother and cleaner adhesion between reinforcement and matrix will make the composite stronger.

The bonding mode of the interface can be divided into mechanical bonding (matrix bonding with reinforcement through the micro pores on the fibre), low energy physical coupling (matrix bonding with reinforcement through Van der Waals force), high energy chemical reaction coupling (matrix bonding with reinforcement through chemical bond), and diffusion bonding (particles from fibre dissolved in matrix) [201-203]. It should be noted that the structure and property of the interface plays a critical role in determining the properties of the composite. Thus, in order to achieve some specified properties of the composite, there is usually the need to make a delicate compromise between the intrinsic property of the reinforcement and the interfacial properties.

When a composite material is loaded, due to the existence of the interface, a complicated deformation within the matrix will transfer the load onto the reinforcement, which, in turn, 'holds' the matrix tightly and results in the enhancement of strength [204, 205]. This can be described as the transfer effect of the interface. In addition, the interface also has a delay effect (it delays the propagation of micro-cracks and reliefs stress concentration to some extent), non-continuous effect (the appearance of non-continuous physical property including magnetic, electrical/thermal resistant, etc.), scatter and absorb property (scattering and 
absorption of sound/shock wave, light wave, etc.) and induction effect (the surface of reinforcement induce the other material to change some of the properties) [206, 207]. A balance of matrix content and reinforcement content needs to be reached to acquire the best interfacial property and achieve the best performance of a composite material.

\subsection{Applications of Graphene in Material Strength}

\section{Enhancement}

As introduced before, graphene is theoretically the 'strongest' material that has been discovered so far. Though its outstanding properties at the micro-level are not the same as the properties applied in real applications, they can still be applied to material enhancement through suitable treatment.

\subsubsection{Metal Materials}

As a form of carbon, it is easy to link graphene with solid solution strengthening mechanism of metal enhancement. Its operation can be simply viewed as mixing reduced or original graphene oxide with metal powder before sintering, or mixing reduced or original graphene oxide particles into liquid metal before its re-solidification.

Aluminum is a widely applied metal material. In order to use graphene to enhance its mechanical properties, its chemical properties needs to be considered. Metal oxide can form easily on the surface of aluminum and influence the bonding quality between graphene and aluminum. In 2011, Bartolucci et al. [166] manufactured graphene-aluminum nanocomposites from aluminum powder and graphite oxide particles following blend-mill-press-extrude process. First, high quality aluminum powder and graphite oxidized graphene powder were finely mixed via an acoustic mixer. Then the mixture was milled in a high power attritor under argon flow and 2 wt\% stearic acid to prevent agglomerations. This operation improves the grain refinement and remove the nascent oxide layer on aluminum powder to ensure a clean metallurgical interface and homogenous composite powder quality, which further consolidates the product. Graphene enhanced aluminum composite was then extruded out after hot isostatic pressing under $65 \mathrm{ksi}$. Theoretically, the refinement of graphene 
flakes will influence the grain boundary of the composite and increase the resistance to dislocation movement while breaking. At macro level, it should show as the strength enhancement of the composite. Unexpectedly, the Vickers hardness and ultimate tensile strength $\left(\sigma_{\text {UTS }}\right)$ test results of the new composite show that $\sigma_{\text {UTS }}$ and hardness both decreased from $330 \mathrm{MPa}$ to $260 \mathrm{MPa}$ and from $96 \pm 7$ to $84 \pm 5$, respectively. They believe that the weakening mechanism is due to graphene flakes, which adhere to the surfaces of aluminum particles during milling. In the subsequent phases of consolidating, heating and extrusion, the graphene flakes react with the aluminum particles at the grain boundaries (between particles) to form aluminum carbide at the interface, which become points of brittle weakness and which make the dislocation of atoms easier under loading and decrease the mechanical properties of the composite.

Wang et al. [208] modified graphene-enhanced aluminum matrix composite by premodified aluminum flakes. To achieve that, $\mathrm{Al}$ powder, comprising spherical balls of about $10 \mu \mathrm{m}$ in diameter and of $99 \%$ purity, was transformed into Al flakes of $2 \mu \mathrm{m}$ thickness by ball milling. The flakes were subsequently immersed in 3wt\% Poly(vinyl alcohol) (PVA) solution. The bonding quality between PVA modified aluminum powder and graphene is better than normal aluminum due to the hydroxyl and epoxy groups introduced by PVA. This improved the water wettability of the aluminum and ensured the uniform distribution of GO nanosheet on the surface of the aluminum to enable stronger interfacial bonding through hydrogen-bonding. The GO in the mixture was reduced through rapid heating to high temperature along with the powder's compaction, sinteration and hot extrusion process to form a bulk composite. With only $0.3 \mathrm{wt} \%$ graphene nanosheet added, the increment of tensile strength of the modified aluminum composite reached $62 \%$.

Similarly, Gao et al. [167], Porwal et al. [209], Rashad et al. [210], Li et al. [211] all successfully synthesised graphene (rGO) enhanced aluminum composites. Porwal et al. [209] used a similar ball-milling process to improve the quality of the composite powder. Similarly, Li et al. [211] ball milled $10 \mu \mathrm{m}$ aluminum micro sphere powder with GO to form the base composite material. Specifically, Li et al. [211] pointed out 
that when the concentration of graphene exceed 2.5 vol\%, micro-cracks will be produced at the interface of graphene-aluminum and increase the brittleness of the interface, which will result in lower mechanical properties of the composite produced. It should be noted that ball milling will not only disperse graphene flacks more uniformly within the composite matrix but it will also provide the required condition for the interfacial reaction to form the interface. However, ball milling cannot be perfectly controlled and might not work as expected. Besides, several researchers point out that ball milling can potentially damage the raw material powder and weaken the enhancement effect caused by graphene. For instance, the heat caused during the high-power milling process can burn the metal particles and influence the quality and properties of the final product.

A different approach to the use of ball milling method to mix aluminum and graphene was proposed by Gao et al. [167]. They used surface surfactant hexadecyl trimethyl ammonium bromide (CTAB) to modify the aluminum, which keeps the integrity of graphene flakes. Through observation of the micro structure, it was noticed that the aluminum grain and graphene flacks are tightly bonded around the interface with no significant carbide. Thus, the detrimental effect of carbide formation on the material enhancement was prevented. Similarly, Rashad et al. [210] introduced a novel method of mixing which involves immersing GNP and aluminum flakes in acetone and finely mixing using a mechanical agitator. After mixing, the slurry was vacuum dried and filtered to acquire the composite powder. The operation ensures good quality of bonding and interface, which enables the interface to bear higher shear stress and, thereby, provide stronger reinforcement of the composite.

The biggest challenge of forming aluminum composites is to remove the influence of oxide on the surface of metal particles. Apart from aluminum, the strength properties of other metal materials have been enhanced by graphene, for example, copper. Chu and Jia [212] produced graphene-enhanced copper composite using procedures that are similar to those of enhanced aluminum composite. The fine composite powder was produced through ball milling as well. The copper-graphene composite, of 8 vol\% of graphene, has a Young's modulus increment of 114MPa, which is an increment of 
$37 \%$ of the Young's modulus of the sintered copper without graphene additive. However, considering the poor interfacial bonding caused by the insufficient wetting of the graphene and copper, the increment achieved was lower than their estimated value. Similar results have been reported by Hwang et al. [213], Li et al. [214], Tang et al. [215] and Jiang et al. [216]. They used similar procedures, except that the composite powders were prepared through mechanical stirring instead of ball milling to maintain the integrity of graphene flacks. Besides, Chen et al. [217] mentioned that graphene added into copper matrix should not exceed 0.8 vol.\%. Otherwise the affinity between graphene and copper is going to become low and lead to poor quality of interface after solidification, which will weaken the performance of the material.

Furthermore, graphene's enhancement effect can take place on various metal materials including, but not limited to, magnesium [218-220] and nickel [168, 221, 222]. From the papers reviewed so far, graphene reinforced metal material has four common features:

A: Graphene (GO/rGO) needs to be finely mixed with metallic particles or powder through mechanical stirring or similar approaches to guarantee the uniformity of distribution in the final product.

B: The properties of the composite is determined by its interface properties, which is related to the distribution, size and quantity of graphene content. It should be noted that too much graphene content will result in aggregation around the interface as well as the appearance of micro-cracks, which might weaken the mechanical properties. Thus, the amount of add-in graphene and metal matrix needs to reach a good compromise in order to receive the best performance.

C: The particle mixture needs to be sintered to form the final product. The process is not only needed to melt the metallic particles but can also contribute to the reduction of GO to rGO at high temperature. This operation is called 'in-situ reduction', which means the reduction of GO is performed with the forming of metal matrix. The in-situ reduction of GO can be achieved by the high temperature during the sintering process. D: Sinteration process typically needs to be placed under a high pressure environment to ensure better bonding quality between graphene flakes and the metal. 


\subsubsection{Plastic Materials}

The previously reviewed articles are all related to graphene-enhanced metallic materials. Apart from only one aluminum-graphene composite with negative strengthening effect (reduced strength), all other metal-graphene composites that have been reviewed show a positive strengthening effect.

The strength of plastic materials can also be similarly enhanced under proper treatment. Liang et al. [223] disperse GO into poly(vinyl alcohol) (PVA) by drying an ultrasonically-treated $\mathrm{GO} / \mathrm{H}_{2} \mathrm{O}-\mathrm{PVA} / \mathrm{H}_{2} \mathrm{O}$ mixture. The mechanism of micro dispersion of GO and good interfacial quality of composite is achieved through hydrogen-bonding and the mechanism is similar to that of Wang et al. [208]. This composite has a 76\% increment in tensile strength and 62\% improvement in Young's modulus comparing with the original PVA. Along the same lines, Zhao et al. [224] produced GO/PVA composite. They reported that $1.8 \mathrm{vol} \%$ graphene add-in boosts the tensile strength of PVA from $17 \mathrm{MPa}$ to $42 \mathrm{MPa}$ despite the breaking elongation rate reduced to $98 \%$ of the original. The GO/PVA that Wang et al. [225] synthesized not only has higher strength and elongation rate but also a better waterproof (lower water absorption rate) ability. Both Zhao et al. [224] and Wang et al. [225] attribute the enhancement of the GO/PVA composites to the good interfacial properties achieved by the homogenous distribution of graphene within the matrix. Ramanathan et al. [226] report that functionalized graphene sheets dispersed in polymethyl methacrylate (PMMA) can increase Young's modulus by $81 \%$ and tensile strength by $20 \%$. Comparing with expanded graphite enhanced PMMA, functionalized graphene can provide a stronger interface to the composite. Yu et al. [227] successfully manufactured high quality graphene-poly vinylidene fluoride (PVDF) composite using high pressure sintering similar to metal composite manufacture. Mechanical test shows a significant improvement on PVDF's storage modulus. Further experiment had been done by Layek et al. [228] on gum arabic (GA), Chiappone et al. [229] on Poly ethyleneglycol diacrylate (PEGDA), Salom et al. [230] on commercial epoxy glue, Chatterjee et al. [231], Prolongo et al. [232], Ashori et al. [233] and Ashori et al. 
[234] on epoxy, Wan and Chen [169] on waterborne polyurethane, Ionita et al. [235] on polysulfone and $\mathrm{Wu}$ et al. [236] on natural rubber. Considering the relatively low melting point of raw material particles, the composite powder is prepared by wet mixing, mechanical stirring or low speed milling instead of the high power high velocity ball milling applied on metallic materials. In most cases, the mechanical properties of the plastic/GO/rGO composites produced unsurprisingly show higher elastic modulus and tensile strength and relatively lower strain rate. However, the tensile strength obtained by Salom el al. [230] for the epoxy/rGO composite that they produced was lower than the tensile strength of the original epoxy composite due to the non-uniform distribution of graphene within the structure.

\subsubsection{Discussion}

The mechanical property and strain rate of some materials that were enhanced with GO from the current reviewed literature has been collated in Table 7.

Table 7: Mechanical properties of graphene enhanced materials

\begin{tabular}{|c|c|c|c|c|c|}
\hline Material & $\begin{array}{c}\text { Enhancement } \\
\text { Filler Type* }\end{array}$ & $\begin{array}{l}\text { Change of Young's } \\
\text { Modulus (GPa) } * *\end{array}$ & $\begin{array}{c}\text { Change of } \sigma_{\mathrm{UTS}} \\
(\mathrm{MPa}) * *\end{array}$ & $\begin{array}{c}\text { Change of strain } \\
(\%) * *\end{array}$ & Ref. \\
\hline Aluminum & GO & r & $330 \rightarrow 260(-21.2 \%)$ & & [166] \\
\hline Aluminum & $\mathrm{GO}$ & & $86 \rightarrow 110(+27.9 \%)$ & $52 \rightarrow 43(-17.3 \%)$ & [167] \\
\hline Aluminum & GO & & $154 \rightarrow 249(+61.7 \%)$ & $26 \rightarrow 13(-50 \%)$ & [208] \\
\hline $\begin{array}{l}\text { Aluminum } \\
\text { Oxide }\end{array}$ & $\begin{array}{l}\text { Exfoliated } \\
\text { graphene }\end{array}$ & $380 \rightarrow 398(+4.7 \%)$ & & & [209] \\
\hline Aluminum & GNP 5-15nm & & $\begin{array}{c}252 \pm 4.5 \rightarrow 280 \pm 5 \\
(+11.1 \%)\end{array}$ & $\begin{array}{c}13.4 \pm 2 \rightarrow 9.53 \pm 1.5 \\
(-28.9 \%)\end{array}$ & [210] \\
\hline Aluminum & GO & & $175 \rightarrow 285(+62.9 \%)$ & $51 \rightarrow 35(-31.4 \%)$ & [211] \\
\hline Copper & GNP & & $150 \rightarrow 320(+113 \%)$ & & [212] \\
\hline Copper & RGO & $102 \rightarrow 131(+28.4 \%)$ & $255 \rightarrow 335(+31.4 \%)$ & $38 \rightarrow 13(-65.8 \%)$ & [213] \\
\hline Copper & $\mathrm{GO}$ & & $175 \rightarrow 240(+37.1 \%)$ & $28 \rightarrow 9(-67.8 \%)$ & [214] \\
\hline Copper & $\mathrm{GO}$ & $82 \rightarrow 132(+61.0 \%)$ & $230 \rightarrow 320(+39.1 \%)$ & $35 \rightarrow 12.5(-64.3 \%)$ & [215] \\
\hline Copper & $\begin{array}{c}\text { 2.4nm pristine } \\
\text { graphene }\end{array}$ & & $210 \rightarrow 230(+9.5 \%)$ & $55 \rightarrow 42(-23.6 \%)$ & [216] \\
\hline Magnesium & GNP 5-15nm & $\begin{array}{c}7.4 \pm 0.3 \rightarrow 14 \pm 0.16 \\
(+89.2 \%)\end{array}$ & $\begin{array}{c}164 \pm 5 \rightarrow 260 \pm 5 \\
(+58.5 \%)\end{array}$ & & [219] \\
\hline Magnesium & $\begin{array}{l}\text { GNP less than } \\
10 \mathrm{~nm}\end{array}$ & & $\begin{array}{c}163 \pm 3 \rightarrow 202 \pm 3 \\
(+23.9 \%)\end{array}$ & $\begin{array}{c}7.5 \pm 1.5 \rightarrow 14.5 \pm 1.2 \\
(-93.3 \%)\end{array}$ & [220] \\
\hline Nickel & GO & $\begin{array}{c}166.7 \rightarrow 252.76 \\
\quad(+51.6 \%)\end{array}$ & & & [168] \\
\hline
\end{tabular}




\begin{tabular}{|c|c|c|c|c|c|}
\hline Nickel & $\begin{array}{l}\text { Graphene } \\
\text { nanoflakes }\end{array}$ & $\begin{array}{c}137-183 \rightarrow 203-239 \\
(+48.2 \%)\end{array}$ & & & [222] \\
\hline PVA & GO & $2.13 \rightarrow 3.45(+61.9 \%)$ & $49 \rightarrow 89(+81.6 \%)$ & $22 \rightarrow 5(-77.3 \%)$ & [223] \\
\hline PVA & GO & $0.1 \rightarrow 1.04(+940 \%)$ & $17 \rightarrow 42(+147 \%)$ & $210 \rightarrow 10(-95.2 \%)$ & [224] \\
\hline PVA & $\mathrm{GO}$ & & $21 \rightarrow 55(+162 \%)$ & $130 \rightarrow 20(-84.6 \%)$ & [225] \\
\hline PMMA & $\begin{array}{c}\text { Functionalized } \\
\text { graphene } \\
\text { sheet }\end{array}$ & $2.1 \rightarrow 3.8(+81 \%)$ & $70 \rightarrow 84(+20 \%)$ & & [226] \\
\hline PVDF & RGO & $0.9 \rightarrow 6.2(+589 \%)$ & & & [227] \\
\hline GA & GO & $\begin{array}{c}0.77 \pm 0.06 \rightarrow 0.27 \pm 0.05 \\
(-64.9 \%)\end{array}$ & $\begin{array}{c}3.3 \pm 0.12 \rightarrow 7.4 \pm 0.15 \\
(+124 \%)\end{array}$ & $\begin{array}{c}25.1 \pm 0.4 \rightarrow 10.6 \pm 1.1 \\
(-57.8 \%)\end{array}$ & [228] \\
\hline PEGDA & GO & $\begin{array}{c}9.3 \times 10^{-3} \rightarrow 1.1 \times 10^{-2} \\
(+18.3 \%)\end{array}$ & & & [229] \\
\hline $\begin{array}{c}\text { Epoxy } \\
\text { Adhesive }\end{array}$ & GNP 6-8nm & $\begin{array}{c}2.9 \pm 0.2 \rightarrow 4 \pm 0.3 \\
(+37.8 \%)\end{array}$ & $65 \pm 4 \rightarrow 48 \pm 1(-26.1 \%)$ & $\begin{array}{c}3.0 \pm 0.2 \rightarrow 1.8 \pm 0.1 \\
(-40 \%)\end{array}$ & [230] \\
\hline Epoxy & GNP & $2.67 \rightarrow 2.86(+7.1 \%)$ & & & [231] \\
\hline Epoxy & GNP 6nm & $\begin{array}{c}2.2 \rightarrow 2.9 \text { (glassy state } \\
+31.8 \% \text { ) }\end{array}$ & $\begin{array}{c}110 \sim 120 \rightarrow 62 \\
(-43.6 \%)\end{array}$ & $5.5 \rightarrow 2.2(-60 \%)$ & [232] \\
\hline Epoxy & GO & & $\begin{array}{c}53 \pm 4 \rightarrow 63.7 \pm 8 \\
(+20.2 \%)\end{array}$ & & [233] \\
\hline Epoxy & GO & $\begin{array}{c}0.3 \times 10^{-3} \rightarrow 0.66 \times 10^{-3} \\
(+120 \%)\end{array}$ & $0.11 \rightarrow 0.145(+31.8 \%)$ & $\begin{array}{c}0.36 \rightarrow 0.22 \\
(-38.9 \%)\end{array}$ & [234] \\
\hline WPU & GO & & $18 \rightarrow 28(+55.6 \%)$ & $\begin{array}{l}1500 \rightarrow 620 \\
(-58.7 \%)\end{array}$ & [169] \\
\hline Polysulfone & GO & $\begin{array}{c}0.187 \times 10^{-3} \rightarrow 0.218 \times 10^{-3} \\
(+16.6 \%)\end{array}$ & $\begin{array}{c}3.33 \pm 0.28 \rightarrow 3.84 \pm 0.39 \\
(+15.3 \%)\end{array}$ & & [235] \\
\hline $\begin{array}{l}\text { Natural } \\
\text { Rubber }\end{array}$ & GO & $\begin{array}{c}1.1 \pm 0.12 \rightarrow 2.3 \pm 0.30 \\
(+109 \%)\end{array}$ & $\begin{array}{c}16.3 \pm 0.45 \rightarrow 22.9 \pm 0.82 \\
(+40.5 \%)\end{array}$ & $\begin{array}{c}849 \pm 45 \rightarrow 693 \pm 24 \\
\quad(-18.4 \%)\end{array}$ & [236] \\
\hline
\end{tabular}

* Raw material before being added into the matrix material

** Some values are approximately calculated from the stress-strain curve in the paper

From the statistics in Table 7 and the procedure used to produce each composite, few conclusions can be made:

A: The process of plastic/rGO composite fabrication is similar to that of metallic/rGO composites. Some researchers use ball milling method to create fine composite powder. However, ball milling can cause the metal micro sphere particle to burn and can sabotage the integrity of graphene flakes. Low integrity of graphene flakes might weaken the enhancement effect. Mechanical stirring and ultrasonication treatment can solve the problem, but if the mixture is not finely mixed, the uniformity of graphene within the final product cannot be ensured and will influence the mechanical 
properties of the final product as well. Thus, a proper method needs to be chosen based on the material quality, purity, size and environment factors. Due to the relatively low melting point of plastic materials, ball-milling is not preferred. Instead, wet mixing and mechanical stirring is widely applied. Besides, some researchers prefer to perform the reduction of GO before adding it to the base plastic material powder in order to optimize the quality of product. Moreover, since the thickness and the quality of raw graphene material cannot be entirely quantified, it is hard to conclude which type of raw graphene material is the best option. After all, different raw materials will be reduced into similar form within the final product. To re-perform these experiments, choosing the most easily obtained material and using similar fabrication operation for the reported ratios of graphene and the matrix material is recommended.

B: The Young's modulus of almost all graphene-enhanced metal material is only slightly changed. However, for plastic material, the magnitudes of changes are relatively high. The main reason for this difference is the large relative difference between the Young's modulus and tensile strength of the virgin materials. For example, the Young's modulus and tensile strength of graphene is about 5 to 14 times the Young modulus and tensile strength of most metals, whereas it is about 200 to 1000 times the Young's modulus and tensile strength of many plastics. Thus, the strength enhancement of graphene-enhanced metal composite is only few percent. However, the enhancement effect is more significant for a plastic material with a strength increase of around 40\%. For both metals and plastics, solid solute enhancement is the main mechanism for the material's enhancement effect.

C: Nearly all values of $\sigma_{\mathrm{UTS}}$ increased for metallic and plastic material but for some epoxy-based resins, commercial adhesive and natural rubber, $\sigma_{\mathrm{UTS}}$ dropped. That is caused by the low bonding quality between the base material and graphene. If we further analyze the data of $\sigma_{\mathrm{UTS}}$, it can be found that some of the increment reaches several times more compared with the original value. However, in some cases, the strength is only slightly changed. For example, Rashad et al. [210]'s experimental results only show $11 \%$ increment and Jiang et al. [216]'s copper enhancement 
achieved an increment of $9.5 \%$. These experiments should be further reviewed because the value of changes is relatively less obvious, which might just be a measurement or system error. To verify the test result, experiments need to be repeated and confirmed on different samples.

D: Breakage strain of almost all experimental samples shows a weakening trend, from a decrease of $20 \%$ of initial strain (i.e. strain of virgin material without graphene) to a decrease of $95 \%$ of initial strain. Around $60 \%$ decrease in strain is the most common statistics among reviewed data.

E: From the experimental procedures reported in most of the literature reviewed so far, all graphene was bonded with the base material at the micro-level and the distribution of graphene flakes in the new composite formed was extremely fine (this was the reason for mechanical stirring or hydraulic mixing). Otherwise, if graphene forms a bulk in the final product, it may cause a stress concentration and further weaken mechanical strength, like in Salom el al. [230]'s experiment.

F: It is not the case that the more the graphene add-in, the better the enhancement effect will be. As much of the data shows, when the amount of graphene add-in exceeds a critical value, the strength of the new material will start to drop, even lower than the initial value $[167,209,229,232,235]$. This is probably due to the aggregation caused by excess amount of add-in GO, which may cause negative effect towards the interfacial properties (more brittle, micro-cracks, weak linkage, etc.) of the final product and reduce its macro mechanical properties.

There are still some other researchers who have recorded their attempts in applying graphene family material to enhance the strength of materials by other methods. For instance, by immersing cellulose paper in GO solution until GO permeates into the cellulose fibre and dries, the tensile strength and breakage strain of cellulose paper can be significantly improved [237]. Kim et al. [221] tested graphene's strength enhancement effect on copper by producing copper-graphene multi-layer pile composite. They achieved this by layering alternatively ultrathin layers of copper followed by graphene, etc. The enhanced effect can reach few hundred times compared to the yield stress of the bulk single-crystal metal [221]. However, the test 
sample is in micro-level and the diameter of the sample is $260 \mathrm{~nm}$, which makes it unlikely to be applied in real life. Similarly, Kim et al. [238] coated graphene on an ultrathin vanadium sheet to form a graphene-vanadium composite though the thickness of the composite is ultrathin (600nm) and may not have too much application potential in real life.

\section{Prospect}

With a rapid development and research on graphene within the last two decades, it is necessary to review what has been done to date.

In the public's view, graphene is a wonder or dramatic material that can be applied in almost all fields in people's daily life. Indeed, theoretically it has superb mechanical properties, good electrical and thermal conductivity as well as good optical transmittance, low electrical resistance, large surface area and large permselectivity. For new comers to research on graphene, the astonishing mechanical properties may stimulate huge interests. However they might get dissappointed after realising that its outstanding mechanical properties are just theroretical values which have only been partially attained on a nano-/micro-scale level but are yet to be releasied on a macro-scale level. The application of micro-level property at macro-level is yet an interesting area that has remained unachievable. Assuming this problem can be solved in the future, then new and exciting engineering products with fantastic and highly desirable and beneficial physical properties can be developed.

It is important to point out that there are few common misunderstandings by the public and new comers to research on graphene:

A: A trully single-atom thick graphene is a 'fancy or wonder' material, theroretically. However, most of the currently isolated graphene is multi-layer and is not the expected 'fancy' material. Essentially, graphene is a form of graphite that can be treated as a stacked structure of multi layers of graphene. A line drawn by a pencil on paper contains a large amount of micro graphene flakes. The current difficultyis to produce a large amount of graphene of good quality, which is also the reason why the price of the very small sizes of graphene that is currently produced is high. 
B: Similarly, single layer graphene is the strongest material currently known.

However, the multi-layer material that is hyped as graphene is not 'strong'. The astonishing mechanical properties of graphene is at the theoretical micro level. At that dimension, a material tends to be flawless without micro defect, while for macro level graphene pieces, the quantity of micro defects can be millions. The strength and properties of macro-level graphene pieces are not that outstanding and are significantly influenced by their quality.

C: Furthermore, while a true single layer graphene material has outstanding properties, in general, graphene is not 'a do-it-all' material that can do anything. Not all products that have names associated with 'graphene' have superb functions. As a matter of fact, currently, in real life, graphene-dominated products are extremely rare. Materials presented as graphene are mostly multilayer graphene which contains many flaws that dominate the property of the product. The graphene content does not have significant influence on the properties of the product and can be replaced by other cheaper carbon-based materials.

As a new and popular material that has been under research and development during the past decade, the achievement in this area is remarkable: from conductive coating to strength enhanced composites, from gas sensor to sea water filter, from high capacity mobile device battery to the scaffold used in tissue engineering, the application potential of graphene has been proposed in many fields. However, it should be noted that most of these applications are still on small scale laboratory level and the successful large-scale commercial application cases of using graphene in real life are rare to find. After a long period of development, the research enthusiasm in applying graphene nowadays is gradually cooling down and seems to have stepped into the 'bottleneck' stage. A breakthrough of graphene application is expected to re-energise the research field. Nevertheless, the potential stimulation of the economy due to large scale production and applications of graphene should not be ignored. Almost all major universities across the world have relevant research projects. Graphene industrial parks have been built in many countries that have created thousands of job opportunities. though graphene-enhanced composites have not been widely applied 
yet, the efforts that researchers have made have received good feedback. With availability of large volume of graphene and good fabrication procedures that produce high quality products, it is seemingly not complicated to produce strength-enhanced graphene composites.

Comparing with traditional strength enhanced composites, graphene-enhanced material has better mechanical properties. Besides, due to the low density of graphene, the reinforced composite has light weight as well. If the interfacial properties of a composite can be fully controlled during the process of large-scaled production, it will be possible to produce large quantities of the composite for real applications. Another challenge is the cost. The add-in graphene is unable to exponentially improve the strength of a material but will massively increase the cost. For instance, the price of aluminum is around $£ 2 / \mathrm{kg}$. With 1 gram of graphene added ( $1 \mathrm{wt} \%)$, the price of the $\mathrm{Al} / \mathrm{G}$ composite produced will increase 40 times, not to mention the loss of material during fabrication. Therefore, further developments are required to enable large-scale production of high quality graphene at competitive prices. The achievement of this goal will ensure that graphene-enhanced composites have bright application potential.

\section{Conclusion}

The four main areas of the review are on the production of graphene-based materials, their physical properties, instrumentation used for characterising their quality, and their applications especially in the area of material strength enhancement. Each of these four areas are summarised in the following paragraphs.

For the production of graphene-based material, if it is not for laboratory use, then reduced graphene oxide is typically used as a replacement to simplify the synthesis process. The fabrication of graphene oxide still follows the Hummer's method discovered almost a century ago. Reduction approaches applied are mainly chemical , thermal and photo reduction methods. One thing that needs to be noticed is that the quality of product is not easy to cotrol and has great randomness.

To analyse the quality of synthesised graphene, apart from morphology observation using optical equipment, it is neecessary to use advanced equipment and procedures 
such as AFM and TEM, Raman test, XRD analysis and FR-IR. These advanced equipment and procedures can provide more details including micro-defects at the edge of a sample and the thickness of material at different regions of the sample. Graphene and graphene-based materials are currently mainly being used in composites, electronics and medical devices. However, considering the current price of graphene-based materials and their current real applications, the commercial development of graphene-based products is still at an initial stage.

For the application of graphene for the enhancement of the strength of conventional materials, current application approaches are similar. This is essentially using graphene as a nanofiller finely mixed with the base material matrix particles at the molecular level to form a stronger material. This synthetization process is not very easy to implement and requires large amounts of graphene, which will increase the cost. Thus, the application of graphene-enhanced material is more likely to be used in the military and aerospace sectors which consider the property of a material as priority rather than its cost. Surface coating enhancement using graphene has not yet been widely researched and it has been applied only on micro samples. Theoretically, associating graphene with surface coating technique like laser cladding can be a future research area. Laser cladding with graphene can potentially reduce the fabrication time of graphene-enhanced materials compared with currently applied graphene-material enhancement method. This is expected to have good application potential including material strength enhancement to extend the lifetime of parts and repair of damaged parts in order to avoid catastrophic damage when they are functioning. This will involve determination of suitable combinations of laser parameters, determining the amount of graphene and the base material type in order to achieve optimum enhancement effect.

Apart from the quality of graphene-based raw materials, their price is the other important factor which limits their application. Only with further development and decrease in the price of raw graphene-based materials can more graphene-based products become part of our daily lives. 


\section{Reference}

[1] K. S. Novoselov et al., "Electric field effect in atomically thin carbon films," (in English), Science, vol. 306, no. 5696, pp. 666-669, Oct 22 2004, doi: 10.1126/science.1102896.

[2] C. Lee, X. D. Wei, J. W. Kysar, and J. Hone, "Measurement of the elastic properties and intrinsic strength of monolayer graphene," (in English), Science, vol. 321, no. 5887, pp. 385-388, Jul 18 2008, doi: 10.1126/science.1157996.

[3] R. Van Noorden, "The Trials of New Carbon," (in English), Nature, vol. 469, no. 7328, pp. 14-16, Jan 6 2011, doi: DOI 10.1038/469014a.

[4] W. S. Hummers and R. E. Offeman, "Preparation of Graphitic Oxide," (in English), Journal of the American Chemical Society, vol. 80, no. 6, pp. 1339-1339, 1958, doi: DOI 10.1021/ja01539a017.

[5] Graphene materials terminology and designation 2018.

[6] H. Sahin, O. Leenaerts, S. K. Singh, and F. M. Peeters, "GraphAne: From Synthesis to Applications," 2015.

[7] J. T. Robinson et al., "Properties of Fluorinated Graphene Films," (in English), Nano Letters, vol. 10, no. 8, pp. 3001-3005, Aug 2010, doi: 10.1021/nl101437p.

[8] D. D. Chronopoulos, A. Bakandritsos, M. Pykal, R. Zboril, and M. Otyepka, "Chemistry, properties, and applications of fluorographene," (in English), Applied Materials Today, vol. 9, pp. 60-70, Dec 2017, doi: 10.1016/j.apmt.2017.05.004.

[9] H. Sahin and S. Ciraci, "Chlorine Adsorption on Graphene: Chlorographene," (in English), Journal of Physical Chemistry C, vol. 116, no. 45, pp. 24075-24083, Nov 15 2012, doi: 10.1021/jp307006c.

[10] K. Chu, W. S. Li, and H. F. Dong, "Role of graphene waviness on the thermal conductivity of graphene composites," (in English), Applied Physics a-Materials Science \& Processing, vol. 111, no. 1, pp. 221-225, Apr 2013, doi: 10.1007/s00339-012-7497-y.

[11] A. Bianco et al., "All in the graphene family - A recommended nomenclature for two-dimensional carbon materials," (in English), Carbon, vol. 65, pp. 1-6, Dec 2013, doi: 10.1016/j.carbon.2013.08.038.

[12] Y. Wei and Z. Y. Sun, "Liquid-phase exfoliation of graphite for mass production of pristine few-layer graphene," (in English), Current Opinion in Colloid \& Interface Science, vol. 20, no. 5-6, pp. 311-321, Oct-Dec 2015, doi: 10.1016/j.cocis.2015.10.010.

[13] X. J. Chen, J. F. Dobson, and C. L. Raston, "Vortex fluidic exfoliation of graphite and boron nitride," (in English), Chemical Communications, vol. 48, no. 31, pp. 3703-3705, 2012, doi: $10.1039 / \mathrm{c} 2 \mathrm{cc} 17611 \mathrm{~d}$.

[14] H. Y. Gao, K. X. Zhu, G. X. Hu, and C. Xue, "Large-scale graphene production by ultrasound-assisted exfoliation of natural graphite in supercritical CO2/H2O medium," (in English), Chemical Engineering Journal, vol. 308, pp. 872-879, Jan 15 2017, doi: 
10.1016/j.cej.2016.09.132.

[15] Q. K. Yu, J. Lian, S. Siriponglert, H. Li, Y. P. Chen, and S. S. Pei, "Graphene segregated on Ni surfaces and transferred to insulators," (in English), Applied Physics Letters, vol. 93, no. 11, Sep 15 2008, doi: Artn 113103

$10.1063 / 1.2982585$.

[16] A. J. Van Bommel, J. E. Crombeen, and A. Van Tooren, "LEED and Auger electron observations of the SiC(0001) surface," Surface Science, vol. 48, no. 2, pp. 463-472, 1975/03/02/ 1975, doi: https://doi.org/10.1016/0039-6028(75)90419-7.

[17] W. A. de Heer et al., "Large area and structured epitaxial graphene produced by confinement controlled sublimation of silicon carbide," (in English), Proceedings of the National Academy of Sciences of the United States of America, vol. 108, no. 41, pp. 16900-16905, Oct 112011 , doi: 10.1073/pnas.1105113108.

[18] V. Singh, D. Joung, L. Zhai, S. Das, S. I. Khondaker, and S. Seal, "Graphene based materials: Past, present and future," (in English), Progress in Materials Science, vol. 56, no. 8, pp. 1178-1271, Oct 2011, doi: 10.1016/j.pmatsci.2011.03.003.

[19] D. C. Marcano et al., "Improved Synthesis of Graphene Oxide," (in English), Acs Nano, vol. 4, no. 8, pp. 4806-4814, Aug 2010, doi: 10.1021/nn1006368.

[20] Y. G. Yang and Q. H. Yang, "Free-Standing Graphene Film with High Conductivity by Thermal Reduction of Self-assembled Graphene Oxide Film," (in English), Springer Theses-Reco, pp. 97-110, 2016, doi: 10.1007/978-3-662-48676-4_4.

[21] S. H. Huh, "Thermal Reduction of Graphene Oxide," (in English), Physics and Applications of Graphene - Experiments, pp. 73-90, 2011, doi: Book_Doi 10.5772/590.

[22] H. C. Schniepp et al., "Functionalized single graphene sheets derived from splitting graphite oxide," (in English), Journal of Physical Chemistry B, vol. 110, no. 17, pp. 8535-8539, May 4 2006, doi: 10.1021/jp060936f.

[23] X. Li et al., "Highly conducting graphene sheets and Langmuir-Blodgett films," Nat Nanotechnol, vol. 3, no. 9, pp. 538-42, Sep 2008, doi: 10.1038/nnano.2008.210.

[24] M. Zainy, N. M. Huang, S. V. Kumar, H. N. Lim, C. H. Chia, and I. Harrison, "Simple and scalable preparation of reduced graphene oxide-silver nanocomposites via rapid thermal treatment," (in English), Materials Letters, vol. 89, pp. 180-183, Dec 15 2012, doi: 10.1016/j.matlet.2012.08.101.

[25] Y. W. Zhu et al., "Exfoliation of Graphite Oxide in Propylene Carbonate and Thermal Reduction of the Resulting Graphene Oxide Platelets," (in English), Acs Nano, vol. 4, no. 2, pp. 1227-1233, Feb 2010, doi: 10.1021/nn901689k.

[26] L. T. Le, M. H. Ervin, H. W. Qiu, B. E. Fuchs, and W. Y. Lee, "Graphene supercapacitor electrodes fabricated by inkjet printing and thermal reduction of graphene oxide," (in English), Electrochemistry Communications, vol. 13, no. 4, pp. 355-358, Apr 2011, doi: 10.1016/j.elecom.2011.01.023.

[27] J. F. Shen et al., "Fast and Facile Preparation of Graphene Oxide and Reduced Graphene 
Oxide Nanoplatelets," (in English), Chemistry of Materials, vol. 21, no. 15, pp. 3514-3520, Aug 11 2009, doi: 10.1021/cm901247t.

[28] W. F. Chen, L. F. Yan, and P. R. Bangal, "Preparation of graphene by the rapid and mild thermal reduction of graphene oxide induced by microwaves," (in English), Carbon, vol. 48, no. 4, pp. 1146-1152, Apr 2010, doi: 10.1016/j.carbon.2009.11.037.

[29] E. Tegou, G. Pseiropoulos, M. K. Filippidou, and S. Chatzandroulis, "Low-temperature thermal reduction of graphene oxide films in ambient atmosphere: Infra-red spectroscopic studies and gas sensing applications," (in English), Microelectronic Engineering, vol. 159, pp. 146-150, Jun 15 2016, doi: 10.1016/j.mee.2016.03.030.

[30] Y. Qiu, F. Guo, R. Hurt, and I. Kulaots, "Explosive thermal reduction of graphene oxide-based materials: Mechanism and safety implications," (in English), Carbon, vol. 72, pp. 215-223, Jun 2014, doi: 10.1016/j.carbon.2014.02.005.

[31] Z. L. Wang, D. Xu, Y. Huang, Z. Wu, L. M. Wang, and X. B. Zhang, "Facile, mild and fast thermal-decomposition reduction of graphene oxide in air and its application in high-performance lithium batteries," (in English), Chemical Communications, vol. 48, no. 7, pp. 976-978, Jan 25 2012, doi: 10.1039/c2cc16239c.

[32] Z. H. Sheng, L. Shao, J. J. Chen, W. J. Bao, F. B. Wang, and X. H. Xia, "Catalyst-Free Synthesis of Nitrogen-Doped Graphene via Thermal Annealing Graphite Oxide with Melamine and Its Excellent Electrocatalysis," (in English), Acs Nano, vol. 5, no. 6, pp. 4350-4358, Jun 2011, doi: 10.1021/nn103584t.

[33] L. Cardenas et al., "Reduced graphene oxide growth on 316L stainless steel for medical applications," (in English), Nanoscale, vol. 6, no. 15, pp. 8664-8670, Aug 7 2014, doi: 10.1039/c4nr02512a.

[34] P. V. Kumar, N. M. Bardhan, S. Tongay, J. Q. Wu, A. M. Belcher, and J. C. Grossman, "Scalable enhancement of graphene oxide properties by thermally driven phase transformation," (in English), Nature Chemistry, vol. 6, no. 2, pp. 151-158, Feb 2014, doi: 10.1038/Nchem.1820.

[35] R. R. Nair et al., "Fine structure constant defines visual transparency of graphene," (in English), Science, vol. 320, no. 5881, pp. 1308-1308, Jun 6 2008, doi: 10.1126/science.1156965.

[36] K. Naito, N. Yoshinaga, and Y. Akasaka, "Material- and process-effects on homogeneity and electric properties of transparent conducting films composed of hydrazine-reduced graphene oxide and/or silver nanowire," (in English), Synthetic Metals, vol. 215, pp. 243-250, May 2016, doi: 10.1016/j.synthmet.2016.03.004.

[37] S. Stankovich et al., "Synthesis of graphene-based nanosheets via chemical reduction of exfoliated graphite oxide," (in English), Carbon, vol. 45, no. 7, pp. 1558-1565, Jun 2007, doi: 10.1016/j.carbon.2007.02.034.

[38] D. Yang et al., "Chemical analysis of graphene oxide films after heat and chemical treatments by X-ray photoelectron and Micro-Raman spectroscopy," (in English), Carbon, vol. 47, no. 1, 
pp. 145-152, Jan 2009, doi: 10.1016/j.carbon.2008.09.045.

[39] L. F. Qiu, H. Y. Zhang, W. G. Wang, Y. M. Chen, and R. Wang, "Effects of hydrazine hydrate treatment on the performance of reduced graphene oxide film as counter electrode in dye-sensitized solar cells," (in English), Applied Surface Science, vol. 319, pp. 339-343, Nov 15 2014, doi: 10.1016/j.apsusc.2014.07.133.

[40] S. Park, J. An, J. R. Potts, A. Velamakanni, S. Murali, and R. S. Ruoff, "Hydrazine-reduction of graphite- and graphene oxide," (in English), Carbon, vol. 49, no. 9, pp. 3019-3023, Aug 2011, doi: 10.1016/j.carbon.2011.02.071.

[41] Y. Si and E. T. Samulski, "Synthesis of water soluble graphene," (in English), Nano Letters, vol. 8, no. 6, pp. 1679-1682, Jun 2008, doi: 10.1021/n1080604h.

[42] M. Zhou, Y. M. Zhai, and S. J. Dong, "Electrochemical Sensing and Biosensing Platform Based on Chemically Reduced Graphene Oxide," (in English), Analytical Chemistry, vol. 81, no. 14, pp. 5603-5613, Jul 15 2009, doi: 10.1021/ac900136z.

[43] O. C. Compton, D. A. Dikin, K. W. Putz, L. C. Brinson, and S. T. Nguyen, "Electrically Conductive "Alkylated" Graphene Paper via Chemical Reduction of Amine-Functionalized Graphene Oxide Paper," (in English), Advanced Materials, vol. 22, no. 8, pp. 892-+, Feb 23 2010, doi: 10.1002/adma.200902069.

[44] W. Gao, L. B. Alemany, L. J. Ci, and P. M. Ajayan, "New insights into the structure and reduction of graphite oxide," (in English), Nature Chemistry, vol. 1, no. 5, pp. 403-408, Aug 2009, doi: 10.1038/Nchem.281.

[45] H. J. Shin et al., "Efficient Reduction of Graphite Oxide by Sodium Borohydride and Its Effect on Electrical Conductance," (in English), Advanced Functional Materials, vol. 19, no. 12, pp. 1987-1992, Jun 23 2009, doi: 10.1002/adfm.200900167.

[46] A. Ambrosi, C. K. Chua, A. Bonanni, and M. Pumera, "Lithium Aluminum Hydride as Reducing Agent for Chemically Reduced Graphene Oxides," (in English), Chemistry of Materials, vol. 24, no. 12, pp. 2292-2298, Jun 26 2012, doi: 10.1021/cm300382b.

[47] S. Pei, J. Zhao, J. Du, W. Ren, and H.-M. Cheng, "Direct reduction of graphene oxide films into highly conductive and flexible graphene films by hydrohalic acids," Carbon, vol. 48, no. 15, pp. 4466-4474, 2010/12/01/ 2010, doi: https://doi.org/10.1016/j.carbon.2010.08.006.

[48] Z. X. Hou et al., "Reduction of Graphene Oxide and its Effect on Square Resistance of Reduced Graphene Oxide Films," (in English), Bulletin of the Korean Chemical Society, vol. 36, no. 6, pp. 1681-1687, Jun 2015, doi: 10.1002/bkcs.10323.

[49] K. X. Sheng, Y. X. Xu, C. Li, and G. Q. Shi, "High-performance self-assembled graphene hydrogels prepared by chemical reduction of graphene oxide," (in English), New Carbon Materials, vol. 26, no. 1, pp. 9-15, Feb 2011, doi: 10.1016/S1872-5805(11)60062-0.

[50] J. L. Zhang, H. J. Yang, G. X. Shen, P. Cheng, J. Y. Zhang, and S. W. Guo, "Reduction of graphene oxide via L-ascorbic acid," (in English), Chemical Communications, vol. 46, no. 7, pp. 1112-1114, 2010, doi: 10.1039/b917705a.

[51] J. Gao, F. Liu, Y. L. Liu, N. Ma, Z. Q. Wang, and X. Zhang, "Environment-Friendly Method 
To Produce Graphene That Employs Vitamin C and Amino Acid," (in English), Chemistry of Materials, vol. 22, no. 7, pp. 2213-2218, Apr 13 2010, doi: 10.1021/cm902635j.

[52] W. B. Wan, Z. B. Zhao, H. Hu, Y. Gogotsi, and J. S. Qiu, "Highly controllable and green reduction of graphene oxide to flexible graphene film with high strength," (in English), Materials Research Bulletin, vol. 48, no. 11, pp. 4797-4803, Nov 2013, doi: 10.1016/j.materresbull.2013.08.031.

[53] I. Calina, M. Demeter, E. Badita, E. Stancu, A. Scarisoreanu, and C. Vancea, "Reduction of Freestanding Graphene Oxide Films Using Continuous Wave Laser," (in English), Romanian Reports in Physics, vol. 69, no. 2, 2017. [Online]. Available: $\leq$ Go to ISI>://WOS:000402495900011.

[54] E. Ghoniem, S. Mori, and A. Abdel-Moniem, "Low-cost flexible supercapacitors based on laser reduced graphene oxide supported on polyethylene terephthalate substrate," (in English), Journal of Power Sources, vol. 324, pp. 272-281, Aug 30 2016, doi: 10.1016/j.jpowsour.2016.05.069.

[55] P. Z. Sun et al., "Suppression of the coffee-ring effect by self-assembling graphene oxide and monolayer titania," (in English), Nanotechnology, vol. 24, no. 7, Feb 22 2013, doi: Artn 075601

10.1088/0957-4484/24/7/075601.

[56] D. Berman, A. Erdemir, and A. V. Sumant, "Few layer graphene to reduce wear and friction on sliding steel surfaces," (in English), Carbon, vol. 54, pp. 454-459, Apr 2013, doi: 10.1016/j.carbon.2012.11.061.

[57] R. Karimzadeh, M. Assar, and M. Jahanbakhshian, "Low cost and facile fabrication of broadband laser power meter based on reduced graphene oxide film," (in English), Materials Research Bulletin, vol. 100, pp. 42-48, Apr 2018, doi: 10.1016/j.materresbull.2017.12.007.

[58] Z. Y. Yin et al., "Organic Photovoltaic Devices Using Highly Flexible Reduced Graphene Oxide Films as Transparent Electrodes," (in English), Acs Nano, vol. 4, no. 9, pp. 5263-5268, Sep 2010, doi: 10.1021/nn1015874.

[59] S. Mortazavi et al., "Modification of graphene oxide film properties using $\mathrm{KrF}$ laser irradiation," (in English), Rsc Advances, vol. 8, no. 23, pp. 12808-12814, 2018, doi: $10.1039 / \mathrm{c} 8 \mathrm{ra00097b}$.

[60] A. Ladron-de-Guevara et al., "Reduced graphene oxide/polyaniline electrochemical supercapacitors fabricated by laser," (in English), Applied Surface Science, vol. 467, pp. 691-697, Feb 15 2019, doi: 10.1016/j.apsusc.2018.10.194.

[61] E. Kymakis, C. Petridis, T. D. Anthopoulos, and E. Stratakis, "Laser-Assisted Reduction of Graphene Oxide for Flexible, Large-Area Optoelectronics," (in English), Ieee Journal of Selected Topics in Quantum Electronics, vol. 20, no. 1, Jan-Feb 2014, doi: Artn 6000410

10.1109/Jstqe.2013.2273414.

[62] H. J. Kim, O. V. Penkov, and D. E. Kim, "Tribological Properties of Graphene Oxide Nanosheet Coating Fabricated by Using Electrodynamic Spraying Process," (in English), 
Tribology Letters, vol. 57, no. 3, Mar 2015, doi: UNSP 27

10.1007/s11249-015-0467-8.

[63] Y. S. Kim and J. G. Kim, "Electroplating of reduced-graphene oxide on austenitic stainless steel to prevent hydrogen embrittlement," (in English), International Journal of Hydrogen Energy, vol. 42, no. 44, pp. 27428-27437, Nov 2 2017, doi: 10.1016/j.ijhydene.2017.09.033.

[64] M. Wang et al., "Large-Area, Conductive and Flexible Reduced Graphene Oxide (RGO) Membrane Fabricated by Electrophoretic Deposition (EPD)," (in English), Acs Applied Materials \& Interfaces, vol. 6, no. 3, pp. 1747-1753, Feb 12 2014, doi: 10.1021/am404719u.

[65] J. X. Hou, Z. L. Liu, S. Q. Yang, and Y. Zhou, "Three-dimensional macroporous anodes based on stainless steel fiber felt for high-performance microbial fuel cells," (in English), Journal of Power Sources, vol. 258, pp. 204-209, Jul 15 2014, doi: 10.1016/j.jpowsour.2014.02.035.

[66] V. K. Ponnusamy and J. F. Jen, "A novel graphene nanosheets coated stainless steel fiber for microwave assisted headspace solid phase microextraction of organochlorine pesticides in aqueous samples followed by gas chromatography with electron capture detection," (in English), Journal of Chromatography A, vol. 1218, no. 39, pp. 6861-6868, Sep 28 2011, doi: 10.1016/j.chroma.2011.08.019.

[67] X. B. Cao et al., "Ambient Fabrication of Large-Area Graphene Films via a Synchronous Reduction and Assembly Strategy," (in English), Advanced Materials, vol. 25, no. 21, pp. 2957-2962, Jun 4 2013, doi: 10.1002/adma.201300586.

[68] Z. Zhen, X. Li, and H. Zhu, "Synthesis of two dimensional materials on extremely clean surfaces," Nano Today, vol. 22, pp. 7-9, 2018, doi: 10.1016/j.nantod.2018.04.013.

[69] R. D. Deegan, O. Bakajin, T. F. Dupont, G. Huber, S. R. Nagel, and T. A. Witten, "Capillary flow as the cause of ring stains from dried liquid drops," (in English), Nature, vol. 389, no. 6653, pp. 827-829, Oct 23 1997, doi: Doi 10.1038/39827.

[70] T. Still, P. J. Yunker, and A. G. Yodh, "Surfactant-Induced Marangoni Eddies Alter the Coffee-Rings of Evaporating Colloidal Drops," (in English), Langmuir, vol. 28, no. 11, pp. 4984-4988, Mar 20 2012, doi: 10.1021/la204928m.

[71] Q. Zhang et al., "Graphene coating on the surface of CoCrMo alloy enhances the adhesion and proliferation of bone marrow mesenchymal stem cells," (in English), Biochemical and Biophysical Research Communications, vol. 497, no. 4, pp. 1011-1017, Mar 18 2018, doi: 10.1016/j.bbrc.2018.02.152.

[72] T. H. Im et al., "Xenon Flash Lamp-Induced Ultrafast Multilayer Graphene Growth," (in English), Particle \& Particle Systems Characterization, vol. 34, no. 9, Sep 2017, doi: ARTN 1600429

10.1002/ppsc.201600429.

[73] N. W. Pu et al., "Graphene grown on stainless steel as a high-performance and ecofriendly anti-corrosion coating for polymer electrolyte membrane fuel cell bipolar plates," (in English), Journal of Power Sources, vol. 282, pp. 248-256, May 15 2015, doi: 10.1016/j.jpowsour.2015.02.055. 
[74] R. John, A. Ashokreddy, C. Vijayan, and T. Pradeep, "Single- and few-layer graphene growth on stainless steel substrates by direct thermal chemical vapor deposition," (in English), Nanotechnology, vol. 22, no. 16, Apr 22 2011, doi: Artn 165701

10.1088/0957-4484/22/16/165701.

[75] H. Gullapalli, A. L. M. Reddy, S. Kilpatrick, M. Dubey, and P. M. Ajayan, "Graphene Growth via Carburization of Stainless Steel and Application in Energy Storage," (in English), Small, vol. 7, no. 12, pp. 1697-1700, Jun 20 2011, doi: 10.1002/smll.201100111.

[76] L. F. Dumee et al., "Growth of nano-textured graphene coatings across highly porous stainless steel supports towards corrosion resistant coatings," (in English), Carbon, vol. 87, pp. 395-408, Jun 2015, doi: 10.1016/j.carbon.2015.02.042.

[77] D. Y. Kim et al., "Self-Healing Reduced Graphene Oxide Films by Supersonic Kinetic Spraying," (in English), Advanced Functional Materials, vol. 24, no. 31, pp. 4986-4995, Aug 20 2014, doi: 10.1002/adfm.201400732.

[78] C. Marquez, N. Rodriguez, R. Ruiz, and F. Gamiz, "Electrical characterization and conductivity optimization of laser reduced graphene oxide on insulator using point-contact methods," (in English), Rsc Advances, vol. 6, no. 52, pp. 46231-46237, 2016, doi: 10.1039/c6ra03630a.

[79] R. Trusovas, G. Raciukaitis, J. Barkauskas, and R. Mazeikiene, "Laser Induced Graphite Oxide/Graphene Transformation," (in English), Journal of Laser Micro Nanoengineering, vol. 7, no. 1, pp. 49-53, Feb 2012, doi: 10.2961/jlmn.2012.01.0009.

[80] W. Gao et al., "Direct laser writing of micro-supercapacitors on hydrated graphite oxide films," (in English), Nature Nanotechnology, vol. 6, no. 8, pp. 496-500, Aug 2011, doi: 10.1038/Nnano.2011.110.

[81] L. Huang, Y. Liu, L. C. Ji, Y. Q. Xie, T. Wang, and W. Z. Shi, "Pulsed laser assisted reduction of graphene oxide," (in English), Carbon, vol. 49, no. 7, pp. 2431-2436, Jun 2011, doi: 10.1016/j.carbon.2011.01.067.

[82] D. F. Yang and C. Bock, "Laser reduced graphene for supercapacitor applications," (in English), Journal of Power Sources, vol. 337, pp. 73-81, Jan 1 2017, doi: 10.1016/j.jpowsour.2016.10.108.

[83] S. F. Spano, G. Isgro, P. Russo, M. E. Fragala, and G. Compagnini, "Tunable properties of graphene oxide reduced by laser irradiation," (in English), Applied Physics a-Materials Science \& Processing, vol. 117, no. 1, pp. 19-23, Oct 2014, doi: 10.1007/s00339-014-8508-y.

[84] P. KUMAR, K. S. SUBRAHMANYAM, and C. N. R. RAO, "GRAPHENE PRODUCED BY RADIATION-INDUCED REDUCTION OF GRAPHENE OXIDE," vol. 10, no. 04n05, pp. 559-566, 2011, doi: 10.1142/s0219581x11008824.

[85] M. A. Buccheri et al., "Modification of graphene oxide by laser irradiation: a new route to enhance antibacterial activity," (in English), Nanotechnology, vol. 27, no. 24, Jun 17 2016, doi: Artn 245704

$10.1088 / 0957-4484 / 27 / 24 / 245704$. 
[86] I. Novodchuk et al., "Controlled volume production of simultaneously B/N co-doped reduced graphene oxide nanoflakes using femtosecond laser ablation," (in English), Materials Research Bulletin, vol. 111, pp. 80-86, Mar 2019, doi: 10.1016/j.materresbull.2018.10.039.

[87] L. Guo et al., "Fast fabrication of graphene oxide/reduced graphene oxide hybrid hydrogels for thermosensitive smart actuator utilizing laser irradiation," (in English), Materials Letters, vol. 237, pp. 245-248, Feb 15 2019, doi: 10.1016/j.matlet.2018.11.116.

[88] J. Tang, X. W. Zhong, H. Q. Li, Y. Li, F. Pan, and B. M. Xu, "In-situ and selectively laser reduced graphene oxide sheets as excellent conductive additive for high rate capability LiFePO4 lithium ion batteries," (in English), Journal of Power Sources, vol. 412, pp. 677-682, Feb 1 2019, doi: 10.1016/j.jpowsour.2018.12.009.

[89] T. Kavinkumar, L. R. Shobin, and S. Manivannan, "Effect of laser irradiation on electrical and gas sensing properties of reduced graphene oxide-graphene oxide heterostructure films," (in English), Journal of Alloys and Compounds, vol. 784, pp. 301-312, May 5 2019, doi: 10.1016/j.jallcom.2018.12.376.

[90] A. Queralto et al., "Reduced graphene oxide/iron oxide nanohybrid flexible electrodes grown by laser-based technique for energy storage applications," (in English), Ceramics International, vol. 44, no. 16, pp. 20409-20416, Nov 2018, doi: 10.1016/j.ceramint.2018.08.034.

[91] M. Kasischke et al., "Femtosecond laser patterning of graphene electrodes for thin-film transistors," Applied Surface Science, vol. 478, pp. 299-303, 2019, doi: 10.1016/j.apsusc.2019.01.198.

[92] M. F. El-Kady, V. Strong, S. Dubin, and R. B. Kaner, "Laser Scribing of High-Performance and Flexible Graphene-Based Electrochemical Capacitors," (in English), Science, vol. 335, no. 6074, pp. 1326-1330, Mar 16 2012, doi: 10.1126/science.1216744.

[93] G. Joseph, A. Kirubaraj, U. Satheesh, and D. D, FABRICATION OF FLEXIBLE SUPER CAPACITOR USING LASER LIGHTSCRIBE TECHNIQUE. 2014.

[94] K. H. Cheng, C. H. Cheng, A. K. A. Chao, and D. K. C. Lo, "LASER Light Scribe and Microwave Annealing Reduction of Graphene Oxide for Supercapacitor Applications," (in English), 2015 Ieee 10th International Conference on Nano/Micro Engineered and Molecular Systems (Nems), pp. 380-383, 2015. [Online]. Available: $\leq$ Go to ISI > //WOS:000380505700090.

[95] W. Feng, X. Li, S. Lin, X. Miao, W. Wang, and Y. Zhang, "Enhancing the Efficiency of Graphene Oxide Reduction in Low-Power Digital Video Disc Drives by a Simple Precursor Heat Treatment," ACS Applied Materials \& Interfaces, vol. 11, no. 51, pp. 48162-48171, 2019/12/26 2019, doi: 10.1021/acsami.9b11469.

[96] N. Akkarachanchainon, P. Rattanawaleedirojn, O. Chailapakul, and N. Rodthongkum, "Hydrophilic graphene surface prepared by electrochemically reduced micellar graphene oxide as a platform for electrochemical sensor," (in English), Talanta, vol. 165, pp. 692-701, Apr 1 2017, doi: 10.1016/j.talanta.2016.12.092. 
[97] C. C. Qiu, D. M. Liu, K. Jin, L. Fang, G. X. Xie, and J. Robertson, "Electrochemical functionalization of 316 stainless steel with polyaniline-graphene oxide: Corrosion resistance study," (in English), Materials Chemistry and Physics, vol. 198, pp. 90-98, Sep 1 2017, doi: 10.1016/j.matchemphys.2017.05.004.

[98] J. Yang, S. Y. Deng, J. P. Lei, H. X. Ju, and S. Gunasekaran, "Electrochemical synthesis of reduced graphene sheet-AuPd alloy nanoparticle composites for enzymatic biosensing," (in English), Biosensors \& Bioelectronics, vol. 29, no. 1, pp. 159-166, Nov 15 2011, doi: 10.1016/j.bios.2011.08.011.

[99] P. Fabbri et al., "In-situ graphene oxide reduction during UV-photopolymerization of graphene oxide/acrylic resins mixtures," (in English), Polymer, vol. 53, no. 26, pp. 6039-6044, Dec 7 2012, doi: 10.1016/j.polymer.2012.10.045.

[100] R. Giardi, S. Porro, A. Chiolerio, E. Celasco, and M. Sangermano, "Inkjet printed acrylic formulations based on UV-reduced graphene oxide nanocomposites," (in English), Journal of Materials Science, vol. 48, no. 3, pp. 1249-1255, Feb 2013, doi: 10.1007/s10853-012-6866-4.

[101] Y. Zhou, Q. L. Bao, L. A. L. Tang, Y. L. Zhong, and K. P. Loh, "Hydrothermal Dehydration for the "Green" Reduction of Exfoliated Graphene Oxide to Graphene and Demonstration of Tunable Optical Limiting Properties," (in English), Chemistry of Materials, vol. 21, no. 13, pp. 2950-2956, Jul 14 2009, doi: 10.1021/cm9006603.

[102] Y. W. Zhu et al., "Graphene and Graphene Oxide: Synthesis, Properties, and Applications (vol 22, pg 3906, 2010)," (in English), Advanced Materials, vol. 22, no. 46, pp. 5226-5226, Dec 7 2010, doi: 10.1002/adma.201090156.

[103] K. I. Bolotin et al., "Ultrahigh electron mobility in suspended graphene," (in English), Solid State Communications, vol. 146, no. 9-10, pp. 351-355, Jun 2008, doi: 10.1016/j.ssc.2008.02.024.

[104] A. A. Balandin et al., "Superior thermal conductivity of single-layer graphene," (in English), Nano Letters, vol. 8, no. 3, pp. 902-907, Mar 2008, doi: 10.1021/n10731872.

[105] S. Ghosh et al., "Extremely high thermal conductivity of graphene: Prospects for thermal management applications in nanoelectronic circuits," (in English), Applied Physics Letters, vol. 92, no. 15, Apr 14 2008, doi: Artn 151911

10.1063/1.2907977.

[106] W. W. Cai, Y. W. Zhu, X. S. Li, R. D. Piner, and R. S. Ruoff, "Large area few-layer graphene/graphite films as transparent thin conducting electrodes," (in English), Applied Physics Letters, vol. 95, no. 12, Sep 21 2009, doi: Artn 123115

10.1063/1.3220807.

[107] J. H. Los, K. V. Zakharchenko, M. I. Katsnelson, and A. Fasolino, "Melting temperature of graphene," (in English), Physical Review B, vol. 91, no. 4, Jan 12 2015, doi: ARTN 045415

10.1103/PhysRevB.91.045415.

[108] D. W. Johnson, B. P. Dobson, and K. S. Coleman, "A manufacturing perspective on graphene dispersions," (in English), Current Opinion in Colloid \& Interface Science, vol. 20, no. 5-6, pp. 
367-382, Oct-Dec 2015, doi: 10.1016/j.cocis.2015.11.004.

[109] S. Suzuki and M. Yoshimura, "Chemical Stability of Graphene Coated Silver Substrates for Surface-Enhanced Raman Scattering," (in English), Scientific Reports, vol. 7, Nov 1 2017, doi: ARTN 14851

$10.1038 / \mathrm{s} 41598-017-14782-2$.

[110] Y. M. Shi, K. K. Kim, A. Reina, M. Hofmann, L. J. Li, and J. Kong, "Work Function Engineering of Graphene Electrode via Chemical Doping," (in English), Acs Nano, vol. 4, no. 5, pp. 2689-2694, May 2010, doi: 10.1021/nn1005478.

[111] Y. Y. Lee et al., "Top Laminated Graphene Electrode in a Semitransparent Polymer Solar Cell by Simultaneous Thermal Annealing/Releasing Method," (in English), Acs Nano, vol. 5, no. 8, pp. 6564-6570, Aug 2011, doi: 10.1021/nn201940j.

[112] T. Maiyalagan, X. C. Dong, P. Chen, and X. Wang, "Electrodeposited Pt on three-dimensional interconnected graphene as a free-standing electrode for fuel cell application," (in English), Journal of Materials Chemistry, vol. 22, no. 12, pp. 5286-5290, 2012, doi: 10.1039/c2jm16541d.

[113] T. Lu, Y. P. Zhang, H. B. Li, L. K. Pan, Y. L. Li, and Z. Sun, "Electrochemical behaviors of graphene- $\mathrm{ZnO}$ and graphene-SnO2 composite films for supercapacitors," (in English), Electrochimica Acta, vol. 55, no. 13, pp. 4170-4173, May 1 2010, doi: 10.1016/j.electacta.2010.02.095.

[114] Y. Qian, S. B. Lu, and F. L. Gao, "Preparation of $\mathrm{MnO}$ 2/graphene composite as electrode material for supercapacitors," (in English), Journal of Materials Science, vol. 46, no. 10, pp. 3517-3522, May 2011, doi: 10.1007/s10853-011-5260-y.

[115] Y. Z. Xie et al., "Stretchable all-solid-state supercapacitor with wavy shaped polyaniline/graphene electrode," (in English), Journal of Materials Chemistry A, vol. 2, no. 24, pp. 9142-9149, 2014, doi: 10.1039/c4ta00734d.

[116] Y. Wang et al., "Wearable and Highly Sensitive Graphene Strain Sensors for Human Motion Monitoring," (in English), Advanced Functional Materials, vol. 24, no. 29, pp. 4666-4670, Aug 6 2014, doi: 10.1002/adfm.201400379.

[117] Y. Liang et al., "Series of in-fiber graphene supercapacitors for flexible wearable devices," (in English), Journal of Materials Chemistry A, vol. 3, no. 6, pp. 2547-2551, 2015, doi: $10.1039 / \mathrm{c} 4 \mathrm{ta0} 6574 \mathrm{c}$.

[118] J. J. Park, W. J. Hyun, S. C. Mun, Y. T. Park, and O. O. Park, "Highly Stretchable and Wearable Graphene Strain Sensors with Controllable Sensitivity for Human Motion Monitoring," (in English), Acs Applied Materials \& Interfaces, vol. 7, no. 11, pp. 6317-6324, Mar 25 2015, doi: 10.1021/acsami.5b00695.

[119] Y. Meng et al., "All-Graphene Core-Sheath Microfibers for All-Solid-State, Stretchable Fibriform Supercapacitors and Wearable Electronic Textiles," vol. 25, no. 16, pp. 2326-2331, 2013, doi: 10.1002/adma.201300132.

[120] L. B. Liu, Y. Yu, C. Yan, K. Li, and Z. J. Zheng, "Wearable energy-dense and power-dense 
supercapacitor yarns enabled by scalable graphene-metallic textile composite electrodes," (in English), Nature Communications, vol. 6, Jun 2015, doi: ARTN 7260

10.1038/ncomms8260.

[121] G. X. Wang et al., "Sn/graphene nanocomposite with 3D architecture for enhanced reversible lithium storage in lithium ion batteries," (in English), Journal of Materials Chemistry, vol. 19, no. 44, pp. 8378-8384, 2009, doi: 10.1039/b914650d.

[122] H. Kim, K. Y. Park, J. Hong, and K. Kang, "All-graphene-battery: bridging the gap between supercapacitors and lithium ion batteries," (in English), Scientific Reports, vol. 4, Jun 132014 , doi: ARTN 5278

10.1038/srep05278.

[123] J. Abraham et al., "Tunable sieving of ions using graphene oxide membranes," (in English), Nature Nanotechnology, vol. 12, no. 6, pp. 546-+, Jun 2017, doi: 10.1038/Nnano.2017.21.

[124] Y. P. Zhang and C. X. Pan, "Measurements of mechanical properties and number of layers of graphene from nano-indentation," (in English), Diamond and Related Materials, vol. 24, pp. 1-5, Apr 2012, doi: 10.1016/j.diamond.2012.01.033.

[125] X. J. Tan, J. Wu, K. W. Zhang, X. Y. Peng, L. Z. Sun, and J. X. Zhong, "Nanoindentation models and Young's modulus of monolayer graphene: A molecular dynamics study," (in English), Applied Physics Letters, vol. 102, no. 7, Feb 18 2013, doi: Artn 071908

10.1063/1.4793191.

[126] I. W. Frank, D. M. Tanenbaum, A. M. Van der Zande, and P. L. McEuen, "Mechanical properties of suspended graphene sheets," (in English), Journal of Vacuum Science \& Technology B, vol. 25, no. 6, pp. 2558-2561, Nov 2007, doi: 10.1116/1.2789446.

[127] J.-U. Lee, D. Yoon, and H. Cheong, "Estimation of Young's Modulus of Graphene by Raman Spectroscopy," Nano Letters, vol. 12, no. 9, pp. 4444-4448, 2012/09/12 2012, doi: 10.1021/n1301073q.

[128] S. W. Weng et al., "Estimating Young's modulus of graphene with Raman scattering enhanced by micrometer tip," (in English), Nanotechnology, vol. 25, no. 25, Jun 27 2014, doi: Artn 255703

$10.1088 / 0957-4484 / 25 / 25 / 255703$.

[129] X. Sun, Z. Fu, M. Xia, and Y. Xu, "Effects of vacancy defect on the tensile behavior of graphene," Theoretical and Applied Mechanics Letters, vol. 4, no. 5, p. 051002, 2014/01/01/ 2014, doi: https://doi.org/10.1063/2.1405102.

[130] Y. Zhang, Q. Pei, Z. Sha, Y. Zhang, and H. Gao, "Remarkable enhancement in failure stress and strain of penta-graphene via chemical functionalization," Nano Research, vol. 10, no. 11, pp. 3865-3874, 2017, doi: 10.1007/s12274-017-1600-9.

[131] Y. Park and S. Hyun, "Size Effect of Defects on the Mechanical Properties of Graphene," (in English), Journal of the Korean Physical Society, vol. 72, no. 6, pp. 681-686, Mar 2018, doi: 10.3938/jkps.72.681.

[132] Y. Zhao, X. Peng, T. Fu, X. Zhu, N. Hu, and C. Yan, "Strengthening mechanisms of graphene 
coated copper under nanoindentation," Computational Materials Science, vol. 144, pp. 42-49, 2018, doi: 10.1016/j.commatsci.2017.12.009.

[133] A. Verma, A. Parashar, and M. Packirisamy, "Tailoring the failure morphology of 2D bicrystalline graphene oxide," (in English), Journal of Applied Physics, vol. 124, no. 1, Jul 7 2018, doi: Artn 015102

$10.1063 / 1.5033542$.

[134] F. Liu, P. M. Ming, and J. Li, "Ab initio calculation of ideal strength and phonon instability of graphene under tension," (in English), Physical Review B, vol. 76, no. 6, Aug 2007, doi: ARTN 064120

10.1103/PhysRevB.76.064120.

[135] S. S. Gupta and R. C. Batra, "Elastic Properties and Frequencies of Free Vibrations of Single-Layer Graphene Sheets," (in English), Journal of Computational and Theoretical Nanoscience, vol. 7, no. 10, pp. 2151-2164, Oct 2010, doi: 10.1166/jctn.2010.1598.

[136] C. Si, W. Duan, Z. Liu, and F. Liu, "Electronic strengthening of graphene by charge doping," Phys Rev Lett, vol. 109, no. 22, p. 226802, Nov 30 2012, doi: 10.1103/PhysRevLett.109.226802.

[137] D. A. Dikin et al., "Preparation and characterization of graphene oxide paper," (in English), Nature, vol. 448, no. 7152, pp. 457-460, Jul 26 2007, doi: 10.1038/nature06016.

[138] H. Chen, M. B. Muller, K. J. Gilmore, G. G. Wallace, and D. Li, "Mechanically strong, electrically conductive, and biocompatible graphene paper," (in English), Advanced Materials, vol. 20, no. 18, pp. 3557-+, Sep 17 2008, doi: 10.1002/adma.200800757.

[139] M. Zhang, Y. L. Wang, L. Huang, Z. P. Xu, C. Li, and G. Q. Shi, "Multifunctional Pristine Chemically Modified Graphene Films as Strong as Stainless Steel," (in English), Advanced Materials, vol. 27, no. 42, pp. 6708-+, Nov 11 2015, doi: 10.1002/adma.201503045.

[140] I. L. Chang and J. A. Chen, "The molecular mechanics study on mechanical properties of graphene and graphite," (in English), Applied Physics a-Materials Science \& Processing, vol. 119, no. 1, pp. 265-274, Apr 2015, doi: 10.1007/s00339-014-8960-8.

[141] J. Han, N. M. Pugno, and S. Ryu, "Nanoindentation cannot accurately predict the tensile strength of graphene or other 2D materials," (in English), Nanoscale, vol. 7, no. 38, pp. 15672-15679, 2015, doi: 10.1039/c5nr04134a.

[142] F. Y. Tu, S. Q. Liu, G. H. Jin, G. Q. Yan, and C. Y. Pan, "Fabrication of graphene from graphene oxide by ultrasonication with high Li storage capability," (in English), Powder Technology, vol. 249, pp. 146-150, Nov 2013, doi: 10.1016/j.powtec.2013.08.006.

[143] G. Lee and B. S. Kim, "Biological reduction of graphene oxide using plant leaf extracts," (in English), Biotechnology Progress, vol. 30, no. 2, pp. 463-469, Mar 2014, doi: 10.1002/btpr.1862.

[144] P. Gnanaprakasam and T. Selvaraju, "Green synthesis of self assembled silver nanowire decorated reduced graphene oxide for efficient nitroarene reduction," (in English), Rsc Advances, vol. 4, no. 47, pp. 24518-24525, 2014, doi: 10.1039/c4ra01798f. 
[145] W. Zhang, Y. Li, S. Peng, and X. Cai, "Enhancement of photocatalytic H2 evolution of eosin Y-sensitized reduced graphene oxide through a simple photoreaction," Beilstein Journal of Nanotechnology, vol. 5, pp. 801-811, 2014, doi: 10.3762/bjnano.5.92.

[146] F. W. Low, C. W. Lai, and S. B. Abd Hamid, "Easy preparation of ultrathin reduced graphene oxide sheets at a high stirring speed," (in English), Ceramics International, vol. 41, no. 4, pp. 5798-5806, May 2015, doi: 10.1016/j.ceramint.2015.01.008.

[147] M. Karim and S. Hayami, "Chemical, Thermal, and Light-Driven Reduction of Graphene Oxide: Approach to Obtain Graphene and its Functional Hybrids," 2017.

[148] J. Page, "GO-graphene are pleased to offer our new Graphene Oxide Flake product," 2016. [Online].

Available: https://www.go-graphene.com/blogs/news/gographene-launch-graphene-oxide-flake.

[149] J. H. Warner, "The influence of the number of graphene layers on the atomic resolution images obtained from aberration-corrected high resolution transmission electron microscopy," (in English), Nanotechnology, vol. 21, no. 25, Jun 25 2010, doi: Artn 255707

10.1088/0957-4484/21/25/255707.

[150] N. R. Wilson et al., "Graphene Oxide: Structural Analysis and Application as a Highly Transparent Support for Electron Microscopy," (in English), Acs Nano, vol. 3, no. 9, pp. 2547-2556, Sep 2009, doi: 10.1021/nn900694t.

[151] T. K. Ghosh et al., "Assessment of morphology and property of graphene oxide-hydroxypropylmethylcellulose nanocomposite films," (in English), International Journal of Biological Macromolecules, vol. 66, pp. 338-345, May 2014, doi: 10.1016/j.ijbiomac.2014.02.054.

[152] Z. Zhang, M. H. Ma, C. Chen, Z. X. Cai, and X. Huang, "The morphology, structure and electrocatalytic ability of graphene prepared with different drying methods," (in English), Rsc Advances, vol. 6, no. 33, pp. 28005-28014, 2016, doi: 10.1039/c5ra23123j.

[153] F. Z. Wang and L. T. Drzal, "Development of Stiff, Tough and Conductive Composites by the Addition of Graphene Nanoplatelets to Polyethersulfone/Epoxy Composites," (in English), Materials, vol. 11, no. 11, Nov 2018, doi: ARTN 2137

10.3390/ma11112137.

[154] D. H. Kim, J. S. Jang, W. T. Koo, and I. D. Kim, "Graphene oxide templating: facile synthesis of morphology engineered crumpled SnO2 nanofibers for superior chemiresistors," (in English), Journal of Materials Chemistry A, vol. 6, no. 28, pp. 13825-13834, Jul 28 2018, doi: 10.1039/c8ta03579b.

[155] L. Fernandez-Garcia et al., "Morphological changes in graphene materials caused by solvents," (in English), Colloids and Surfaces a-Physicochemical and Engineering Aspects, vol. 558, pp. 73-79, Dec 5 2018, doi: 10.1016/j.colsurfa.2018.08.030.

[156] BME. "Inspection and test techniques." Faculty of Electrical Engineering and Informatics (VIK). https://www.ett.bme.hu/our_department (accessed 12th, November, 2018).

[157] D. W. Li, Y. S. Zhou, X. Huang, L. Jiang, J. F. Silvain, and Y. F. Lu, "In situ imaging and 
control of layer-by-layer femtosecond laser thinning of graphene," (in English), Nanoscale, vol. 7, no. 8, pp. 3651-3659, 2015, doi: 10.1039/c4nr07078j.

[158] K. Muthoosamy et al., "Exceedingly biocompatible and thin-layered reduced graphene oxide nanosheets using an eco-friendly mushroom extract strategy," (in English), International Journal of Nanomedicine, vol. 10, pp. 1505-1519, 2015, doi: 10.2147/Ijn.S75213.

[159] J. Coates, "Interpretation of Infrared Spectra, A Practical Approach," in Encyclopedia of Analytical Chemistry, 2000.

[160] R. A. Nyquist and R. O. Kagel, Handbook of Infrared and Raman Spectra of Inorganic Compounds and Organic Salts. 1971.

[161] A. Kuptsov and G. Zhizhin, Handbook of Fourier Transform Raman and Infrared Spectra of Polymers. Elsevier Science, Amsterdam, 1998, 581 p. 1998.

[162] F. Tuinstra and J. L. Koenig, "Raman Spectrum of Graphite," (in English), Journal of Chemical Physics, vol. 53, no. 3, pp. 1126-\&, 1970, doi: Doi 10.1063/1.1674108.

[163] T. H. T. Vu, T. T. T. Tran, H. N. T. Le, P. H. T. Nguyen, N. Q. Bui, and N. Essayem, "A new green approach for the reduction of graphene oxide nanosheets using caffeine," (in English), Bulletin of Materials Science, vol. 38, no. 3, pp. 667-671, Jun 2015, doi: 10.1007/s12034-015-0896-x.

[164] S. Perumbilavil, P. Sankar, T. Priya Rose, and R. Philip, "White light Z-scan measurements of ultrafast optical nonlinearity in reduced graphene oxide nanosheets in the $400-700 \mathrm{~nm}$ region," Applied Physics Letters, vol. 107, no. 5, p. 051104, 2015, doi: 10.1063/1.4928124.

[165] M. Wall, The Raman Spectroscopy of Graphene and the Determination of Layer Thickness. 2012.

[166] S. F. Bartolucci et al., "Graphene-aluminum nanocomposites," (in English), Materials Science and Engineering a-Structural Materials Properties Microstructure and Processing, vol. 528, no. 27, pp. 7933-7937, Oct 15 2011, doi: 10.1016/j.msea.2011.07.043.

[167] X. Gao et al., "Preparation and tensile properties of homogeneously dispersed graphene reinforced aluminum matrix composites," (in English), Materials \& Design, vol. 94, pp. 54-60, Mar 15 2016, doi: 10.1016/j.matdes.2016.01.034.

[168] D. Kuang, L. Xu, L. Liu, W. Hu, and Y. Wu, "Graphene-nickel composites," Applied Surface Science, vol. 273, pp. 484-490, 2013/05/15/ 2013, doi: https://doi.org/10.1016/j.apsusc.2013.02.066.

[169] T. Wan and D. J. Chen, "Mechanical enhancement of self-healing waterborne polyurethane by graphene oxide," (in English), Progress in Organic Coatings, vol. 121, pp. 73-79, Aug 2018, doi: 10.1016/j.porgcoat.2018.04.016.

[170] G. Yasin et al., "Exploring the Nickel-Graphene Nanocomposite Coatings for Superior Corrosion Resistance: Manipulating the Effect of Deposition Current Density on its Morphology, Mechanical Properties, and Erosion-Corrosion Performance," (in English), Advanced Engineering Materials, vol. 20, no. 7, Jul 2018, doi: ARTN 1701166

10.1002/adem.201701166. 
[171] C. Navas, R. Colaco, J. de Damborenea, and R. Vilar, "Abrasive wear behaviour of laser clad and flame sprayed-melted NiCrBSi coatings," (in English), Surface \& Coatings Technology, vol. 200, no. 24, pp. 6854-6862, Aug 1 2006, doi: 10.1016/j.surfcoat.2005.10.032.

[172] J. B. Lei, C. Shi, S. F. Zhou, Z. J. Gu, and L. C. Zhang, "Enhanced corrosion and wear resistance properties of carbon fiber reinforced Ni-based composite coating by laser cladding," (in English), Surface \& Coatings Technology, vol. 334, pp. 274-285, Jan 25 2018, doi: 10.1016/j.surfcoat.2017.11.051.

[173] P. Feltham and J. D. Meakin, "On the Mechanism of Work Hardening in Face-Centred Cubic Metals, with Special Reference to Polycrystalline Copper," (in English), Philosophical Magazine, vol. 2, no. 13, pp. 105-112, 1957, doi: Doi 10.1080/14786435708231728.

[174] J. G. Sevillano, P. Vanhoutte, and E. Aernoudt, "Large Strain Work-Hardening and Textures," (in English), Progress in Materials Science, vol. 25, no. 2-4, pp. 69-412, 1980, doi: Doi 10.1016/0079-6425(80)90001-8.

[175] M. Petersen, "Nonphysical Factors That Affect Work-Hardening Success - a Retrospective Study," (in English), Journal of Orthopaedic \& Sports Physical Therapy, vol. 22, no. 6, pp. 238-246, Dec 1995, doi: DOI 10.2519/jospt.1995.22.6.238.

[176] X. R. Zuo, Y. B. Chen, and M. H. Wang, "Study on Microstructures and Work Hardening Behavior of Ferrite-Martensite Dual-Phase Steels with High-Content Martensite," (in English), Materials Research-Ibero-American Journal of Materials, vol. 15, no. 6, pp. 915-921, Nov-Dec 2012, doi: 10.1590/S1516-14392012005000118.

[177] T. K. Liu et al., "Twinning-mediated work hardening and texture evolution in CrCoFeMnNi high entropy alloys at cryogenic temperature," (in English), Materials \& Design, vol. 131, pp. 419-427, Oct 5 2017, doi: 10.1016/j.matdes.2017.06.039.

[178] K. R. Evans and W. F. Flanagan, "Solid-solution strengthening of f.c.c. alloys," The Philosophical Magazine: A Journal of Theoretical Experimental and Applied Physics, vol. 18, no. 155, pp. 977-983, 1968/11/01 1968, doi: 10.1080/14786436808227520.

[179] R. Labusch, "A Statistical Theory of Solid Solution Hardening," (in English), Physica Status Solidi, vol. 41, no. 2, pp. 659-\&, 1970, doi: DOI 10.1002/pssb.19700410221.

[180] H. W. Rosenberg and W. D. Nix, "Solid-Solution Strengthening in Ti-Al Alloys," (in English), Metallurgical Transactions, vol. 4, no. 5, pp. 1333-1338, 1973, doi: Doi 10.1007/Bf02644529.

[181] T. J. Rupert, "Solid solution strengthening and softening due to collective nanocrystalline deformation physics," (in English), Scripta Materialia, vol. 81, pp. 44-47, Jun 15 2014, doi: 10.1016/j.scriptamat.2014.03.006.

[182] L. Xin et al., "Strengthening behavior in SiC nanowires reinforced pure Al composite," (in English), Journal of Alloys and Compounds, vol. 695, pp. 2406-2412, Feb 25 2017, doi: 10.1016/j.jallcom.2016.11.134.

[183] A. Kelly, J. D. Bernal, C. E. H. Bawn, A. H. Cottrell, and F. C. Frank, "The strengthening of metals by dispersed particles," vol. 282, no. 1388, pp. 63-79, 1964, doi: doi:10.1098/rspa.1964.0214. 
[184] B. A. Wilcox and A. H. Clauer, "The role of grain size and shape in strengthening of dispersion hardened nickel alloys," Acta Metallurgica, vol. 20, no. 5, pp. 743-757, 1972/05/01/ 1972, doi: https://doi.org/10.1016/0001-6160(72)90103-4.

[185] J. Huang and A. Ardell, Strengthening mechanisms associated with T1 particles in two Al-Li-Cu alloys. 1987.

[186] F. Wallow and E. Nembach, "Synergisms of grain boundary and \{gamma\}\{prime\}-particle strengthening in nickel-base superalloys," (in English), 1996-02-01 1996, doi: 10.1016/S0956-716X(95)00548-A.

[187] D. G. Morris, "The origins of strengthening in nanostructured metals and alloys," (in English), Revista De Metalurgia, vol. 46, no. 2, pp. 173-186, Mar-Apr 2010, doi: 10.3989/revmetalm.1008.

[188] M. M. Hutchison and R. T. Pascoe, "Grain-Boundary Strengthening in Copper-Base Solid Solutions," Metal Science Journal, vol. 6, no. 1, pp. 90-95, 1972/01/01 1972, doi: 10.1179/030634572790445957.

[189] R. Mahmudi, "Grain boundary strengthening in a fine grained aluminium alloy," Scripta Metallurgica et Materialia, vol. 32, no. 5, pp. 781-786, 1995/03/01/ 1995, doi: https://doi.org/10.1016/0956-716X(95)91603-M.

[190] Y. J. He, A. J. A. Winnubst, C. D. SagelRansijn, A. J. Burggraaf, and H. Verweij, "Enhanced mechanical properties by grain boundary strengthening in ultra-fine-grained TZP ceramics," (in English), Journal of the European Ceramic Society, vol. 16, no. 6, pp. 601-612, 1996, doi: Doi 10.1016/0955-2219(95)00181-6.

[191] J. P. Buban et al., "Grain boundary strengthening in alumina by rare earth impurities," (in English), Science, vol. 311, no. 5758, pp. 212-215, Jan 13 2006, doi: 10.1126/science.1119839.

[192] D. H. Kim, Y. S. Yoo, C. Y. Jo, and C. N. Jones, "Effect of minor elements on the grain boundary strengthening of a single crystal superalloy RR2072," (in English), Advances in Nanomaterials and Processing, Pts 1 and 2, vol. 124-126, pp. 1405-+, 2007, doi: DOI 10.4028/www.scientific.net/SSP.124-126.1405.

[193] T. J. Rupert, J. R. Trelewicz, and C. A. Schuh, "Grain boundary relaxation strengthening of nanocrystalline Ni-W alloys," (in English), Journal of Materials Research, vol. 27, no. 9, pp. 1285-1294, May 2012, doi: 10.1557/jmr.2012.55.

[194] D. Wu, J. Y. Zhang, J. C. Huang, H. Bei, and T. G. Nieh, "Grain-boundary strengthening in nanocrystalline chromium and the Hall-Petch coefficient of body-centered cubic metals," (in English), Scripta Materialia, vol. 68, no. 2, pp. 118-121, Jan 2013, doi: 10.1016/j.scriptamat.2012.09.025.

[195] V. V. Vasiliev and E. V. Morozov, "Chapter 1 - Introduction," in Advanced Mechanics of Composite Materials (Third Edition), V. V. Vasiliev and E. V. Morozov Eds. Boston: Elsevier, 2013, pp. 1-27.

[196] J. W. Martin, "6 - Composite materials," in Materials for Engineering (Third Edition), J. W. 
Martin Ed.: Woodhead Publishing, 2006, pp. 185-215.

[197] M. Loos, "Chapter 2 - Composites," in Carbon Nanotube Reinforced Composites, M. Loos Ed. Oxford: William Andrew Publishing, 2015, pp. 37-72.

[198] S. L. Ogin, P. Brøndsted, and J. Zangenberg, "1 - Composite materials: constituents, architecture, and generic damage," in Modeling Damage, Fatigue and Failure of Composite Materials, R. Talreja and J. Varna Eds.: Woodhead Publishing, 2016, pp. 3-23.

[199] S. Sethi and B. C. Ray, "Environmental effects on fibre reinforced polymeric composites: Evolving reasons and remarks on interfacial strength and stability," Advances in Colloid and Interface Science, vol. 217, pp. 43-67, 2015/03/01/ 2015, doi: https://doi.org/10.1016/j.cis.2014.12.005.

[200] J.-K. Kim and Y.-W. Mai, "3.05 - Effect of Interface Strength on MMC Properties," in Comprehensive Composite Materials, A. Kelly and C. Zweben Eds. Oxford: Pergamon, 2000, pp. 117-138.

[201] P. Ehrburger, J. B. Donnet, A. R. Ubbelohde, J. W. Johnson, M. O. W. Richardson, and R. A. M. Scott, "Interface in Composite Materials [and Discussion]," Philosophical Transactions of the Royal Society of London. Series A, Mathematical and Physical Sciences, vol. 294, no. 1411, pp. 495-505, 1980. [Online]. Available: www.jstor.org/stable/36374.

[202] M. GU, G. ZHANG, and R. WU, "Interfacial bondings in Grf/Al composites," Progress in Natural Science, vol. 7, 1997.

[203] P. Krishnan, "18 - Evaluation and methods of interfacial properties in fiber-reinforced composites," in Mechanical and Physical Testing of Biocomposites, Fibre-Reinforced Composites and Hybrid Composites, M. Jawaid, M. Thariq, and N. Saba Eds.: Woodhead Publishing, 2019, pp. 343-385.

[204] D. Hull and T. Clyne, "General introduction," in An Introduction to Composite Materials, D. Hull and T. W. Clyne Eds., 2 ed. (Cambridge Solid State Science Series. Cambridge: Cambridge University Press, 1996, pp. 1-8.

[205] D. Aleksendrić and P. Carlone, "1 - Introduction to composite materials," in Soft Computing in the Design and Manufacturing of Composite Materials, D. Aleksendrić and P. Carlone Eds. Oxford: Woodhead Publishing, 2015, pp. 1-5.

[206] J. F. Yang, Q. H. Wang, L. J. Yang, and P. Zhao, "Interfacial properties of fiber-reinforced polymer composites," vol. 21, pp. 6-10, 05/01 2005.

[207] S. Z. Rumin Wang, Yaping Zheng, Polymer Based Composites. 2011. Beijing Science Press.

[208] J. Y. Wang, Z. Q. Li, G. L. Fan, H. H. Pan, Z. X. Chen, and D. Zhang, "Reinforcement with graphene nanosheets in aluminum matrix composites," (in English), Scripta Materialia, vol. 66, no. 8, pp. 594-597, Apr 2012, doi: 10.1016/j.scriptamat.2012.01.012.

[209] H. Porwal, P. Tatarko, S. Grasso, J. Khaliq, I. Dlouhy, and M. J. Reece, "Graphene reinforced alumina nano-composites," (in English), Carbon, vol. 64, pp. 359-369, Nov 2013, doi: 10.1016/j.carbon.2013.07.086.

[210] M. Rashad, F. S. Pan, A. T. Tang, and M. Asif, "Effect of Graphene Nanoplatelets addition on 
mechanical properties of pure aluminum using a semi-powder method," (in English), Progress in Natural Science-Materials International, vol. 24, no. 2, pp. 101-108, Apr 2014, doi: 10.1016/j.pnsc.2014.03.012.

[211] Z. Li et al., "Enhanced Mechanical Properties of Graphene (Reduced Graphene Oxide)/Aluminum Composites with a Bioinspired Nanolaminated Structure," (in English), Nano Letters, vol. 15, no. 12, pp. 8077-8083, Dec 2015, doi: 10.1021/acs.nanolett.5b03492.

[212] K. Chu and C. C. Jia, "Enhanced strength in bulk graphene-copper composites," (in English), Physica Status Solidi a-Applications and Materials Science, vol. 211, no. 1, pp. 184-190, Jan 2014, doi: 10.1002/pssa.201330051.

[213] J. Hwang et al., "Enhanced Mechanical Properties of Graphene/Copper Nanocomposites Using a Molecular-Level Mixing Process," (in English), Advanced Materials, vol. 25, no. 46, pp. 6724-6729, Dec 2013, doi: 10.1002/adma.201302495.

[214] M. X. Li, H. W. Che, X. Y. Liu, S. X. Liang, and H. L. Xie, "Highly enhanced mechanical properties in $\mathrm{Cu}$ matrix composites reinforced with graphene decorated metallic nanoparticles," (in English), Journal of Materials Science, vol. 49, no. 10, pp. 3725-3731, May 2014, doi: 10.1007/s10853-014-8082-x.

[215] Y. X. Tang, X. M. Yang, R. R. Wang, and M. X. Li, "Enhancement of the mechanical properties of graphene-copper composites with graphene-nickel hybrids," (in English), Materials Science and Engineering a-Structural Materials Properties Microstructure and Processing, vol. 599, pp. 247-254, Apr 2 2014, doi: 10.1016/j.msea.2014.01.061.

[216] R. R. Jiang, X. F. Zhou, and Z. P. Liu, "Electroless Ni-plated graphene for tensile strength enhancement of copper," (in English), Materials Science and Engineering a-Structural Materials Properties Microstructure and Processing, vol. 679, pp. 323-328, Jan 2 2017, doi: 10.1016/j.msea.2016.10.029.

[217] F. Chen, J. Ying, Y. Wang, S. Du, Z. Liu, and Q. Huang, "Effects of graphene content on the microstructure and properties of copper matrix composites," Carbon, vol. 96, pp. 836-842, 2016/01/01/ 2016, doi: https://doi.org/10.1016/j.carbon.2015.10.023.

[218] L. Y. Chen et al., "Novel nanoprocessing route for bulk graphene nanoplatelets reinforced metal matrix nanocomposites," (in English), Scripta Materialia, vol. 67, no. 1, pp. 29-32, Jul 2012, doi: 10.1016/j.scriptamat.2012.03.013.

[219] M. Rashad, F. S. Pan, M. Asif, and A. Ullah, "Improved mechanical properties of magnesium-graphene composites with copper-graphene hybrids," (in English), Materials Science and Technology, vol. 31, no. 12, pp. 1452-1461, Sep 2015, doi: 10.1179/1743284714y.0000000726.

[220] S. L. Xiang, M. Gupta, X. J. Wang, L. D. Wang, X. S. Hu, and K. Wu, "Enhanced overall strength and ductility of magnesium matrix composites by low content of graphene nanoplatelets," (in English), Composites Part a-Applied Science and Manufacturing, vol. 100, pp. 183-193, Sep 2017, doi: 10.1016/j.compositesa.2017.05.011.

[221] Y. Kim et al., "Strengthening effect of single-atomic-layer graphene in metal-graphene 
nanolayered composites," (in English), Nature Communications, vol. 4, Jul 2013, doi: ARTN 2114

10.1038/ncomms3114.

[222] Z. Ren et al., "Mechanical properties of nickel-graphene composites synthesized by electrochemical deposition," (in English), Nanotechnology, vol. 26, no. 6, Feb 13 2015, doi: Artn 065706

10.1088/0957-4484/26/6/065706.

[223] J. J. Liang et al., "Molecular-Level Dispersion of Graphene into Poly(vinyl alcohol) and Effective Reinforcement of their Nanocomposites," (in English), Advanced Functional Materials, vol. 19, no. 14, pp. 2297-2302, Jul 24 2009, doi: 10.1002/adfm.200801776.

[224] X. Zhao, Q. H. Zhang, D. J. Chen, and P. Lu, "Enhanced Mechanical Properties of Graphene-Based Poly(vinyl alcohol) Composites," (in English), Macromolecules, vol. 43, no. 5, pp. 2357-2363, Mar 9 2010, doi: 10.1021/ma902862u.

[225] J. C. Wang, X. B. Wang, C. H. Xu, M. Zhang, and X. P. Shang, "Preparation of graphene/poly(vinyl alcohol) nanocomposites with enhanced mechanical properties and water resistance," (in English), Polymer International, vol. 60, no. 5, pp. 816-822, May 2011, doi: 10.1002/pi.3025.

[226] T. Ramanathan et al., "Functionalized graphene sheets for polymer nanocomposites," (in English), Nature Nanotechnology, vol. 3, no. 6, pp. 327-331, Jun 2008, doi: 10.1038/nnano.2008.96.

[227] C. Z. Yu, D. L. Li, W. H. Wu, C. Z. Luo, Y. P. Zhang, and C. X. Pan, "Mechanical property enhancement of PVDF/graphene composite based on a high-quality graphene," (in English), Journal of Materials Science, vol. 49, no. 24, pp. 8311-8316, Dec 2014, doi: 10.1007/s10853-014-8539-y.

[228] R. K. Layek, M. E. Uddin, N. H. Kim, A. K. T. Lau, and J. H. Lee, "Noncovalent functionalization of reduced graphene oxide with pluronic F127 and its nanocomposites with gum arabic," (in English), Composites Part B-Engineering, vol. 128, pp. 155-163, Nov 1 2017, doi: 10.1016/j.compsitesb.2017.07.010.

[229] A. Chiappone et al., "Study of graphene oxide-based 3D printable composites: Effect of the in situ reduction," (in English), Composites Part B-Engineering, vol. 124, pp. 9-15, Sep 1 2017, doi: 10.1016/j.compositesb.2017.05.049.

[230] C. Salom, M. G. Prolongo, A. Toribio, A. J. Martinez-Martinez, I. A. de Carcer, and S. G. Prolongo, "Mechanical properties and adhesive behavior of epoxy-graphene nanocomposites," (in English), International Journal of Adhesion and Adhesives, vol. 84, pp. 119-125, Aug 2018, doi: 10.1016/j.ijadhadh.2017.12.004.

[231] S. Chatterjee, F. Nafezarefi, N. H. Tai, L. Schlagenhauf, F. A. Nuesch, and B. T. T. Chu, "Size and synergy effects of nanofiller hybrids including graphene nanoplatelets and carbon nanotubes in mechanical properties of epoxy composites," (in English), Carbon, vol. 50, no. 15, pp. 5380-5386, Dec 2012, doi: 10.1016/j.carbon.2012.07.021. 
[232] S. G. Prolongo, R. Moriche, A. Jimenez-Suarez, M. Sanchez, and A. Urena, "Advantages and disadvantages of the addition of graphene nanoplatelets to epoxy resins," (in English), European Polymer Journal, vol. 61, pp. 206-214, Dec 2014, doi: 10.1016/j.eurpolymj.2014.09.022.

[233] A. Ashori, A. Fallah, M. Ghiyasi, and M. Rabiee, "Reinforcing effects of functionalized graphene oxide on glass fiber/epoxy composites," vol. 39, no. S4, pp. E2324-E2333, 2018, doi: 10.1002/pc.24646.

[234] A. Ashori, M. Ghiyasi, and A. Fallah, "Glass fiber-reinforced epoxy composite with surface-modified graphene oxide: enhancement of interlaminar fracture toughness and thermo-mechanical performance," (in English), Polymer Bulletin, vol. 76, no. 1, pp. 259-270, Jan 2019, doi: 10.1007/s00289-018-2387-x.

[235] M. Ionita, A. M. Pandele, L. Crica, and L. Pilan, "Improving the thermal and mechanical properties of polysulfone by incorporation of graphene oxide," (in English), Composites Part B-Engineering, vol. 59, pp. 133-139, Mar 2014, doi: 10.1016/j.compositesb.2013.11.018.

[236] L. M. Wu, S. Q. Liao, S. J. Zhang, X. Y. Bai, and X. Hou, "Enhancement of mechanical properties of natural rubber with maleic anhydride grafted liquid polybutadiene functionalized graphene oxide," (in English), Chinese Journal of Polymer Science, vol. 33, no. 7, pp. 1058-1068, Jul 2015, doi: 10.1007/s10118-015-1652-9.

[237] Y. Ling, X. Li, S. Zhou, X. Wang, and R. Sun, "Multifunctional cellulosic paper based on quaternized chitosan and gold nanoparticle-reduced graphene oxide via electrostatic self-assembly," Journal of Materials Chemistry A, 10.1039/C4TA07160C vol. 3, no. 14, pp. 7422-7428, 2015, doi: 10.1039/C4TA07160C.

[238] Y. Kim et al., "Radiation Resistant Vanadium-Graphene Nanolayered Composite," (in English), Scientific Reports, vol. 6, Apr 21 2016, doi: ARTN 24785

$10.1038 /$ srep24785. 


\section{Highlights}

- Classification of graphene fabrication methods

- Differences in mechanical properties of graphene at micro and macro levels

- Differences in morphological and physical properties of graphene family material

- Comparative mechanical data of graphene enhanced materials 


\section{Declaration of interests}

$\bigotimes$ The authors declare that they have no known competing financial interests or personal relationships that could have appeared to influence the work reported in this paper.

$\square$ The authors declare the following financial interests/personal relationships which may be considered as potential competing interests: 